University of Windsor

Scholarship at UWindsor

$1-1-1962$

\title{
Simultaneous development of velocity and temperature profiles for laminar flow of a non-Newtonian fluid in the entrance region of flat ducts.
}

Joseph Y. Yau

University of Windsor

Follow this and additional works at: https://scholar.uwindsor.ca/etd

\section{Recommended Citation}

Yau, Joseph Y., "Simultaneous development of velocity and temperature profiles for laminar flow of a nonNewtonian fluid in the entrance region of flat ducts." (1962). Electronic Theses and Dissertations. 6322. https://scholar.uwindsor.ca/etd/6322

This online database contains the full-text of PhD dissertations and Masters' theses of University of Windsor students from 1954 forward. These documents are made available for personal study and research purposes only, in accordance with the Canadian Copyright Act and the Creative Commons license-CC BY-NC-ND (Attribution, Non-Commercial, No Derivative Works). Under this license, works must always be attributed to the copyright holder (original author), cannot be used for any commercial purposes, and may not be altered. Any other use would require the permission of the copyright holder. Students may inquire about withdrawing their dissertation and/or thesis from this database. For additional inquiries, please contact the repository administrator via email (scholarship@uwindsor.ca) or by telephone at 519-253-3000ext. 3208. 
SIMULTANEOUS DEVELOPMENT OF VELOCITY AND TEMPERATURE PROFILES FOR IAMINAR FIOW OF A NON-NEWTONIAN FLUID

IN THE ENTRANCE REGION OF FLAT DUCTS

\title{
A Thesis
}

Submitted to the Faculty of graduate Studies through the Department of Chemical Engineering in Partial Fulfillment of the Requirements for the Degree of Master of Applied Science at Assumption University of Windsor

\author{
by \\ JOSEPH Y. YAU \\ B.A.Sc., Assumption University of Windsor, 1961
}

Windsor, Ontario, Canada

1962 
UMI Number: EC52501

\section{INFORMATION TO USERS}

The quality of this reproduction is dependent upon the quality of the copy submitted. Broken or indistinct print, colored or poor quality illustrations and photographs, print bleed-through, substandard margins, and improper alignment can adversely affect reproduction.

In the unlikely event that the author did not send a complete manuscript and there are missing pages, these will be noted. Also, if unauthorized copyright material had to be removed, a note will indicate the deletion.

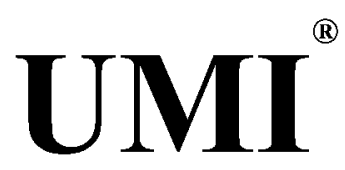

\section{UMI Microform EC52501}

Copyright 2008 by ProQuest LLC.

All rights reserved. This microform edition is protected against unauthorized copying under Title 17, United States Code.

ProQuest LLC

789 E. Eisenhower Parkway

PO Box 1346

Ann Arbor, MI 48106-1346 
APRROVED BY:
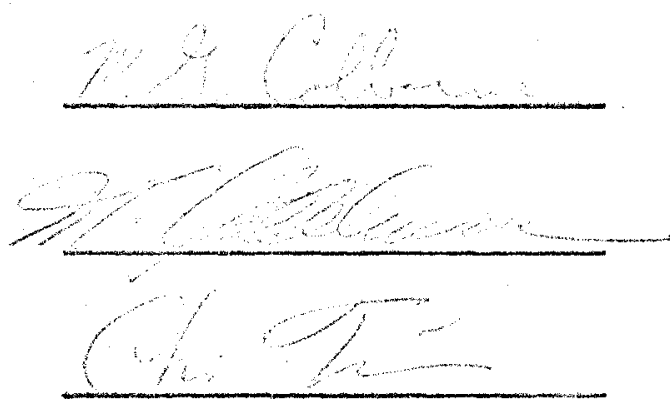

Reproduced with permission of the copyright owner. Further reproduction prohibited without permission. 


\section{ABSTRACT}

A theoretical analysis for the laminar non-Newtonian fluid flow in the entrance region of a flat duct is presented in this thesis. The non-Newtonian fluid is assumed to be of the 0stwald-de Waele model and its physical properties are assumed to be constant. The initial velocity and temperature profiles of the fluid prior to its entry are considered to be flat, and the walls of the duct are maintained at uniform but different temperatures. The momentum and energy integral method of von Karman and Pohlhausen is applied for the solution of entrance heat transfer problems. Dimensionless expressions for velocity and temperature profiles, as well as pressure loss and Nusselt's modulus are obtained from numerical methods.

The results of this thesis indicate that, as in the case of Newtonian fluid, the parameters which influence entrance heat transfer are $\mathrm{I} / \mathrm{D}$ ratio, Reynolds number and Prandtl number, provided these groups are properly defined for non-Newtonian fluids. 


\section{ACKNOWLEDGEMENT}

The author wishes to express his gratitude to Dr. C. Tien, whose aupervision, able direction and continuous help make this thesis possible. Thanks are extended to Steven Nuspl for the assistance in programming for the use of LGP-30 digital computer, and to B.Y. Tam for carrying out part of the numerical calculations. Grateful acknowledgement is also made to the Ontario Research Foundation for the grant in support of this work. 


\section{MABIE OR CONIENIS}

\begin{tabular}{|c|c|c|c|c|c|c|c|c|c|}
\hline ABSTRACA & • & . & . & . & . & . & . & . & iii \\
\hline ACKIOWLE & EDATHENT & . & . & . & . & . & . & - & iv \\
\hline TAESE OB & Conmwirs & . & . & . & 。 & . & . & - & $\mathrm{v}$ \\
\hline IIST OP & FIGURES & . & . & 。 & . & . & . & . & $\operatorname{vi} i$ \\
\hline IIST OF & MABLES & 。 & . & 。 & - & 。 & . & 。 & Viii \\
\hline $\begin{array}{c}\text { Chapter } \\
I\end{array}$ & INIRODUCTIO & & . & . & . & . & . & . & 1 \\
\hline II & $\begin{array}{l}\text { ASSUMPIIONS } \\
\text { A. Descri } \\
\text { B. Assump } \\
\text { C. Basto }\end{array}$ & $\begin{array}{l}\text { AND } \\
\text { ption } \\
\text { tions } \\
\text { Equati }\end{array}$ & $\begin{array}{l}\text { MUNDA } \\
\text { of } \mathrm{P} \\
\text { sions }\end{array}$ & $\begin{array}{l}\text { Morad } \\
\text { roblen }\end{array}$ & $\mathrm{I}$ & UARIONS & & • & \\
\hline III & $\begin{array}{r}\text { DEVELOPIDN } \\
\text { A. Soluti } \\
\text { B. Entran } \\
\text { C. Pressu }\end{array}$ & $\begin{array}{l}\text { on } V \\
\text { on ox } \\
\text { ce Lex } \\
\text { se Lot }\end{array}$ & $\begin{array}{l}\text { DifocI } \\
\text { engua } \\
\text { ength } \\
\text { oss }\end{array}$ & $\begin{array}{l}\text { Ty PRO } \\
\text { tion }\end{array}$ & $\begin{array}{l}O P I I \\
O P \mathrm{M}\end{array}$ & otion & . & - & 11 \\
\hline IV & $\begin{array}{l}\text { DEVELOPITENT } \\
\text { A. Soluti } \\
\text { B. Numeri } \\
\text { Soluti }\end{array}$ & $\begin{array}{l}\text { or } \mathrm{II} \\
\text { on of } \\
\text { cel Ir } \\
\text { ons }\end{array}$ & $\begin{array}{l}\text { WhER } \\
\text { e the } \\
\text { ntivegr }\end{array}$ & $\begin{array}{l}\text { MUUR } \\
\text { mergy } \\
\text { ation }\end{array}$ & $\begin{array}{l}\text { PRO } \\
y^{2} \text { Iq } \\
\text { of? }\end{array}$ & $\begin{array}{l}\text { FIII } \\
\text { vation } \\
\text { Tempere }\end{array}$ & - & - & 20 \\
\hline$V$ & $\begin{array}{r}\text { HEAT TRATST } \\
\text { A. Defini } \\
\text { B. Caloul } \\
\text { Tumber }\end{array}$ & $\begin{array}{l}\text { me CH } \\
\text { tion } \\
\text { ation } \\
\text { by } \mathrm{Bo}\end{array}$ & $\begin{array}{l}\text { InRACR } \\
\text { of th } \\
2 \text { of } t \\
\text { ta. }\end{array}$ & $\begin{array}{l}\text { gristi } \\
\text { o Nusa } \\
\text { he Loo } \\
-9)\end{array}$ & $\begin{array}{l}\text { TCs } \\
\text { selt } \\
\text { cal }\end{array}$ & $\begin{array}{l}\text { Mumber } \\
\text { musselt }\end{array}$ & $x^{0}$ & - & 27 \\
\hline$V I$ & $\begin{array}{l}\text { DISCUSSTON } \\
\text { A. Veloci } \\
\text { B. Intron } \\
\text { C. Pressu } \\
\text { D. Pemper } \\
\text { B. Heat }\end{array}$ & $\begin{array}{l}\text { Op RE } \\
\text { by pro } \\
\text { oe Len } \\
\text { re Los } \\
\text { ature } \\
\text { ransie }\end{array}$ & $\begin{array}{l}\text { ibUTIS } \\
\text { cofile } \\
\text { ength } \\
\text { oss } \\
\text { eror } \\
\text { exch }\end{array}$ & $\begin{array}{l}\cdot \\
\\
\text { ile } \\
\text { aracte }\end{array}$ & eris & tics & 。 & . & 31 \\
\hline VII & CONOLUSION & . & . & . & . & . & . & . & 35 \\
\hline BIBIIOGH & ZAPHY & . & . & . & . & . & . & . & 36 \\
\hline MOLENOIA & MURE & . & - & . & . & . & . & . & 38 \\
\hline
\end{tabular}


APPENDIX A Semple Calculation for Determination

of Coefficients $C_{i}$ in $\mathrm{Eg} \cdot(3-2)$. . 42

APPENDIX B Munerical Integration of $\mathrm{Eq} \cdot(3-23)$

by the Method of clippinger and

Dirnsale

APPENDIX C Flat Plate Analysts . . . . 48

APPENDIX C Flat Plate Malyats . . . . 48

APPINIX D Numerical Integration of Eas. (4-15) and $(4-16)$ by Funge-Kutta Hethod. . 51

APPENDIX E Sample Colculation for the Local

Nusselt Number. . . 57

APPENDIX F Fisures. . . . . 61

APPENDIX \& Tables. . . . . . 79

VITA AUOTORIS • . . . . . . . 96

$\nabla \dot{i}$ 
IIST OF FIGURES

Figure 1 Schematic Diagram • • • • 62

Figure 2 Coefficients $C_{i}$ 's of the Approximate Expression for Velocity Distribution for Various Fluids . • • • 63

Figure 3 Comparison of Exact and Approximate Velocity Profiles . • • . . 64

Figure 4 Fully Developed Velocity Prolllea 65

Figure 5 Dimensionless Velocity U* vs. . . . 66
Dimensionless Distance $x^{*}$

Figure 6 Dimensionless Velocity Boundary Layer Thickness $\delta^{*}$ Vs. Dimensionles Distance $x^{*}$ • $\quad$ • . . . . 69

Figure 7 Entrance Iength $\left(x^{\prime \prime}\right)$ ent $\nabla s$. Flow 70

F1gure $8 \quad \begin{aligned} & \text { Pressure Drop } \Delta p^{*} \nabla s . \text { Dimensionless } \\ & \text { Distance } x^{*} \cdot \bullet^{*}\end{aligned}$

Figure 9 Entry Pressure Drop Correction "Cor." vs. Flow Behavior Index " $n$ " • . 72

Figure 10 Dimensionless Thermal Boundary Layer Thickness $\Delta^{*}$ vs. Dimensionless

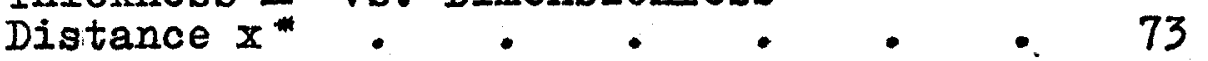

Figure 11 The Local Nusselt Number $\mathrm{Nu}_{\mathbf{x}}$ vs. Dimensionless Distance $\mathrm{x}^{*}$. . . . 76

Figure E.1 Schematic Diagram of $1 / \Delta^{*}$ vs. $x^{*} \cdot \ldots 58$ 


\section{IIST OF TABITSS}

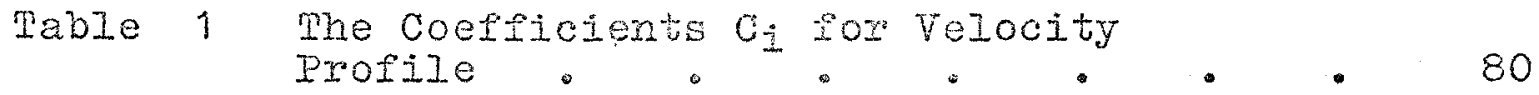

rable 2 Dimensionless Velocity $\left(U^{*}\right)$ and

Dimensionless Volocity Bomdary Layer

Thiclness $\left(\delta^{2}\right)$ as muctions of Dimension-

less Distance $\left(x^{*}\right)$. : . .

Table 3 Dinensioniess Themal. Boundary Layer

Thiolness $\left(\Delta^{*}\right)$ as Wunction of Dimension-

Iess Distance $(x)$, Prencti Inaber $(\mathrm{Pr})$,

and Plow Behavior Index $(n)$. .

Table 4 The Local Wusselt Humber (Tu-) as

Function of Dimensioniess Dítence (x) . 89

Mabie 5 Sample computer Results of Irtogration

of Bquations $(4-15)$ and $(4-16)$ for

$n=1 / 4$ and $P r=100$ by Runge-Kutte

Wethod

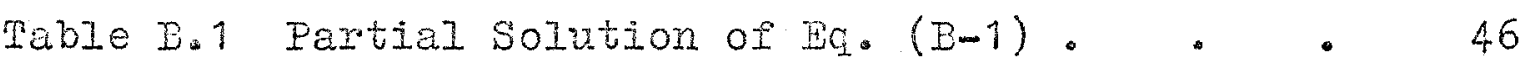

Mable D.1 Rungewhte Scheme for the Difrerential

Equetion $d \mathrm{U} / \mathrm{a}=I\left(U^{*}, \Delta^{*}, \delta^{*}\right) .54$

Vizi 


\section{CHAPTHR I}

\section{INDEODUOTION}

The problem to be considered here is the simultaneous development of velocity and temperature profiles of a non. Newtonian iluid initially at uniform temperature, and with a flat velocity profile entering a rlat duct. A constant temperature (but different from the fluid temperature) is imposed on the walls of the duct. Besides its academic interest, the study of this problon has certain practioal significance. The nodel under present investigation is believed to give a closer approximation of a short-tube heat exchanger. Previous work has shown that the development of velocity profile has a profound effect on the heat transier characteristics $(7,8,15)$.

During recent years, considerable research has been developed in the study of non-Nertonian fluids. This is because an increasing number of fluids treated in industry behave differently from the well-established Newtonian theory. Their shear stress $\left(\tau_{y x}\right)$ is not directly proportionel so the velocity gradient ( $-d u / d y)$. They are refexred to as non-liewtonian pluids. However, most of the woris done in the past deals with the physical and chemical properties of the fluid and the establishnent of mathematical models 
to descibe its behavior. Wurther work in the investigation of the flow and heat transfer characteristics of nonNewtonian fluids would be desireble and most helpiul to the engineer.

Pheoretical analysis and experimental work have been carried out for laminar flow of various non-litewtonain models $(2,6,12,19)$ whose steady-state relation between shear stress and velocity gradient can be represented by empirical equations. The study of velocity development in the entrance region has been reported by Bouge (3), Tomaya (18), and recenty by collins and Schowalter (5). Heat transfer study with fully dereloped Ilow has been investigated by Lyche and Bird (11) and Tien (17). However, studies on simultaneous developnent of velocity and temperature proPiles have not yet been published in literature.

Entrance heat transfer studies for Newtonian fluid have been made only recently. Based on the results of Langhaar (10) on velocity profile development, temperature aistribution in the entrance region of a pipe was obtained by Kays (8) and Goldberg (7) using different techniques. Similar study for the case of a flat duct was given by Sparrow (15) in which the integral method was employed. The study of non-lNewtonian flow is a branch of the "science of deformation and flow" known as the science of rheology. As implied by their generalized name, nonNewtonian fluids include all gases, liquids, colloidal 
suspensions, polymeric solutions, and crystalline materials which do not obey the Newtonian postulate of viscosity that viscosity depends only on temperature and pressure and is independent of the rate of shear. Wilkinson (19) classified the non-Newtonian fluids into three broad types:

(1) time-independent fluids for which the rate of shear at any point is a function of the shearing stress at that point.

(2) time-dependent fluids for which the relation between shear stress and shear rate depends on 1 ts previous history.

(3) viscoelastic fluids which exhibit partial elastic recovery after deformation.

The steady-state rheological behavior of the timeindependent fluids may be described by the equation of the form :

$$
\tau_{y x}=-\eta \frac{d u}{d y}
$$

where $\eta$ is the non-Newtonian viscosity and may be expressed as a function of either the shear rate $(-d u / d y)$ or the shear stress $\left(\tau_{\mathrm{yx}}\right) . \quad \eta$ may be represented by the slope at a given point of the so-called " flow curve ", i.e. the diagram relating shear stress and shear rate for nonNewtonian fluids. Time-independent fluids can further be divided into three distinct groups: (1) Bingham plastics, (2) pseudoplastic fluids and (3) dilatant fluids. 
Bingham plastics have a flow curve which, like that of Newtonian fluids, is a straight line but does not pass through the origin. The slope of the straight line gives the plastic viscosity, $\mu_{0}$. The Bingham model which expresses the rheological relation between the shear stress $\left(\tau_{y x}\right)$ and the shear rate $(-d u / d y)$ may be written as:

$$
\begin{array}{ll}
\tau_{y x}=-\mu_{0} \frac{d u}{d y} \pm \tau_{0} & \text { if }\left|\tau_{y x}\right|>\tau_{0} \\
\frac{d u}{d y}=0 & \text { if }\left|\tau_{y x}\right|<\tau_{0}
\end{array}
$$

- where $\tau_{0}$ is the yield stress. When the shear stress is less than the yield stress the structure of the fluid remains rigid, but when the shear stress exceeds $\tau_{0}$, the structure disintegrates completely, and the fluid flows like Newtonian. Examples of bingham plastics are oil paints and pasty materials.

Pseudoplastic fluids have a non-Newtonian viscosity $(\eta)$ which decreases with increasing rate of shear ( $-d u / d y)$, but for dilatant fluids $\eta$ increases with increasing shear rate. The rheological behavior of both types of fluids can be described by the following models:

The Ostwald-de Waele model (or the power-law model)

$$
\tau_{y x}=-M\left|\frac{d u}{d y}\right|^{n-1} \frac{d u}{d y}
$$

The Eyring model

$$
\tau_{y x}=A \arcsin \left(-\frac{1}{B} \frac{d x}{d y}\right)
$$


The Elis model

$$
-\frac{d u}{d y}=\left(\varphi_{0}+\varphi_{1} /\left.\tau_{y x}\right|^{\beta-1}\right) \tau_{y x}
$$

The Reiner-Phitipport rodel

$$
-\frac{d u}{d y}=\left[\frac{1}{\mu_{\infty}+\frac{\mu_{0}-\mu_{\infty \beta}}{1+\left(q_{y x} / r_{5}\right)^{2}}}\right] \tau_{y x}
$$

With proper choice of the parameter, $\mathrm{Egs} .(1-4)$ to $(1-7)$ can be applied to pseudoplastic, Newtonian, or dilatant fluids. Approximate values of $\mathrm{H}_{2} n, \varphi_{0}, \varphi_{1}, \beta_{9} \cdot \mu_{0}, \mu_{0}$, and $\tau_{s}$ for various luids are tabulated in Bira, stewart, and Iightfoot (2).

Time-dependent luids nay be subdivided into two classes: (1) thixotropic hluids and (2) rheopectic fluids. The first class includes Pluids whose viscosity $(\eta)$ decreases with time under a suddenly applied constant stress $\left(\tau_{y x}\right)$, whereas the second are those whose $\eta$ increases with time. Iven though experimental work and theoretical study have beon made about time-dependent pluids as well as viscoelastic fluids much of their behavior still remains unknown to engineers.

Since pseudoplastic fluids are most common in industry, this thesis will restrict its investigation to then. It is also found that the power-law model is best adapted because of its simplicity. 
CHAPTER II

ASSUMPTIONS AND FUNDAMENTAI EQUATIONS

A. Description of Problem

Fig. 1 gives the schematic description of the problem under investigation. The fluid before entering the duct is assumed to have a uniform velocity profile $u=U_{\infty}$ and at a uniform temperature $T_{\infty}$. The walls of the duct are maintained at a constant temperature $\mathrm{T}_{\mathrm{W}}$ where $\mathrm{T}_{\mathrm{W}} \neq \mathrm{T}_{\infty}$, and the distance between the walls being $2 \mathrm{~b}$. Since the lower and upper halves of the conduit are symmetrical to each other, it is only necessary to study either half. For convenience, the origin of the rectangular coordinates is taken at the entrance point of the lower wall with $x-$ axis parallel to the direction of flow and $\mathrm{y}$-axis perpendicular to it. The $x$-component of the velocity vector is termed $u$ and the $y$-component $v$.

\section{B. Assumptions}

The assumptions used in this thesis are:

1. The flow is two dimensional.

2. The flow is steady.

3. The fluid is incompressible and has constant physical properties.

4. The dissipative heat due to friction is negligible. 
5. The velocity and temperature profiles are flat at the inlet of the duct.

6. There is a thin layer of pluid ajjacent to the wall in which the velocity is zero at the wall, but approaches to very near main now velocity at a distance $\delta$ from the wall. Whis rluid layer is called the velocity boundary layer of thiclness $\delta$, and outside this layer, potential flow occurs in the core and the core velocity profile is flat. The velocity boundary layer is assumed to be of zero thickness at the inlet point. It increases in thicimess with distance from the inlet point until it reaches the centre line of the duct where the two boundary layems from both walls merge. It is assumed that the viscous effect is confined within the boundary layer, and outside the region the forces due to friction are small and may be neglected.

7. There is a transfer of heat between the fluid and the wall because of the temperature difference. The major part of this transfer takes place in a thin layer of fluid adjacent to the wall. Within the layer temperature varies from $T_{W}$ at the wall to $T_{\infty}$ of the undisturbed flow. In an exactiy analogous manner to the velocity boundary layer, this thin layer is called the thermal boundary layer of thickness $\Delta$. Outside the thermal boundary layer 
the fluid is not materially affected by the heat transfer and the temperature remains the same as that of the fluid before entering. This layer will grow from zero thickness at the inlet point to a value equal to $b$ at the centre line where the two identical thermal boundary layers from both walls meet. It is further assumed that the effect of longitudinal conduction of heat in the fluid is insignificant.

8. The usual boundary layer simplification can be applied to the equations of motion and energy.

$$
\text { C. Basic Equations }
$$

For the steady-state laminar flow along the flat duct, the equations of motion, continuity, and energy can be written as follows:

$$
\begin{aligned}
& u \frac{\partial u}{\partial x}+v \frac{\partial u}{\partial y}=-\frac{1}{\rho} \frac{\partial p}{\partial x}-\frac{1}{\rho} \frac{\partial}{\partial y}\left(\tau_{y x}\right) \\
& \frac{\partial p}{\partial y}=0 \\
& \frac{\partial u}{\partial x}+\frac{\partial v}{\partial y}=0 \\
& u \frac{\partial T}{\partial x}+v \frac{\partial T}{\partial y}=\alpha \frac{\partial^{2} T}{\partial y^{2}}
\end{aligned}
$$

For a non-Newtonian fluid obeying Ostwald-de Waele model, its rheological behavior can be described by 


$$
\tau=-\left[M\left|\sqrt{\frac{1}{2}(\Delta: \Delta)}\right|^{n-1}\right] \Delta
$$

where $\mathbb{M}=$ consistency index

$\mathrm{n}=$ flow behavior index

$\Delta=$ rate of deformation tensor

values of $M$ and $n$ for various fluids may be found in Bird, Stewart, and Lightfoot (2), Metzner (12) and St. Pierre (13). It should be noted that the flow behavior index ( $n$ ) is a measure of the degree of non-Newtonian behavior.' The farther the value of $n$ deviates from unity, the more pronounced is the non-Newtonian behavior, and for $n=1$, Eq. $(1-4)$ and $(2-5)$ reduce to the Newtonian law of Viscosity with $M=\mu$.

For Eq. (2-5) the stress component is given by

$$
\tau_{i j}=-\left[M /\left.\frac{1}{2} I_{2}\right|^{\frac{n-1}{2}}\right]\left(\frac{\partial u_{i}}{\partial x_{j}}+\frac{\partial u_{j}}{\partial x_{i}}\right)
$$

where $I_{2}$, the second invariant of stress tensor, is given as:

$$
I_{z}=\sum_{i} \sum_{j}\left[\frac{\partial u_{i}}{\partial x_{j}}+\frac{\partial u_{j}}{\partial x_{i}}\right]^{2}
$$

In the core, the flow is assumed to be nonviscous and the equation of motion, Eq. (2-1), reduces to

$$
U \frac{d U}{d x}=-\frac{1}{\rho} \frac{d p}{d x}
$$

Combining Eqs. $(2-6),(2-7),(2-8)$ and $(2-1)$, the equation of motion can be simplified to 


$$
\begin{aligned}
u \frac{\partial u}{\partial x}+v \frac{\partial u}{\partial y} & =U \frac{d U}{\partial x}+\frac{M}{\rho} \frac{\partial}{\partial y}\left[\left[\left(\frac{\partial u}{\partial y}\right)^{z}\right]^{\frac{x-1}{2}} \frac{\partial u}{\partial y}\right\} \\
& =U \frac{d U}{d x}+\frac{M}{\rho} \frac{\partial}{\partial y}\left[\left(\frac{\partial u}{\partial y}\right)^{n}\right]
\end{aligned}
$$


CHAPTER III

DEVELOPMENT OF VELOCITY PROFIIE

A. Solution of the Equation of Motion

The momentum integral method of von Karman and

Pohlhausen (14) is used for the approximate solution of Eq. $(2-9)$. It has been assumed that there exists a finite boundary layer of thickness $\delta(x)$ such that the viscous effect is within that layer; and for $y \geq \delta$, the velocity is uniform and is known as the core velocity. Integrating Eq. (2-9) from $y=0$ to $y=\delta$, we have

$$
\int_{0}^{\delta} u \frac{\partial u}{\partial x} d y+v \int_{0}^{\delta} \frac{\partial u}{\partial y} d y=\int_{0}^{\delta} U \frac{d U}{d x} d y+\int_{0}^{\delta} \frac{M}{\rho} \frac{\partial}{\partial y}\left[\left(\frac{\partial u}{\partial y}\right)^{n}\right] d y
$$

From the equation of continuity $[\mathrm{Eq} \cdot(2-3)]$,

$$
v=-\int_{0}^{y} \frac{\partial u}{\partial x} d y
$$

Substitute $\mathrm{v}$ into Eq. $(3-1 a)$ and after rearrangement, we have

$$
\begin{aligned}
\frac{d}{d x} \int_{0}^{\delta}[u(U & -u)] d y+\frac{d U}{d x} \int_{0}^{\delta}(U-u) d y \\
& =-\frac{M}{\rho} \int_{0}^{\delta} \frac{\partial}{\partial y}\left(\frac{\partial u}{\partial y}\right)^{n} d y \\
& =-\frac{M}{\rho}\left[\left(\frac{\partial u}{\partial y}\right)_{y=\delta}^{n}-\left(\frac{\partial u}{\partial y}\right)_{y=0}^{n}\right]
\end{aligned}
$$

But $\frac{\partial u}{\partial y}=0$ at $y=\delta$. 
therefore the momentur integral equation is obtained in the form

$$
\frac{d}{d x} \int_{0}^{\delta}[u(U-u)] d y+\frac{d U}{d x} \int_{0}^{\delta}(U-u) d y=\frac{M}{\rho}\left[\left(\frac{\partial u}{\partial y}\right)_{y=0}^{n}\right]
$$

A polynomial of the fourt degree is assuned for the velocity distribution, $u(y)$, inside the boundary layex. This is given by

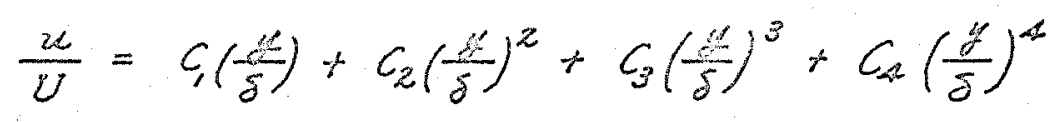

The coefficients $C_{1}, c_{2}, c_{3}$ and $c_{4}$ can be detemined by compatibility conditions which are given as

$$
\begin{array}{rlrl}
u & =0 & \text { at } & y=0 \\
u=U & \text { at } & y=\delta \\
\frac{\partial u}{\partial y}=0 & \text { at } & y=\delta
\end{array}
$$

Equation $(3-3)$ is automatically satispied by $\mathrm{Eq} \cdot(3-2)$. Two aditional conditions are required for the determination of $C_{1}$. They are obtained from the following considerations:

1. The velocity boundary layer thickness, $\delta(x)$, increases along the down-stream direction, and when the upper and Lower layers meet, $i . e . \delta=b$, the flow is considered to be fully developed. For a power-law non-Newtonian fluid in laminar flow along a liat duct, the exact fully developed velocity profile (12) is known to be

$$
\frac{u}{U}=1-\left(1-\frac{g}{b}\right)^{\frac{x+1}{x}}
$$

\section{ASSUAPTION UNIEESSTY UBRARY}


It becomes obvious that any properly assumed axpression for u such as Eq. (3-2) should be reduced to Eq. (3-6) when $\delta=b$. This provides a strngle and dinect way to solve for $C_{i}$ in Eq. $(3-2)$. Howovew, this is only possible for $n=1$, $1 / 2$ and $1 / 3$; for values of $n$ other than these, we have to seek other means to determine the coefricients $C_{i}$. Appendix A.1 gives a somple calculation for the determination of the coeficients $C_{i}$ by matching $\mathrm{Eq}$. (3-2) with $\mathrm{Bq} \cdot(3-6)$.

2. The total volumetric flow rate across the section of the developed profile as calculated by the approximate velocity expression $[\mathrm{Eq}$. (3-2)] should be the same as that calculated by the exact one $[\mathrm{Eq} \cdot(3-6)]$. Thus we have

$$
\begin{aligned}
\int_{0}^{b}\left[c_{1}\left(\frac{y}{b}\right)\right. & \left.+c_{2}\left(\frac{y}{b}\right)^{2}+c_{3}\left(\frac{y}{b}\right)^{3}+c_{4}\left(\frac{y}{b}\right)^{4}\right] d y \\
& =\int_{0}^{b}\left[1-\left(1-\frac{y}{b}\right)^{\frac{2 n+1}{x}}\right] d y
\end{aligned}
$$

3. The kinetic energy of the fluid crossing the section of the developed profile as determined by the approximate and exact expressions should be equal, i.e.:

$$
\begin{gathered}
\int_{0}^{b}\left[c_{1}\left(\frac{y}{b}\right)+C_{2}\left(\frac{y}{b}\right)^{2}+c_{3}\left(\frac{y}{b}\right)^{3}+C_{A}\left(\frac{y}{b}\right)^{4}\right]^{2} d y \\
=\int_{0}^{b}\left[1-\left(1-\frac{y}{b}\right)^{\frac{x+1}{x}}\right]^{2}
\end{gathered}
$$

Hence Equations $(3-4),(3-5),(3-7)$ and $(3-8)$ complete 
the necessary conditions for determinating $C_{i}$ in the assumed velocity distribution $\mathrm{Eq} \cdot(3-2)$.

From $\mathrm{Eq} \cdot(3-4) \quad c_{1}+c_{2}+c_{3}+c_{4}=1$

From II. $(3-5) \quad C_{1}+2 C_{2}+3 C_{3}+4 C_{4}=0$

From $\mathbb{A C}_{1} \cdot(3-7) \quad 1-\frac{n}{1+2 n}=\frac{C_{1}}{2}+\frac{C_{2}}{3}+\frac{C_{3}}{4}+\frac{C_{3}}{5}$

From $\mathbb{E}$. (3-8) $1-\frac{2 n}{1+2 n}+\frac{n}{2+3 n}$

$$
\begin{aligned}
& =C_{1}\left(\frac{C_{1}}{3}+\frac{C_{2}}{4}+\frac{C_{3}}{5}+\frac{C_{4}}{6}\right)+C_{2}\left(\frac{C_{1}}{4}+\frac{C_{2}}{5}+\frac{C_{3}}{6}+\frac{C_{3}}{7}\right) \\
& +C_{3}\left(\frac{C_{1}}{5}+\frac{C_{2}}{6}+\frac{C_{3}}{7}+\frac{C_{2}}{8}\right)+C_{4}\left(\frac{C_{1}}{6}+\frac{C_{2}}{7}+\frac{C_{3}}{8}+\frac{C_{4}}{9}\right)
\end{aligned}
$$

Appendix A.2 gives a sample caloulation for determination of $C_{i}$ by Equations $(3-9)$ to $(3-12)$. It ghoula be noted that the above equations fail to determine $C_{i}$ for $n<0.11355$, because the fourtin power polynomial approximation of the velocity distribution is no longer sufficient to describe the flow behavior.

ivmerical values of $c_{i}$ for various values of the flow behavior index $(n)$ are given in Table 1 and Fig. 2. A comparison between the assumed expression for $u$ at fully developed condition and that of the exact for $n=3 / 4,1 / 4$. and $1 / 5$ is show in Fig. 3. The fully developed velocity propiles are reproduced in the form $u / 0$ vo. n in Fig. 4.

whe non-Newtowian fluid enters the duct at a uniform Velocity $\left(U_{\infty}\right)$. As the pluid moves along the duct, 
the fluid within the velocity boundary layer near the wall is retarded due to the viscous effect, while the fluid in the core will be accelerated from the initial uniform velocity to a final velocity which is attained when the two boundary layers meet at the center line. This continuity requirement can be expressed as

$$
\bar{U} b=\int_{0}^{\delta} u d y+U(b-\delta)
$$

where $\quad \bar{\sigma}=$ average velocity of fluid

$$
\text { or } \quad \begin{aligned}
f(U-\bar{U}) & =\int_{0}^{\delta}(U-u) d y \\
& =U \delta\left(1-\frac{c_{1}}{2}-\frac{c_{2}}{3}-\frac{c_{3}}{4}-\frac{c_{4}}{5}\right)
\end{aligned}
$$

or

$$
U \delta=\frac{l}{k,}(U-\bar{U})
$$

where $K_{1}=1-\frac{C_{1}}{2}-\frac{C_{z}}{3}-\frac{C_{3}}{4}-\frac{C_{A}}{5}$

When the approximate velocity expression [Eq. (3-2)].

is substituted into the momentum integral equation [Eq. (31).], and after integration, we have

$$
\frac{d}{d x}\left(K_{2} U^{2} \delta\right)+\frac{d U}{d x}(K, U \delta)=\frac{M}{\rho} \frac{U^{n} C_{1}^{x}}{\delta^{n}}
$$

where $k_{2}=\frac{c_{1}}{2}+\frac{c_{2}}{3}+\frac{c_{3}}{4}+\frac{c_{4}}{5}-\frac{c_{1}^{2}}{3}-\frac{c_{2}^{2}}{5}-\frac{c_{3}^{2}}{7}$

$$
\begin{aligned}
& -\frac{c_{4}^{2}}{9}-\frac{c_{1} c_{2}}{2}-\frac{2 c_{1} c_{3}}{5}-\frac{c_{1} c_{4}}{3}-\frac{c_{2} c_{3}}{3} \\
& -\frac{2 c_{2} c_{4}}{7}-\frac{c_{3} c_{4}}{4}
\end{aligned}
$$


Substitute Eq. $(3-14)$ into Eq. $(3-16)$ and carry out the operation:

$$
\begin{gathered}
\quad\left[\frac{K_{2} b}{K_{1}}(2 U-\bar{U})+b(U-\bar{U})\right] \frac{d U}{d x}=\left[\frac{M U^{2 n} C_{1}^{n} k_{1}^{n}}{\rho b^{n}(U-\bar{U})^{n}}\right] \\
\text { or } \quad d x=\frac{\rho b^{n+1}(U-\bar{U})^{n}}{M U^{2 n} c_{1}^{n} k_{1}^{n}}\left[\left(\frac{2 K_{2}+k_{1}}{k_{1}}\right) U-\left(\frac{K_{2}+K_{1}}{K_{1}}\right) \bar{U}\right] d U
\end{gathered}
$$

If the following transformations are made,

$$
\begin{aligned}
U^{*} & =\frac{U}{\bar{U}} \\
R e_{b} & =\frac{\rho b^{n} \bar{U}^{2-n}}{M} \\
x^{*} & =\frac{x}{b R e_{b}} \\
\delta^{*} & =\frac{\delta}{b}
\end{aligned}
$$

Eq. (3-18) becomes

$$
\frac{d x^{*}}{d U^{*}}=\frac{\left(U^{*}-1\right)^{n}}{c_{1}^{n} k_{1}^{n}}\left[\left(\frac{k_{1}+2 k_{2}}{k_{1}}\right) U^{*}-\left(\frac{k_{1}+k_{2}}{k_{1}}\right)\right] \frac{1}{U^{* 2 n}}
$$

Eq. (3-14) can also be written as

$$
\delta^{*}=\frac{1}{k_{1}}\left(1-\frac{1}{U^{*}}\right)
$$

Eq. (3-23) was integrated numerically by the method of Clippinger and Dimsdale over the interval $\mathrm{x}^{*}=0$ and $U^{*}=1$ to $U^{*}=$ fully developed value, i.e. $\delta^{*}=1$. Appendix $B$ gives a sample calculation. Table 2 gives the results of 
$U^{*}$ and $\delta^{*}$ as a function of $x^{*}$ for $n=1 / 4,1 / 2$ and $3 / 4$; and these are also presented graphically in Fig. 5 and 6 . In the neighborhood of the entrance section, $x^{*}=0$. and $U^{*}=1 ; E q .(3-23)$ is integrated to be

$$
U^{*}-1=\left[\frac{c_{1}^{n} k_{1}^{n+1}(1+n)}{k_{2}} x^{*}\right]^{\frac{1}{1+n}}
$$

At the fully dereloped section; $\delta^{*}=1$; Eq. (3-24) becomes.

$$
U^{*}=\frac{1}{1-K,}
$$

Other expressions may be assumed for the velocity distribution.. For example, $u$ may be assumed to have the following form:

$$
\frac{u}{U}=1-\left(1-\frac{y}{\delta}\right)^{\frac{1+n}{x}}
$$

If it is substituted into the momentum integral equation and similar operation is carried out as shown previously, the following equations are derived:

$$
\begin{aligned}
& \frac{d x^{*}}{d U^{*}}=\frac{(2 n+1)^{n}(U-1)^{n}}{(3 n+2)(n+1)^{n}}\left[(5 n+4) U^{*}-(4 n+3)\right] \frac{1}{U^{* 2 n}} \\
& \delta^{*}=\frac{2 n+1}{n}\left(1-\frac{1}{U^{*}}\right)
\end{aligned}
$$

In the neighborhood of the entrance region the solution for the velocity is

$$
U^{*}-1=\left[\frac{(3 n+2)(n+1)^{n}}{(2 n+1)^{n}} x^{*}\right]^{\frac{1}{1+n}}
$$


The fully developed velocity is given by

$$
U^{*}=\frac{2 n+1}{n+1}
$$

By letting $n=1, E q .(3-23)$ to $(3-31)$ will be valid for Newtonian fluid flow, and the equations reduce to the forms developed by Sparrow (.15).

\section{B. Entrance Length}

The axial distance from the inlet to the point where the two boundary layers from the walls meet at the center line is known as the entrance length. Its dimensionless quantity $\left(x^{*}\right)$ ent is obtained as $\delta^{*}=1$ or $U^{*}$ reaches the fully developed value as given by Eq. (3-26) or $(3-31)$. Fig. 7 shows the dependence of $\left(\dot{x}^{*}\right)$ ent on the flow behavior index $(n)$.

\section{Pressure Loss}

The pressure drop in the entrance region consists of the resistance due to viscous effect and the pressure loss due to momentum change of the accelerating fluid in the core. The pressure drop between the inlet $\left(x^{*}=0\right)$ and any point within the entrance length $\left[x^{*} \leqslant\left(x^{*}\right)\right.$ ent $]$ can be obtained by integrating Eq. (2-8) with the lower limit taken as $x^{*}=0$ and $U^{*}=1$. This gives

$$
\frac{p_{\infty}-p}{\rho \bar{U}^{2} / 2}=U^{* 2}-1
$$


In the fully developed region, the pressure drop over a length $\Delta \mathrm{x}$ is given by

$$
\frac{\Delta p}{\rho \bar{U}^{2} / 2}=2\left(\frac{1+2 n}{n}\right)^{n}\left(\frac{\Delta x}{b R e_{b}}\right)
$$

The dependence of the pressure drop on $x^{*}$ is given in Fig. 8 . Conventionally, the total pressure drop between the inlet and any point in the fully developed region $\left[x^{*} \geq\left(x^{*}\right)_{\text {ent }}\right]$ is given as

$$
\frac{\Delta p}{\rho \bar{U}^{2} / 2}=2\left(\frac{1+2 n}{n}\right)^{n} x^{*}+\text { Cor. }
$$

where "Cor." is the excess pressure due to the entrance effect in addition to the pressure loss from $x^{*}=0$ to the point at $x^{*}$ if the velocity profile is assumed to be fully developed. The correction term "Cor." is represented mathematically by

$$
\text { Cor. }=\left[\left(U^{*}\right)_{\delta^{*}=1}^{2}-1\right]-2\left(\frac{1+2 n}{n}\right)^{n}\left(x^{*}\right)_{\text {ent }}
$$

Substitution of Eq. (3-31) into (3-35) gives

$$
\text { Cor. }=\frac{n(3 n+2)}{(n+1)^{2}}-2\left(\frac{1+2 n}{n}\right)^{n}\left(x^{*}\right)_{\text {ent }}
$$

The pressure correction factor (C̣or.) is plotted in Fig. 9 as a function of the flow behavior index $(n)$. 
CHAPTER IV

\section{DEVELOPMENT OF TEMPERATURE PROFILE}

A. Solution of the Energy Equation

The solution of the temperature distribution is obtained in a similar way. In addition to the existence of a velocity boundary layer, a thermal boundary layer with thickness equal to $\Delta$ is assumed to exist in the neighborhood of the wall. The effect of heat transfer between the fluid and the wall is confined within this layer and the temperature of the fluid outside the layer remains unchanged. The energy integral equation is obtained by integrating the energy equation $(2-4)$ from $y=0$ to $y=\Delta$, and after rearrangement, we have

$$
\frac{d}{d x} \int_{0}^{\Delta} u\left(T_{\infty}-T\right) d y=\alpha\left(\frac{\partial T}{\partial y}\right)_{y=0}
$$

The temperature distribution in the thermal boundary layer is assumed to have the form:

$$
T^{*}=\frac{T-T_{w}}{T_{\infty}-T_{w}}=\frac{3}{2}\left(\frac{y}{\Delta}\right)-\frac{1}{2}\left(\frac{y}{\Delta}\right)^{3}
$$

which satisfies the following boundary conditions:

$$
\begin{array}{rlrl}
\mathrm{T} & =\mathrm{T}_{\mathrm{W}} & \text { at } & \mathrm{y}=0 \\
\mathrm{~T} & =\mathrm{T}_{\infty} & \text { at } & \mathrm{y}=\Delta \\
\frac{\partial T}{\partial y}=0 & \text { at } & \mathrm{y}=\Delta .
\end{array}
$$


Eq. (3-2) and (4-2) can be substituted into (4-1) which in tuirn will lead to an expression for $\Delta$. However, the integral on the left hand side of Eq. (4-1) would yield different expressions depending on the relative magnitude of $\delta$ and $\Delta$. These will be treated seperately:

Case (a) $\Delta>\delta$

The velocity profile is given by

$$
\begin{array}{lrl}
\frac{u}{U}=C_{1}\left(\frac{y}{\delta}\right)+C_{2}\left(\frac{y}{\delta}\right)^{2}+C_{3}\left(\frac{y}{\delta}\right)^{3}+C_{4}\left(\frac{y}{\delta}\right)^{4} & \text { for } & \begin{array}{c}
0 \leq \mathrm{y} \\
(3-2)
\end{array} \\
u=U & \text { for } & \delta \leq y \leq \Delta
\end{array}
$$

Hence $E q \cdot(4-1)$ can be written as

$$
\frac{d}{d x}\left[\int_{0}^{\delta} u\left(T_{\infty}-T\right) d y+U \int_{0}^{\Delta}\left(T_{\infty}-T\right) d y\right]=\alpha\left(\frac{\partial T}{\partial y}\right)_{y=0}
$$

Substituting Equations (3-2), (4-2) and (4-6) into (4-1b) and carrying out the operation, one has

$$
\frac{d}{d x}\left[K_{3} U \delta+K_{4} U \frac{\delta^{2}}{\Delta}+k_{5} U \frac{\delta^{4}}{\Delta^{3}}+\frac{3}{8} U \Delta\right]=\frac{3 \alpha}{2 \Delta}
$$

where

$$
\begin{aligned}
& K_{3}=\frac{c_{1}}{2}+\frac{c_{2}}{3}+\frac{c_{3}}{4}+\frac{c_{4}}{5}-1=-K_{1} \\
& K_{4}=-\frac{c_{1}}{2}-\frac{3 c_{2}}{8}-\frac{3 c_{3}}{10}-\frac{C_{4}}{4}+\frac{3}{4} \\
& K_{5}=\frac{c_{1}}{10}+\frac{c_{2}}{12}+\frac{c_{3}}{14}+\frac{c_{4}}{16}-\frac{1}{8}
\end{aligned}
$$

Introducing the following dimensionless forms in addition 
to those given before [Equations $(3-19)$ to $(3-22)]$,

$$
\begin{aligned}
& \Delta^{*}=\frac{\Delta}{b} \\
& \operatorname{Pr}=\frac{C_{p} \rho b \bar{U}}{R e_{b}}
\end{aligned}
$$

Eq. (4-7) becomes

$$
\begin{aligned}
{\left[k_{3} \delta^{*}\right.} & \left.+k_{4} \frac{\delta^{*} z}{\Delta^{*}}+k_{5} \frac{\delta^{* 4}}{\Delta^{*}}+\frac{3}{8} \Delta^{*}\right] d U^{*} \\
& +\left[k_{3} U^{*}+2 k_{4} \frac{\delta^{*}}{\Delta^{*}} U^{*}+4 k_{5} \frac{U^{*} \Delta^{* 3}}{\Delta^{* 3}}\right] d \delta^{*} \\
& +\left[-k_{4} \frac{\delta^{* 2}}{\Delta^{* 2}}-3 k_{5} \frac{\delta^{* 4}}{\Delta^{* 4}}+\frac{3}{8}\right] U^{*} d \Delta^{*} \\
& =\frac{3 d x^{*}}{2 \Delta^{*} P r}
\end{aligned}
$$

From Eq. (3-23), we have

$$
d x^{*}=\frac{\left(U^{*}-1\right)^{n}\left[\left(\frac{k_{1}+2 k_{2}}{k_{1}}\right) U^{*}-\left(\frac{k_{1}+k_{2}}{k_{1}}\right)\right]}{C_{1}^{n} k_{1}^{n} U^{* 2 n}} d U^{*}
$$

Also, from Eq. (3-24) we obtain

$$
d \delta^{*}=\frac{d U^{*}}{k, U^{* 2}}
$$

Substituting Eqs.(3-23) and (4-14) into (4-13) and after rearrangement, we obtain

$$
\begin{aligned}
& \frac{d U^{*}}{d \Delta^{*}}=\frac{\left[\frac{3}{8}-K_{4}\left(\frac{\delta^{*}}{\Delta^{*}}\right)^{2}-3 K_{5}\left(\frac{\delta^{*}}{\Delta^{*}}\right)^{4}\right] U^{*}}{\left\{\frac{3\left[\left(\frac{K_{1}+2 K_{2}}{k_{1}}\right) U^{*}-\left(\frac{K_{1}+K_{2}}{k_{1}}\right)\right]}{2 \Delta^{*} \operatorname{Pr} C_{1}^{n} K_{1}^{n} U^{* 2 n}}\right\}} \\
& -\left\{k_{3} \delta^{*}+k_{4} \frac{\delta^{* 2}}{\Delta^{*}}+k_{5} \frac{\delta^{* 4}}{\Delta^{* 3}}+\frac{3}{8} \Delta^{*}+\frac{k_{3}}{k_{1} U^{*}}+\frac{2 K_{4} \delta^{*}}{K_{1} U^{*} \Delta^{*}}+\frac{4 k_{5} \delta^{* 3}}{k_{1} U^{*} \Delta^{* 3}}\right\} \\
& (4-15)
\end{aligned}
$$


Case (b) $\Delta<\delta$

Since the thermal boundary layer is within the velocity boundary layer, one single expression is required to describe the velocity profile $[\mathrm{Eq} .(3-2)]$ in the region $0 \leq y \leq \delta$. Following the same technique as in previous case, we derive the following equation:

$$
\begin{aligned}
& \frac{d U^{*}}{d \Delta^{*}}=\frac{\left[\frac{c_{1}}{5}\left(\frac{\Delta^{*}}{\delta^{*}}\right)+c_{2}\left(\frac{\Delta^{*}}{\delta^{*}}\right)^{2}+3 c_{3}\left(\frac{\Delta^{*}}{\delta^{*}}\right)^{3}+1 c_{4}\left(\frac{\Delta^{*}}{\delta^{*}}\right)^{4}\right] U^{*}}{\left\{\frac{3\left[\left(\frac{k_{1}+2 k_{2}}{k_{1}}\right) U^{*}-\left(\frac{k_{1}+k_{2}}{k_{1}}\right)\right]}{2 \Delta^{*} \operatorname{Pr} c_{1}^{n} k_{1}^{*} U^{* 2 \pi}}\right\}-\left\{\frac{c_{1} \Delta^{* 2}}{10 \delta^{*}}+\frac{c_{2} \Delta^{* j}}{24 \delta^{* 2}}\right\}} . \\
& -\left\{\frac{3 C_{3} \Delta^{* 4}}{140 \delta^{* 3}}+\frac{C_{4} \Delta^{* 5}}{80 \delta^{* 4}}-\frac{C_{1} \Delta^{* 2}}{10 K_{1} U^{*} \delta^{* 2}}-\frac{C_{2} \Delta^{* 3}}{12 k_{1} U^{*} \delta^{* 3}}\right\} \\
& -\overline{-\left\{\frac{9 C_{3} \Delta^{* 4}}{140 K_{1} U^{*} \delta^{* 4}}-\frac{C_{4} \Delta^{* 5}}{20 K_{1} U^{*} \delta^{* 5}}\right\}}
\end{aligned}
$$


B. Numerical Integration of Iemperature Solutions Equation (4-15) or (4-16) will be used in conjunction with the results obtained from IqE. (3-23) and (3-24) [relationship between $U^{*}, \delta^{*}$, and $x^{*}$ ] to obtain a relationship between $\Delta^{*}$ and $X_{*}^{*}$. Humerical integration of Equations (4-15) and (4-16) are carried out using Runge-rutta method (9). The initial conditions corresponding to $x^{\text {m }}=0$ or $U^{*}=1$ are $\Delta^{*}=\delta^{*}=0$. However, this Ieads to the indeterminate form for $\Delta^{*} / \delta^{*}$ or $\delta^{*} / \Delta^{*}$. In order to overcome this dificulty, computation will not start exactly at the entrance point, but a small distance dom-strearn. Since in the imediate neighborhood of the entrance point $U^{*}$ is almost unity. Consequentry, the flow may be assumed to be the same as that over a flat plate. The solution of velocity and temperature distributions over a flat plate for power-law non-Newtonian fluid has been studied by Acrivos et al. Their results on heat transfer rate ana shear stress, expressed in terms of themal boundary layer thickness and velocity boundary layer thickness, are

$$
\begin{aligned}
& \delta^{*}=\left[\frac{(n+y) c_{1}^{n}}{\kappa_{2}}\right]^{\frac{1}{1+n}} x^{\frac{1}{1+n}} \\
& \Delta^{*}=\frac{2.658681}{\sqrt{P_{r}}} x^{* 2} \quad \text { for } x^{*}<x_{1}^{*} \quad(4-18) \\
& \Delta^{*}=1.3395\left[\frac{k_{0}^{\frac{1}{2}} \operatorname{Pr}}{18}\left(\frac{1+2 n}{1+2 n}\right)\right]^{-\frac{1}{3}} x^{3 * \frac{2+n}{3(1+n)}} \\
& \text { for } x^{2 / 1}>x_{1}^{*} \quad(4-19)
\end{aligned}
$$




$$
x_{1}^{*}=\left\{\frac{2.658681}{1.3395\left(P_{r}\right)^{t}}\left[\frac{K_{6}^{\frac{1}{n}}(1+2 n)}{18(1+n}\right]^{\frac{1}{3}}\right\}^{6\left(\frac{1+n}{1-n}\right)}
$$

where $\quad K_{6}=\left[\frac{39}{280}\left(\frac{1.5}{1+n}\right)\right]^{\frac{n}{1+n}}$

Appendix $C$ gives the detailed derivation of these expressions. In the immediate neighborhood of the entrance region, Eq. $(3-25)$ is valid to determine the starting value of $U^{*}$ :

$$
U^{*}=\left[\frac{c_{1}^{n} K_{1}^{1+n}(1+n)}{K_{2}} x^{*}\right]^{\frac{1}{1+n}}-1
$$

Equations (4-17) to (4-21) and (3-25) provide sufficient relationships to start the numerical integration of $\mathrm{dU} * / \mathrm{d} \Delta^{*}$. Computation starts at $\Delta^{*}=1 \times 10^{-4}$. This value of - $\Delta^{*}$ will give two values of $x^{*}$, one from $E q .(4-18)$ and the other Eq. (4-19). The correct $x^{*}$ should be chosen from the appropiate equation satisfying the limiting conditions, $x^{*}<x_{1}^{*}$ or $x^{*}>x_{1}^{*}$. Once the value of $x^{*}$ is known, other values for $\delta^{*}$ and $U^{*}$ can be calculated. The relative magnitudes of $\delta^{*}$ and $\Delta^{*}\left(\Delta^{*}=1 \times 10^{-4}\right)$ will determine either Eq. (4-15) or (4-16) should be used to continue the integration. In usual cases $\Delta^{*}$ is greater than $\delta^{*}$ in the inlet region so that $\mathrm{Eq} \cdot(4-15)$ is integrated first. But somewhere down-stream the ratio of $\delta^{*} / \Delta^{*}$ becomes greater than unity, and a switch to Eq. $(4-16)$ is necessary. Actual computation was carried out by a IGP-30 digital computer. Computation stops when either $\Delta^{*}$ or $\delta^{*}$ reaches unity.

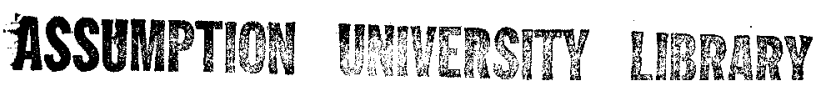


In cases where $\delta^{*}$ tirst reaches unity, the subsequent growth of $\Delta^{*}$ can be obtained from Eq. (4-1) using the fully developed velocity profile [namely replacing $\delta$ by $b$ in Eq. (3-2)]. The resultant equation is found to be

$$
\begin{aligned}
& \frac{1}{1-k_{1}}\left\{\frac{c_{1}}{15}\left[\Delta^{* 3}-\left(\Delta^{*}\right)_{\delta^{*}=1}^{3}\right]+\frac{c_{2}}{32}\left[\Delta^{* 4}-\left(\Delta^{*}\right)_{\delta^{*}=1}^{4}\right]\right. \\
& \left.+\frac{3 C_{3}}{175}\left[\Delta^{* 5}-\left(\Delta^{*}\right)_{\delta^{*}=1}^{5}\right]+\frac{C_{\Delta}}{96}\left[\Delta^{* 6}-\left(\Delta^{*}\right)_{\delta^{*}=1}^{6}\right]\right\} \\
& =\frac{3}{2 \operatorname{Pr}}\left[x^{*}-\left(x^{*}\right)^{*}=1\right]
\end{aligned}
$$

An illustrative example of the numerical integration is given in Appendix D. Numerical values of $U^{*}$ as a function of $\Delta^{*}, \operatorname{Pr}$ and $n$ are tabulated in tables; and if these values are plotted in graphs, (not shown in this thesis) they can be matched with Fig. 5 to obtain the corresponding values of $\Delta^{*}$ and $x^{*}$. The final results, $\Delta^{*}$ and $x^{*}$, are given in Table 3 and presented in Fig. 10. 


\section{CHAPTER $V$}

\section{HEAT TRANSFER CHARACTERISTICS}

A. Definition of the Nusselt Number

The Nusselt number is defined as

$$
N_{u}=\frac{b h}{k}=\frac{b k \frac{\partial T}{\partial y} / y=0}{k\left(T_{b}-T_{w}\right)}
$$

where $T_{b}$ is the bulk temperature.

. If the following dimensionless quantities are introduced,

$$
\begin{aligned}
& T_{b}^{*}=\frac{T_{b}-T_{w}}{T_{\infty}-T_{w}} \\
& T^{*}=\frac{T-T_{w}}{T_{\infty}-T_{w}}=\frac{3}{2}\left(\frac{y}{\Delta}\right)-\frac{1}{2}\left(\frac{y}{\Delta}\right)^{3} \\
& y^{*}=\frac{y}{b}
\end{aligned}
$$

the Nusselt number becomes

$$
N_{u}=\frac{\frac{\partial T^{*}}{\partial y^{*}} / y^{*}=0}{T_{b}^{*}}
$$

$\mathbb{T}_{b}$ can be found from energy balance and is given by

$$
\bar{U} b_{p} C_{p}\left(T_{\infty}-T_{b}\right)=\int_{0}^{x} k\left(\frac{\partial T}{\partial y}\right)_{y=0} d x
$$

The left hand side gives the change of enthalpy of fluid between the entering point and any point $x$ along the axial direction. The right hand side represents the total amount of heat transferred from fluid to wall in this distance. 
After rearrangement, Eq. (5-5) becomes

$$
\begin{aligned}
\frac{T_{\infty}-T_{b}}{T_{\infty}-T_{w}} & =\frac{k}{\bar{U} \rho C_{p} b^{2}} \int_{0}^{x}\left(\frac{\partial T^{*}}{\partial y^{*}}\right)_{y^{*}=0} d x \\
& =\frac{1}{P r} \int_{0}^{x^{*}}\left(\frac{\partial T^{*}}{\partial y^{*}}\right)_{y^{*}=0} d x^{*} \\
& =1-\frac{T_{b}-T_{w}}{T_{\infty}-T_{w}} \\
& =1-T_{b}^{*}
\end{aligned}
$$

or

$$
T_{b}^{*}=1-\frac{1}{\operatorname{Pr}} \int_{0}^{x^{*}}\left(\frac{\partial T^{*}}{\partial y^{*}}\right)_{y^{*}=0} d x^{*}
$$

and

$$
\left(\frac{\partial T^{*}}{\partial y^{*}}\right)_{y^{*}=0}=\frac{3}{2 \Delta^{*}}
$$

Combining Equations $(5-4),(5-7)$ and $(5-8)$, we have

$$
N u_{x}=\frac{\frac{3}{2} \frac{1}{\Delta^{*}}}{1-\frac{3}{2 P_{r} \int_{0}} \frac{d x^{*}}{\Delta^{*}}}
$$

B. Calculation of the Local Nusselt Number by Eq. (5-9) The integral $\int_{0}^{x^{*}} \frac{d x^{*}}{\Delta^{*}}$ in $\mathrm{Eq} \cdot(5-9)$ can be evaluated as follow:

$$
\begin{array}{r}
\int_{0}^{x^{*}} \frac{d x^{*}}{\Delta^{*}}=\int_{0}^{x^{*}} \frac{d x^{*}}{\Delta^{*}}+\int_{0}^{10^{-4}} \frac{d x^{*}}{\Delta^{*}}+\int_{10^{-4}}^{x^{*}} \frac{d x^{*}}{\Delta^{*}} \\
\text { for } x_{1}^{*} \leq 1 \times 10^{-4}
\end{array}
$$




$$
\begin{gathered}
\int_{0}^{x^{*}} \frac{d x^{*}}{\Delta^{*}}=\int_{0}^{10^{-4}} \frac{d x^{*}}{\Delta^{*}}+\int_{0^{-4}}^{x^{*}} \frac{d x^{*}}{\Delta^{*}} \\
\text { for } x_{1}^{*} \geq 1 \times 10^{-4} \quad(5-11) .
\end{gathered}
$$

where $\mathrm{x}_{1}^{*}$ is determined by Eq. $(4-20)$.

The last integral in both equations can be obtained graphically. However, for the other integrals, $\Delta^{*} \rightarrow 0$ as $x^{*} \rightarrow 0$, or $1 / \Delta^{*} \rightarrow \infty$; and graphical integration becomes unreliable. On the other hand, in the interval, $0 \leq x^{*} \leq 10^{-4}$, flow can be assumed as that of a flat plate, and the solutions for flat plate given by Eq. (4-18) and (4-19) can be utilized. For $x_{1}^{*} \leq 1 \times 10^{-4}$, the Eq. $(5-10)$ becomes

$$
\begin{aligned}
& \int_{0}^{x^{*}} \frac{d x^{*}}{\Delta^{*}}=\int_{0}^{x_{1}^{*}} \frac{\sqrt{P_{r}} d x^{*}}{2.65868 / \sqrt{x^{*}}} \\
& +\int_{x_{1}^{*}}^{10^{-4}} \frac{\left[\frac{K_{6}^{4}}{18} \operatorname{Pr}\left(\frac{1+2 n}{1+n}\right)\right]^{\frac{1}{3}} d x^{*}}{1.3395\left(x^{*}\right)^{2+n} \frac{1+n}{3+n}}+\int_{10^{-4}}^{x^{*}} \frac{d x^{*}}{\Delta^{*}} \\
& \int_{0}^{x^{*}} \frac{d x^{*}}{\Delta^{*}}=\frac{\left(\operatorname{Pr} x^{*}\right)^{\frac{1}{2}}}{1.329340} \\
& +\frac{3}{1.3395}\left(\frac{k_{6}^{\frac{1}{n}} P_{r}}{18}\right)^{\frac{1}{3}}\left(\frac{1+n}{1+2 n}\right)^{\frac{2}{3}}\left[10^{-4}-x_{1}^{*}\right]^{\frac{1+2 n}{3(1+n)}} \\
& +\int_{0-4}^{x^{*}} \frac{d x^{*}}{\Delta^{*}}
\end{aligned}
$$

For $x_{1}^{*} \geq 1 \times 10^{-4}$, Eq. $(5-11)$ is given by

$$
\int_{0}^{x^{*}} \frac{d x^{*}}{\Delta^{*}}=\frac{\sqrt{P_{r}}}{132.934}+\int_{10^{-4}}^{x^{*}} \frac{d x^{*}}{\Delta^{*}}
$$


If a graph of $\frac{1}{\Delta^{*}}$ Vs. $x^{*}$ for each $\operatorname{Pr}$ and $n$ is plotted, the integral $\int_{10^{-4}}^{x^{*}} \frac{d x^{*}}{\Delta^{*}}$ can be integrated from the graph, and hence the local Nusselt number is obtained. Appendix E gives a . sample calculation. The values of $\mathrm{Nu}_{\mathrm{x}}$ and $\mathrm{x}^{*}$ are given in Table 4 and also presented in Fig. 11. 
CHAPTER VI DISCUSSION OF RESUITS

A. Velocity Profile

In this thesis the velocity distribution given by Eq. (3-2) coincides with the fully developed profile when $\delta=b$, but its approach is not asymptotic. It is believed that the boundary layer approach is not suitable as velocity becomes fully developed. Collins and schowalter (5) used another method to obtain more exact expressions. No apparent difference between their results and those obtained in this work is detected when compared.

\section{B. Entrance Length}

It has been pointed out that a fully developed velocity profile is defined in this thesis as the profile when $\delta=b$. This means that the velocity approaches its fully developed value finitely. But the actual approach should be asymptotic. Some authors define entrance length differently. Whey choose the distance required for the centerline velocity to reach an arbitrary percentage (usually 99\%) of its fully developed value as the entrance length. This gives an entrance length larger than that obtained by the "finite" definition. In Bogue's work (3) on non- 
Newtonian fluid flowing in the entrance of a pipe, it was found that the values of entrance length obtained by the "finite" definition are about half of those by the "asymptotic" definition. Similar verark may be said about flow in a duct, but the ratio between the values of the entrance length may not be half. In Colizins and schowalter's work they used the "asymptotic" definition for entrance length and their values are definitely higher than those obtained here.

It is known in Newtonian fluid lov that $95 \%$ of the additional pressure loss is accomplished in one halp of the entrance length. Since a pseudoplastic iluid has a flatter profile, its Iully developed form is established more quickly than that for a Newtonian fluid. As a result the distance for the velocity development should be shorter. Therefore the "Iinite" definition of entrance length should be more appropiate when applied to a pseudoplastic fluid.

\section{Pressure Drop}

Values of the entry pressure arop correction fector "Cor." for different $n$ are lower then those obtained by Collins and schowalter. This is contrary to expectation. For a given $n$, their value of entrance length is higher end should give a smaller "Cor." according to (3-36). For Newtonian fluid, "Cor." was found to be 0.584 compared with their value 0.67 and 0.60 reported by Schlichting (14). 


\section{Temperature Profiles}

The smoothness of the $\Delta^{34} \nabla s . X^{*}$ curves in Fig. 10 indicates that there is no sudaen change of slope when Eqs. (4-15) and $(4-16)$ are joined together. This shows that even though each set of these equations is applicable within certain ranges, it will not break down completely if they were used beyond theix applicable ranges. Since the velocity and themal boundary layers are analogous to each other, their growth should follow a general shape, which is quite evident when fig. 6 and 10 are compared.

No othex results are available to test the accuracy of Eqs. $(4-15),(4-16)$ end $(4-22)$. It has been discussed that the boundary layer analysis is not suitable to the development of velocity profile for the region when $\delta \rightarrow 1$. Can the same be said about boundary layer calculation for $\triangle$ when $\Delta$ approaches b? No conclusive answer has been found. It is a general belies that the boundary concept will give good results if the interaction of heat transfer between the two walls is negligible.

\section{Heat Transier Characteristics}

Fron Fig. 11, it may be concluded for a fixed value of $x^{*}$; the Nusselt number increases with increasing Prandt number, but decreases with increasing "n". The Nusselt number reaches the same value (about 0.199 ) when $\Delta^{*}=1$, 
regardless of the values of Prandt number and " $n$ ". Ihis means that the Nusselt number is independent of the PrandtI number and the flow behavior index $(n)$ once the temperature. profile is fully developed. Another observation is that the values of $x^{*}$ decreases with decreasing Prandt number for fully developed heat transfer. 
CHAPIER VI

CONOLUSION

Laminar flow behavior and heat transfer of pseudoplastic fluids obeying the power law in the entrance region of a flat duct have been studied. Boundary layer theory is applied in the simultaneous development of velocity and temperature profiles, and solutions are obtained with simplicity by the approximate nethod of von Karman and Pohlhausen. Numerical values for $U^{* \prime}, \delta^{*}, \Delta^{*}$ and Musselt number as a function of $x^{*}$ are tabulated and plotted for $n=3 / 4,1 / 2$ and $1 / 4$ over the range of Prandt number from $i$ to 200. Other results include entrance length and pressure Ioss. Comparison between results of this thesis and those of other theoretical analyses reported in the literature is favorable. The simplicity of the approximate method employed here is obvious and certainly an advantage over the tine consuming and laborous exact method. No efrort is made to compared the theoretical results with those obtained by experimental work since no such findings have ever been published. 


\section{BIBIIOGRAPHY}

1. Acrivos, A., M.J. Shah, and E.E. Petersen, A.I.Ch.E. Journal, $6,312(1960)$.

2. Bird, R.B., W.E. Stewart, and E.N. Lightfoot, "Transport Phenomena," pp. 10-15 and 101-108, Wiley, New York (1960).

3. Bogue, D.C., Ind. Eng. Chem., 51, 874 (1959).

4. Collatz, I., "The Numerical Ireatment of Differential Equations"; pp.61-78, Springer-Verlag, Berlin (1960).

5. Collins, M., and W.R. Schowalter, "Behavior of nonNewtonian Fluids in the Inlet Region of a Channel," technical paper published by Princeton University, Princeton, New Jersey.

7. Goldberg, P., M.S. Thesis, Mech. Eng. Dept., M.I.T., Jan., 1958.

8. Kays, W.M., Trans. A.S.M.E., 77, 1265 (1955).

9. Kunz, K.S., "Numerical Analysis," pp. 206-208, McGraw-Hill, New York (1957).

10. Ianghaar, H.I. Jour. AppI. Mechanics, 9. No. 2, A-55 (1942).

11. Iyche, B.C., and R.B. Bird, Chem. Ing. Sci., 6, $(1957)$.

12. Metzner, A.B., "Advances in Chemical Engineering," ed. by T.B. Drew and J.W. Hookes, Jr., VoI. I, pp. 79-150, Academic Press, New York (1956).

13. St. Pierre, C., M.A.Sc. Thesis, Chem. Eng. Dept., Essex College, Assumption University of Windsor, Windsor, Ontario.

14. Schlicting, H., "Boundary Layer Theory," McGraw-Hill, New York $(1960)$.

15. Sparrow, E.M., Nat. Advisory Comm. Aero. Tech. Note 3331 ( Jan T955). 
16. Tien, C., Can. Jour. Chem. Eng., 40, No. 3, 130 (June 1962)

17. Tien, C., "Approximate Calculation on Two-Dimensional Boundary Layer of non-frewtonian Fluid," to be published.

18. Tomita, Y., Bulletin of J.S.M.E., 4, 77 (1961).

19. Vilkinson, W.I., "Non-Newtonian Fluids," Pergamon Press, New York (1960). 


\section{NOMENCLATURE}

Equation numbers given after description refer to equations in which the symbols are first used or thoroughly defined. Dimensions are given in terms of mass (M), length $(I)$, time $(t)$, and temperature $(T)$.

$$
\begin{aligned}
& \mathrm{A}=\text { constant in Eyring model, Eq. (1-5). } \\
& B=\text { constant in Eyring model, Eq. (1-5). } \\
& \mathrm{b} \text { = half-spacing between parallel walls in the duct, I. } \\
& c_{1}, c_{2}, c_{3} \& c_{4} \\
& \text { = coefficients of the polynomial expression for } \\
& \text { velocity distribution, Eq. (3-2). } \\
& \text { Cor. = Entry Pressure Drop Correction, Eq. (3-35), M/Lt }{ }^{2} \text {. } \\
& c_{p}=\text { heat capacity at constant pressure, } I^{2} / t^{2} \text {. } \\
& \mathrm{h} \text { = heat transfer coefficient, or increment. } \\
& I_{2}=\text { second invariant of stress tensor, } \mathrm{Eq} \cdot(2-7) \text {. } \\
& \mathrm{K}_{1}=\text { constant, } \mathrm{Eq} \cdot(3-15) \text {. } \\
& \mathrm{K}_{2}=\text { constant, } \mathrm{Eq} \cdot(3-17) \text {. } \\
& \mathrm{K}_{3}=\text { constant, } \mathrm{Eq} \cdot(4-8) \text {. } \\
& \mathrm{K}_{4} \text { = constant, } \mathrm{Eq} \cdot(4-9) \text {. } \\
& \mathrm{K}_{5}=\text { constant, } \mathrm{Eq} \cdot(4-10) \text {. } \\
& K_{6}=\text { constant, Eq. (4-21). } \\
& \mathrm{k}=\text { thermal conductivity, } M I / t^{3} \mathrm{~T} \text {. } \\
& K_{\nabla}=\text { correction term in Appendix } D \text {. }
\end{aligned}
$$




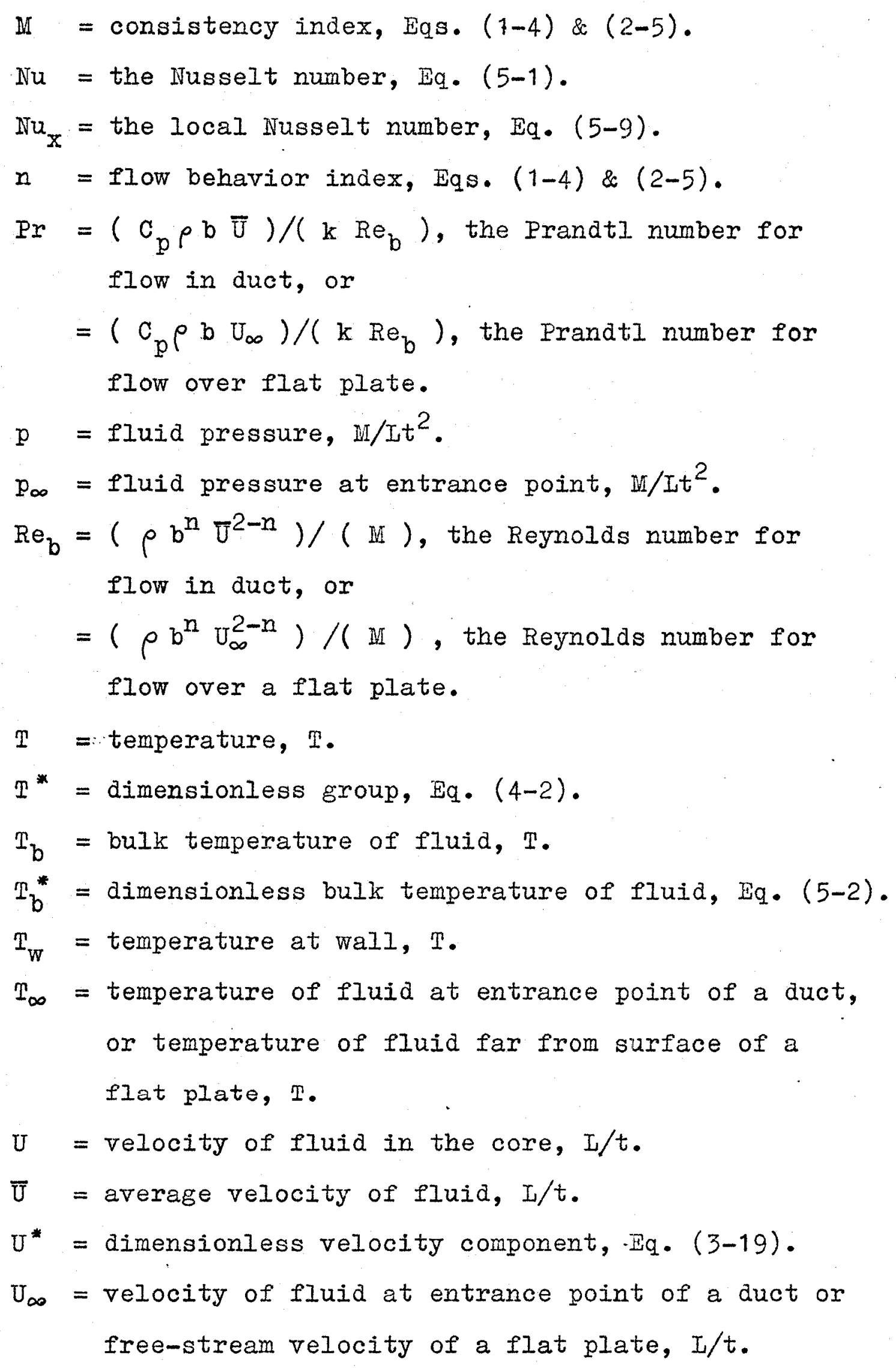




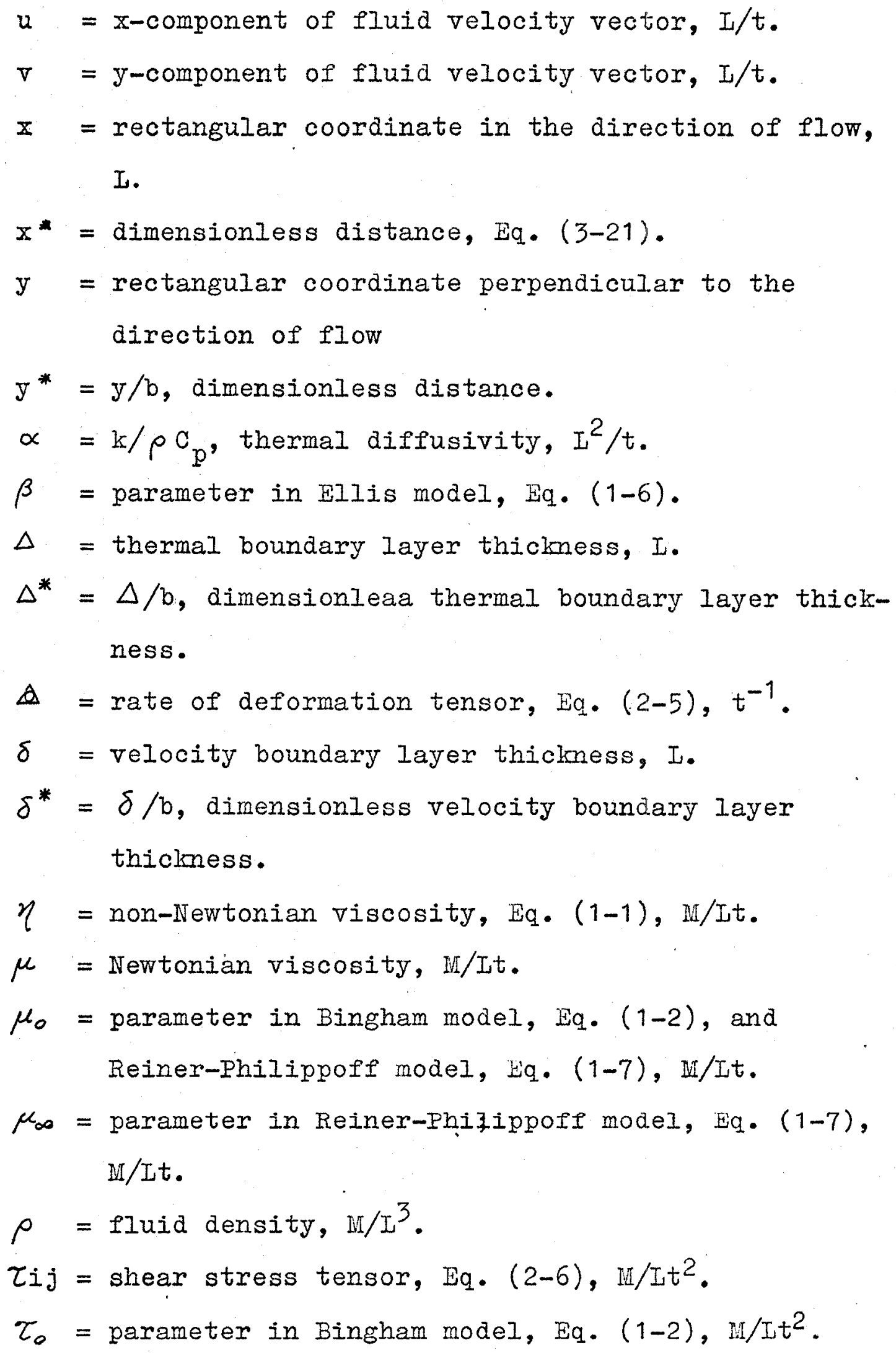




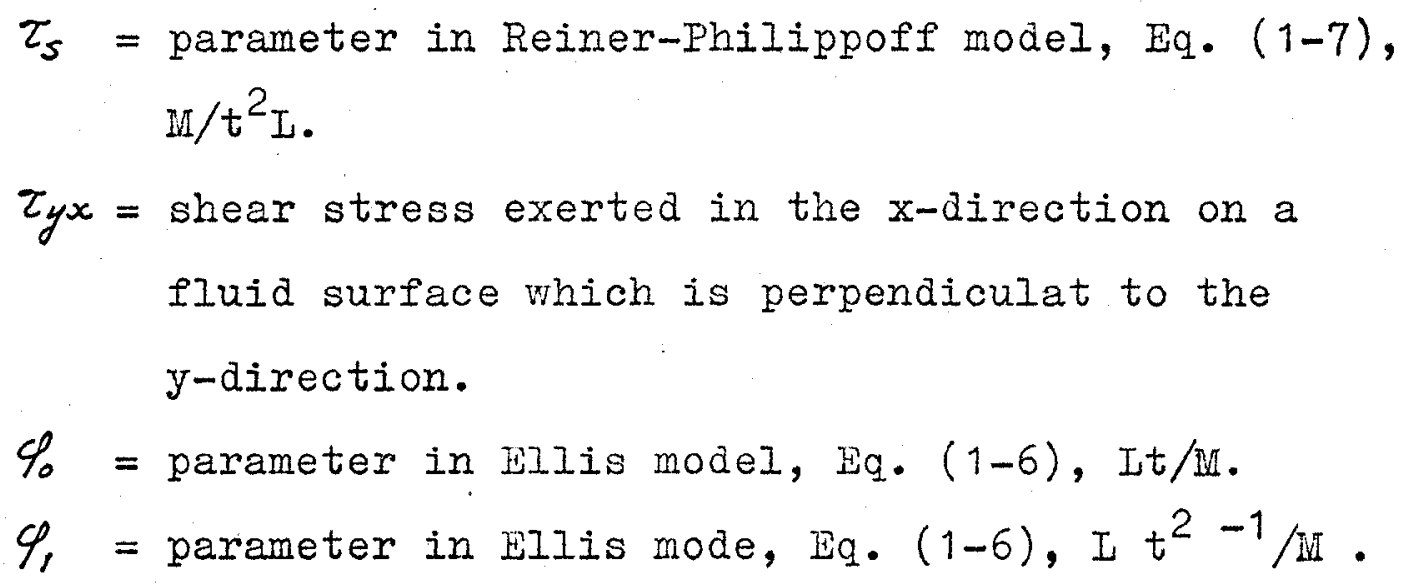




\section{APPINDIX A \\ SAMPIE CALCULATION FOR DETERHINATION \\ OF COEPICIMNS $C_{i}$ IN $E Q \cdot(3-2)$}

1. By matching $\equiv q \cdot(3-2)$ with $(3-6)$

Eq. $(3-2)$ is given as

$$
\frac{u}{U}=c_{1}\left(\frac{\ddot{q}}{\delta}\right)+c_{2}\left(\frac{\ddot{z}}{\delta}\right)^{2}+c_{3}\left(\frac{\mathscr{z}}{\delta}\right)^{3}+c_{4}\left(\frac{\xi}{\delta}\right)^{4}
$$

If $n=1 / 2 . \mathbb{q} \cdot(3-6)$ is equal to

$$
\begin{aligned}
\frac{u}{U} & =1-\left(1-\frac{y}{\delta}\right)^{3} \\
& =3\left(\frac{y}{\delta}\right)-3\left(\frac{y}{\delta}\right)^{2}+\left(\frac{y}{\delta}\right)^{3}
\end{aligned}
$$

Comparing with Eq. $(3-2)$, we have

$$
\begin{aligned}
& c_{1}=3 \\
& c_{2}=-3 \\
& c_{3}=1 \\
& c_{4}=0
\end{aligned}
$$

2. By Eq. $(3-9)$ to $(3-12)$

Eq. $(3-9),(3-10)$ and $(3-11)$ can be rearranged to the Iorm

$$
\begin{aligned}
c_{1}+C_{2}+C_{3} & =1-c_{4} \\
c_{1}+2 c_{2}+3 c_{3} & =-4 c_{4} \\
\frac{C_{1}}{2}+\frac{c_{2}}{3}+\frac{c_{3}}{4} & =1-\frac{n}{1+2 n}-\frac{c_{4}}{5}
\end{aligned}
$$


Applying the method of determinant to the above equations, one can obtain expressions for $c_{1}, c_{2}$ and $c_{3}$ in terms of $c_{4}$ and $n$. These are

$$
\begin{aligned}
& c_{1}=6-\frac{12 n}{1+2 n}-\frac{2}{5} C_{4} \\
& c_{2}=-9+\frac{24 n}{1+2 n}+\frac{9}{5} C_{4} \\
& c_{3}=4-\frac{12 n}{1+2 n}-\frac{12}{5} c_{4}
\end{aligned}
$$

Substitution of Eq. $(A-6),(A-7)$ and $(A-8)$ into $(3-11)$ gives. $\mathrm{C}_{4}$ in terms of $\mathrm{n}$ :

$$
\begin{aligned}
c_{4}= & \frac{7875}{4}\left\{-\left[\frac{1}{175}+\frac{n}{175(1+2 n)}\right]\right. \\
& \pm \sqrt{\left.\left[\frac{1}{175}+\frac{n}{175(1+2 n)}\right]^{2}-\frac{8}{7875\left[\frac{48 n^{2}}{35(1+2 n)^{2}}-\frac{n}{2+3 n}-\frac{4 n}{35(1+2 n)}+\frac{3}{35}\right]}\right]}
\end{aligned}
$$

Therefore, once the value of $n$ is chosen, $C_{4}$ is first obtained by $(A-9)$, then $C_{1}, C_{2}$ and $C_{3}$ can be found by $(A-6),(A-7)$ and $(A-8)$.

For example, if $n=1 / 4$, we have

$$
\begin{aligned}
& c_{4}=\frac{7875}{4}\left\{\left[\frac{1}{175}+\frac{.25}{175(1.5)}\right]\right. \\
& \left. \pm \sqrt{\left[\frac{1}{175}+\frac{.25}{175(1.5)}\right]^{2}-\frac{8}{1875}\left[\frac{48(.25)^{2}}{35(1.5)^{2}}-\frac{.25}{2.75}-\frac{1}{35(1.5)}+\frac{3}{35}\right]}\right\} \\
& =-2.27642 \\
& \text { or } \quad-23.95968 \text { (invalid) }
\end{aligned}
$$




$$
\begin{aligned}
& c_{3}=4-\frac{12(.25)}{1.5}-\frac{12}{5}(2.27642)=7.46340 \\
& c_{2}=-9+\frac{24(.25)}{1.5}+\frac{9}{5}(2.27642)=9.09755 \\
& c_{1}=6-\frac{12(.25)}{1.5}-\frac{2}{5}(2.27642)=4.91056
\end{aligned}
$$




\begin{abstract}
APPENDIX B
NUVERICAI INTEGRATION OF EQ.'(3-23)

BY THE NEIHOD OF CIIPPINGER \& DIMSDALE ${ }^{+}$
\end{abstract}

Sample calculation is based on $n=1 / 2$, and Eq. $(3-23)$. becomes

$$
\begin{aligned}
\frac{d x^{*}}{d U^{*}} & =\frac{\left(U^{*}-1\right)^{\frac{1}{2}}}{U^{*}(.75)^{\frac{1}{2}}}\left\{\left[\frac{.25+2(.107143)}{\cdot 25}\right] U^{*}-\left(\frac{.25+.107143}{.25}\right)\right\} \\
& =\left(U^{*}-1\right)^{\frac{1}{2}}\left[2 \cdot 144449-\frac{1.649576}{U^{*}}\right]
\end{aligned}
$$

The solution is required over the interval $U^{*}=1$ to $U=$ fully developed value which is $4 / 3$ by Eq. (3-24) given that $U^{*}=1$ at $x^{*}=0$.

The expressions involved in the Clippinger and Dimsdale method are listed below:

$$
\begin{aligned}
& x^{*}\left(U_{2}^{*}\right)=x^{*}\left(U_{0}^{*}\right)+2 h x^{* \prime}\left(U_{0}^{*}\right) \\
& x^{*}\left(U_{1}^{*}\right)=\frac{1}{2}\left[x^{*}\left(U_{0}^{*}\right)+x^{*}\left(U_{2}^{*}\right)\right]+\frac{h}{4}\left[x^{*}\left(U_{0}^{*}\right)-x^{*}\left(U_{2}^{*}\right)\right](B-3)
\end{aligned}
$$

Simpson's rule,

$$
x^{*}\left(U_{2}^{*}\right)=x^{*}\left(U_{0}^{*}\right)+\frac{h}{3}\left[x^{* \prime}\left(U_{0}^{*}\right)+4 x^{* \prime}\left(U_{1}^{*}\right)+x^{*^{\prime \prime}}\left(U_{2}^{*}\right)\right]
$$

Hethod given in reference (9), pp 206-208.

45 
where $x^{*}\left(U_{i}^{*}\right)=$ value of $x^{*}$ when $U^{*}$ is equal to $U_{i}^{*}$ $x^{*}\left(U_{i}^{*}\right)=$ value of $d x^{*} / d U^{*}$ when $U^{*}$ is equal to $U_{i}^{*}$ $\mathrm{h}=$ increment of $U^{*}$

The first few results of Eq. (B-1) are given in Table B. 1 where $h$ is chosen to be 0.01 .

Table B.1 Partial Solution of $\mathrm{Eq} \cdot(\mathrm{B}-1)$

\begin{tabular}{|c|c|c|c|c|}
\hline$U^{*}$ & $\left(U^{*}-1\right)^{\frac{1}{2}}$ & $2.144449-\frac{1.649576}{U^{*}}$ & $d x^{*} / d U^{*}$ & $x^{*}$ \\
\hline 1.00 & 0 & 0.49491 & 0 & 0 \\
1.01 & 0.10000 & 0.51125 & 0.51125 & $-1.8641 \times 10^{-4}$ \\
& & 0.52726 & 0.74656 & 0 \\
1.02 & 0.14142 & $0.393 \times 10^{-4}$ \\
& & 0.54296 & 0.094046 & $6.4288 \times 10^{-4}$ \\
1.03 & 0.17321 & 0.55836 & 0.111672 & $1.4913 \times 10^{-4}$ \\
& & & & $2.7095 \times 10^{-4}$ \\
\hline
\end{tabular}

The computing procedures are:

1. From Eq. $(B-1)$, find $d x^{*} / d U^{*}$ at $U^{*}=1.0$ which is 0 .

2. Applying $E q .(B-2)$, the first value of $x^{*}(1.02)$ is found to be 0 .

3. Use Eq. (B-3) to obtain a first approximation to $x^{*}(1.01)$, namely, $-1.8641 \times 10^{-4}$. 
4. Use Sinipson's rule, Eq. $(B-4)$, to get a better value for $x^{*}(1.02)$ which is $8.3560 \times 10^{-4}$.

5. Using $x(1.02)=8.3560 \times 10^{-4}$ instead of the old value, $x^{\prime \prime}(1.01)$ is recomputed by $\mathrm{Eq} \cdot(\mathrm{B}-2)$ to obtain $3.2992 \times 10^{-4}$.

6. Successive approximations to $x^{*}(1.01)$ and $x^{*}(1.02)$ by the above procedure are terminated when no further change takes place.

7. The next two values $x^{*}(1.03)$ and $x^{*}(1.04)$ are obtained in exactly the same way from the knowledge of only $x *(1.02)$. Thus, each step involves a calculation of two new values and entails exactly the same procedure.

Actual computation was carried out by an IGP-30 digital computer. The results are tabulated in Table 2 and presented graphically in Fig. 5 . 


\section{- APPENDTX o \\ FING PIARE ANATYSTS}

The boundary layer theory is applied here as in the analysis for fiow in the auct. The core velocity is constant and equals the free streom velocity $\left(U_{\infty}\right)$. An expression for velocity distribution within the velocity boundary layer is assumed and the momentun integral method is used. to obtain relation for velocity boundary thicmess. The velocity distribution is given by

$$
\begin{array}{ll}
\frac{u}{U_{\infty}}=C_{1}\left(\frac{y}{\delta}\right)+C_{2}\left(\frac{y}{\delta}\right)^{2}+C_{3}\left(\frac{\mathscr{y}}{\delta}\right)^{3}+C_{A}\left(\frac{y}{\delta}\right)^{4} & \text { for } 0 \leqslant \mathrm{y} \leq \delta \\
u=U_{\infty} & \text { for } \mathrm{y} \geqslant \delta
\end{array}
$$

The nonentum integral equotion is given by

$$
\frac{d}{d x} \int_{0}^{\delta} u\left(U_{\infty}-u\right) d y=\frac{M}{\rho}\left[\left(\frac{\partial u}{\partial y}\right)_{y=0}^{n}\right]
$$

When $\mathrm{Eq} \cdot(\mathrm{C}-1)$ is substituted into $\mathrm{Eq} \cdot(\mathrm{C}-3)$, we have

$$
\delta^{n+1}=\frac{(1+n) M C_{1}^{n} U_{\infty}^{n-2} x}{K_{2} \rho}
$$

Transforming Eq. (C-4) into dimensionless quantities as defined before except where $\mathbb{U}$ is replaced by $U_{\infty}$ in the dimensionless forms gives 


$$
\begin{aligned}
& \delta^{*+n}=\frac{(1+n) c_{1}^{n} x^{*}}{k_{2}} \\
& \delta^{*}=\left[\frac{(1+n) c_{1}^{n}}{k_{2}} x^{*}\right]^{\frac{1}{1+n}}
\end{aligned}
$$

Acrivos et al. (1) have investigated the heat transfer problem for non-Newtonian fluid flow over a flat plate.

For $n<1$ and $x-\infty$ their result, expressed in terms of present variables, is given as

$$
\left(\frac{\partial T^{*}}{\partial y}\right)_{y=0}=\frac{1}{0.8930}\left[\frac{k_{6}^{\frac{1}{n}} \operatorname{Pr}}{18}\left(\frac{1+2 n}{1+n}\right)\right]^{\frac{1}{3} x^{*-\frac{2+n}{3(1+n)}}}
$$

where $\quad k_{6}=\left[\frac{39}{280}\left(\frac{1.5}{1+n}\right)\right]^{\frac{n}{1+n}}$

If a temperature profile is assumed of the form

$$
T^{*}=\frac{T-T_{w}}{T_{\infty}-T_{w}}=\frac{3}{2}\left(\frac{y}{\Delta}\right)-\frac{1}{2}\left(\frac{y}{\Delta}\right)^{3}
$$

we obtain

$$
\left(\frac{\partial T^{*}}{\partial y}\right)_{y=0}=\frac{3}{2 \Delta}
$$

Therefore, combining Equations $(c-5)$ and $(c-7)$, we have in dimensionless form

$$
\begin{array}{r}
\Delta^{*}=1.3395\left[\frac{K_{6}^{\frac{1}{n}} p_{r}}{18}\left(\frac{1+2 n}{1+n}\right)\right]^{-\frac{1}{3}} x^{* \frac{2+n}{3(1+n)}} \\
\text { for } x^{*}>x_{1}^{*}
\end{array}
$$

For $n<1$ and $x \rightarrow 0$, the velocity distribution in the boundary may be disregarded and the resulting expression 
for $\Delta^{*}$ is

$$
\Delta^{*}=\frac{3}{2} \sqrt{\frac{\pi}{P r}} x^{* \frac{1}{2}}=\frac{2 \cdot 65868 /}{\sqrt{\operatorname{Pr}}} x^{* \frac{1}{2}}
$$

At some point $x_{1}^{*}$ the two equation for $\Delta^{*}$ will be joined. By equating Equations (4-18) and (4-19) we can solve for $x_{i}^{*}$,

$$
x_{1}^{*}=\left\{\frac{2.658681}{1.3395\left(P_{r}\right)^{\frac{1}{6}}}\left[\frac{K_{6}^{\frac{1}{n}}}{18}\left(\frac{1+2 n}{1+n}\right)\right]^{\frac{1}{3}}\right]^{6\left(\frac{1+n}{1-n}\right)}
$$




\section{APPENDIX D \\ NUWERICAI INTEGRATION OF EQ. (4-15) AND (4-16) \\ BY RUNGE -KUTMA METHOD ${ }^{+}$}

As it has been noted in Ch. 4, integration will not start at the entrance point, but a small distance downstream. In the immediate neighborhood of the entrance point, the flow is assumed to be the same as that over a flat plate. Therefore computation is made to start at $\Delta^{*}=10^{-4}$ which is selected because it will give a corresponding value of $x^{*}$ so small that within this distance the assumption of llat plate behavior is applicable. However, for $\Delta^{*}=10^{-4}$, two values of $\mathrm{x}^{*}$, one from Eq. (4-18) and the other from (4-19) may be obtaired. The starting values for integration depend on the correct choice of $x^{*}$ among these two values. Sample calculation is based on $n=1 / 4$ and $\operatorname{Pr}=100$. From Eq. (4-21)

$$
\begin{aligned}
K_{6} & =\left[\frac{39}{280}\left(\frac{1.5}{1+n}\right)\right]^{\frac{n}{1+n}} \\
& =\left[\frac{39}{280}\left(\frac{1.5}{1.25}\right)\right]^{\frac{.25}{1.25}} \\
& =0.69938
\end{aligned}
$$

\footnotetext{
+Mevod given in reference (4), pp 61-78.
} 
From Eq. (4-18)

$$
x^{*}=\left(\frac{\Delta^{*} \sqrt{P \gamma}}{2.658681}\right)^{2}=\left(\frac{10^{-4} \sqrt{100}}{2.658681}\right)^{2}=1.4147 \times 10^{-7}
$$

From Eq. (4-19)

From Eq. (4-20)

$$
\begin{aligned}
x^{*} & =\left\{\frac{\Delta^{*}}{1.3395}\left[\frac{k_{6}^{\frac{1}{n}} \operatorname{Pr}}{18}\left(\frac{1+2 n}{1+n}\right)\right]^{\frac{1}{3}}\right\}^{\frac{3(1+n)}{2+n}} \\
& =\left\{\frac{10^{-4}}{1.3395}\left[\frac{(.69938)^{4} 100}{18}\left(\frac{1.5}{1.25}\right)\right\}^{\frac{1}{3}}\right\}^{\frac{3.75}{2.25}}=1.71705 \times 10^{-7}
\end{aligned}
$$

$$
\begin{aligned}
x_{1}^{*} & =\left\{\frac{2.658681}{1.3395\left(P_{r}\right)^{\frac{t}{6}}}\left[\frac{k_{6}^{\frac{1}{n}}}{18}\left(\frac{1+2 n}{1+n}\right)\right]^{\frac{1}{3}}\right\}^{6\left(\frac{1+n}{1-n}\right)} \\
& =\left\{\frac{2.658681}{1.3395(100)^{\frac{1}{6}}}\left[\frac{(.69938)^{4}}{18}\left(\frac{1.5}{1.25}\right)\right]\right\}^{10} \\
& =5.81376 \times 10^{-7}
\end{aligned}
$$

Values of $x$ * from Eq. (4-18) and (4-19) are both smaller than $x_{1}^{*}$. Since Eq. $(4-18)$ is applicable for $x^{*}<x_{1}^{*}$, its $x^{*}$ value is the correct choice.

From Eq. (4-17)

$$
\begin{aligned}
\delta^{*} & =\left[\frac{(n+1) c_{1}^{x}}{\kappa_{2}} x^{*}\right]^{\frac{1}{1+n}} \\
& =\left[\frac{1.25(4.91056)^{\frac{1}{4}}}{.07577^{13}}\left(1.41471 \times 10^{-7)}\right]^{\frac{1}{1.25}}\right. \\
& =4.29256 \times 10^{-5}
\end{aligned}
$$

In the neighborhood of the entrance point, $U^{*}$ is given by Eq. $(3-25)$

$$
U^{*}=\left[\frac{c_{1}^{n} k_{1}^{n+1}(1+n)}{k_{2}} x^{*}\right]^{\frac{1}{1+n}}+1
$$




$$
\begin{aligned}
U^{*} & =\left[\frac{(4.91056)^{\frac{1}{0}}(.166671)^{1.25}(1.25)}{.0757713}\left(1.41471 \times 10^{-7}\right)\right]^{\frac{1}{1.25}}+1 \\
& =1.0000071
\end{aligned}
$$

Since $\Delta^{*}=10^{-4}>C^{*}=4.29256 \times 10^{-5}, \mathrm{Eq} \cdot(4-15)$ should be integrated first. For $n=1 / 4 \cdot \mathrm{Eq} \cdot(4-15)$ reduces to

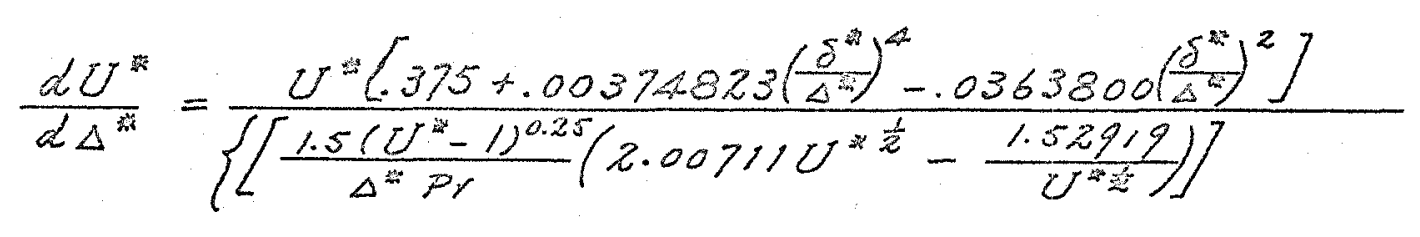$$
+\left[.1666715^{4}-.0363800 \frac{\delta^{42}}{\Delta^{2}}+.00124941 \frac{\delta^{24}}{\Delta^{43}}\right]
$$$$
\left.+\left[-.375 \Delta^{20}+\frac{1}{U^{2}}-.436547 \frac{\delta^{2}}{U^{2} \Delta^{2}}+.0299850 \frac{\delta^{23}}{U^{24} \Delta^{23}}\right]\right\}
$$

$(D-1)$

If the values of $\Delta^{\circ}, \delta^{*}$ and $U^{*}$ are substituted into $\mathrm{Eq} \cdot(D-1)$, we have

$$
\frac{d U^{*}}{d \Delta^{*}}=8.1464648 \times 10^{-2}
$$

Hence all the starting values are obtained and we are ready to proceed to the integretion of $\mathrm{Eq} \cdot(4-15)$.

$\mathrm{Bg} \cdot(\mathrm{D}-1)$ cen be written as

$$
\frac{d U^{*}}{\alpha^{*} \Delta^{*}}=f\left(U^{*}, \delta^{*}, \Delta^{*}\right)
$$

and the conputing procedure for its integration by RungeKutta metiod may be sumarized in the following table: 
Table D.1 Runge-Kutta Scheme for the Differential Equation $\mathrm{dU} U^{*} / \mathrm{d} \Delta^{*}=f\left(U^{*}, \delta^{*}, \Delta^{*}\right)$

\begin{tabular}{|c|c|c|c|c|c|}
\hline Step & $\Delta^{*}$ & $U^{*}$ & $\delta^{*}$ & $\frac{k_{v}}{2}=\frac{h}{2} f\left(U, \delta^{*}, \Delta^{*}\right)$ & Correction \\
\hline 1 & $\Delta_{0}^{*}$ & $U_{0}^{2}$ & $\delta_{0}^{*}$ & $k_{1} / 2$ & \multirow{4}{*}{$k=\frac{1}{3}\left(\frac{k_{1}}{2}+k_{2}+k_{3}+\frac{k_{k}}{2}\right)$} \\
\hline 2 & $\Delta_{0}^{*}+\frac{1}{2} h$ & $U_{0}^{*}+\frac{1}{2} k_{1}$ & $\frac{1}{K_{1}}\left(1-\frac{1}{U^{*}}\right)$ & $k_{2} / 2$ & \\
\hline 3 & $\Delta_{0}^{*}+\frac{1}{2} h$ & $U_{0}^{*}+\frac{1}{2} k_{2}$ & $\frac{1}{K_{1}}\left(1-\frac{1}{U^{*}}\right)$ & $k_{3} / 2$ & \\
\hline 4 & $\Delta_{0}^{*}+h$ & $U_{0}^{*}+k_{3}$ & $\frac{1}{K_{1}}\left(1-\frac{1}{U^{*}}\right)$ & $k_{4} / 2$ & \\
\hline 5 & $\Delta_{1}^{*}=\Delta_{0}^{*}+h$ & $U_{1}^{*}=U_{0}^{*}+k$ & $\delta_{1}^{*}=\frac{1}{K_{1}}\left(1-\frac{1}{U_{0}}\right)$ & & \\
\hline
\end{tabular}

where $k_{\nabla}$ is the correction and $h$ is the increment.

The values in step 1 are the starting values which were found previously. The increment $h$ should be small but its value may be increased later to speed up the integration. For this example the first increment $h$ is set to be $5 \times 10^{-4}$; $10^{-3}, 5 \times 10^{-3}, 10^{-2}$, and $2 \times 10^{-2}$ as integration proceeds. The values in step 1 are:

$$
\begin{aligned}
& \Delta_{0}^{*}=10^{-4} \quad \delta_{0}^{*}=4.29256 \times 10^{-5} \\
& U_{0}^{*}=1.0000071 \\
& \frac{d U^{*}}{\alpha \Delta^{*}}=8.1464648 \times 10^{-2} \\
& k_{1} / 2=8.1464648 \times 10^{-6}
\end{aligned}
$$

The values in step 2 are:

$$
\begin{aligned}
\Delta_{0}^{*}+\frac{1}{2} h & =10^{-4}+\frac{1}{2}\left(2 \times 10^{-4}\right) \\
& =2 \times 10^{-4} \\
U_{0}^{*}+\frac{1}{2} k_{1} & =1.0000071+8.1464648 \times 10^{-6} \\
& =1.0000153
\end{aligned}
$$


from Eq. (3-24)

$$
\begin{aligned}
\delta^{*} & =\frac{1}{K_{1}}\left(1-\frac{1}{U^{*}}\right) \\
& =\frac{1}{.166671}\left(1-\frac{1}{1.0000153}\right) \\
& =9.1773805 \times 10^{-5}
\end{aligned}
$$

from Eq. (D-1)

$$
\begin{aligned}
& \frac{d U^{*}}{d \Delta^{*}}=12072320 \\
& k_{2} / 2=1.2072320 \times 10^{-5}
\end{aligned}
$$

The calculation for the other steps follows the same procedure. The actual results of the calculation are given in Step 5 whereas the steps in between are for better approximation. These results in step 5 serve as starting value for the next $\Delta_{2}^{*}$ in the continuation of the solution. When $\Delta^{*}$ becomes less than $\delta^{*}$, integration is switched to Eq. $(4-16)$. For $n=1 / 4, E q \cdot(4-16)$ reduces to

$$
\begin{aligned}
& \frac{d U^{*}}{d \Delta^{*}}=\frac{U^{*}\left[\left[.982112\left(\frac{\Delta^{*}}{\delta}\right)-1.13719\left(\frac{\Delta^{*}}{\delta^{*}}\right)^{2}+.639720 \frac{\Delta^{* 3}}{\delta^{* 3}}\right]\right.}{\left[\left[\frac{1.5}{\Delta^{*} \operatorname{Pr}}\left(U^{*}-1\right)^{*}\left(2.00711 U^{*} \frac{1}{2}-\frac{1.52919}{U^{*}}\right)\right]\right.} \\
& \frac{\left.\left[+.142276\left(\frac{\Delta^{*}}{\delta^{*}}\right)^{4}\right]\right\}}{+\left[-.491056 \frac{\Delta^{* 2}}{\delta^{*}}+.379064 \frac{\Delta^{* 3}}{\delta^{* 2}}-.15993 \frac{\Delta^{* 4}}{\delta^{* 3}}+.0284552 \frac{\Delta^{* 5}}{\delta^{* 4}}\right]} \\
& \overline{\left.+\left[\frac{2.94626}{U^{*}}\left(\frac{\Delta^{*}}{\delta^{*}}\right)^{2}-\frac{4.54866}{U^{*}}\left(\frac{\Delta^{*}}{\delta^{*}}\right)^{3}+\frac{2.878670}{U^{*}}\left(\frac{\Delta^{*}}{\delta^{*}}\right)^{4}-\frac{.682908}{U_{(D-3)}^{*}}\left(\frac{\Delta^{*}}{\delta^{*}}\right)^{5}\right]\right\}}
\end{aligned}
$$


In this example, $\delta^{*}$ first reaches unity and the subsequent growth of $\Delta^{*}$ is obtained by Eq. (4-22).

The actual computarion was carpied out by an IGP-30 digital computer. A programe is set up so the selection of the correct $x$ " for the starting values, the choice of $\mathrm{Eq} \cdot(4-15)$ or $(4-16)$ to be integrated, and the use of Eq. $(4-22)$ to calculate the continued growth of $\Delta^{*}$ are done autonatically. Table 5 shows a sanple computer results of the integration of $\mathrm{Eq} \cdot(4-15)$ and $(4-16)$ for $n=1 / 4$ and $P_{r}=100$. 


\section{APPENDIX E}

SANOPLE CALCULATION FOR THE LOCAI NUSSELT NUNBER, $N u_{x}$

In order to find the $\mathrm{Nu}_{\mathrm{x}}$ at certain value of $\mathrm{x}^{*}$, the integral $\int_{0}^{x^{*}} \frac{d x^{*}}{\Delta^{*}}$ must be determined first. This integral can be calculated either by Eq. $(5-10 a)$ or $(5-11 a)$ depending whether $x_{1}^{*} \leqslant 10^{-4}$ or $x_{1}^{*} \geq 10^{-4}$. If $n=3 / 4$ and $\operatorname{Pr}=100$, $\mathrm{x}_{1}^{*}$ as computed by $\mathrm{Eq} .(4-20)$ is

$$
\begin{aligned}
x_{1} & =\left\{\frac{2.658681}{1.3395\left(P_{r}\right)^{t}}\left[\frac{K_{6}^{\frac{1}{n}}}{18}\left(\frac{1+2 n}{1+n}\right)\right]^{\frac{1}{3}}\right\}^{6\left(\frac{1+n}{1-n}\right)} \\
& =\left\{\frac{2.658681}{1.3395(100)^{\frac{1}{3}}}\left[\frac{(.40186)^{\frac{4}{3}}}{18} \frac{2.5}{1.75}\right]^{\frac{1}{3}}\right\}^{42} \\
& =5.1187 \times 10^{-25}
\end{aligned}
$$

Since $x_{1}^{\prime \prime}=5.1187 \times 10^{-25}<10^{-4}$ Eq. $(5-10 a)$ is used to determine the integral. Hence

$$
\begin{aligned}
& \int_{0}^{x^{*}} \frac{d x^{*}}{\Delta^{*}}=\frac{\sqrt{\operatorname{Pr}} x^{* \frac{1}{2}}}{1.32934}+\frac{3}{1.3395}\left[\frac{K_{6}^{\frac{1}{n}} \operatorname{Pr}}{18}\right]^{\frac{1}{3}}\left(\frac{1+n}{1+2 n}\right)^{\frac{2}{3}}\left[10^{-4}-x_{1}^{*}\right]^{\frac{1+2 n}{3(1+n)}} \\
& +\int_{10^{-4}}^{x^{*}} \frac{d x^{*}}{\Delta^{*}} \\
& =\frac{\sqrt{100}\left(5.1187 \times 10^{-25}\right)^{\frac{1}{2}}}{1.32934} \\
& +\frac{3}{1.3395}\left[\frac{(1.40186)^{\frac{4}{3}} 100}{18}\right]^{\frac{1}{3}}\left(\frac{1.75}{2.5}\right)^{\frac{2}{3}}\left[10^{-4}-5.1187 \times 10^{-25}\right]^{\frac{2.5}{4.25}} \\
& +\int_{10^{-4}}^{x^{*}} \frac{d x^{*}}{\Delta^{*}}
\end{aligned}
$$




$$
\begin{aligned}
\int_{0}^{x^{*} \frac{d x^{*}}{\Delta^{*}}=} & 5.32565 \times 10^{-12}+2.59679 \times 10^{-2} \\
& +\int_{10^{-4}}^{x^{*}} \frac{d x^{*}}{\Delta^{*}} \\
= & 2.59679 \times 10^{-2}+\int_{10^{-4}}^{x^{*}} \frac{d x^{*}}{\Delta^{*}}
\end{aligned}
$$

The last integral in Eq. ( $\mathrm{E}-1$ ) is found by graphically integration. The figure below shows a schematic diagram of $1 / \Delta^{*}$ vs. $x^{*}$ (the diagram drawn to scale is not presented in this thesis):

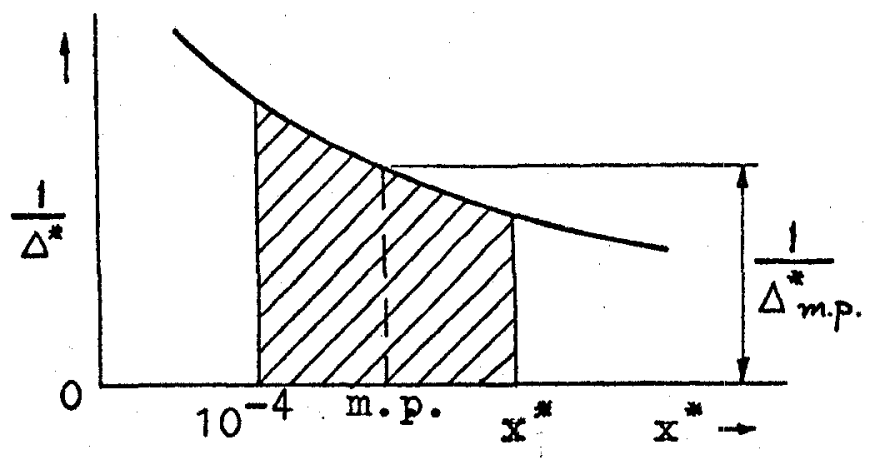

Fig. E.1 Schematic Diagram of $1 / \Delta^{*}$ vs. $x^{*}$ where m.p. is the mid-point between $10^{-4}$ and $x^{*}$. Therefore,

$$
\begin{aligned}
\int_{10^{-4}}^{x^{*}} \frac{d x^{*}}{\Delta^{*}} & \simeq \text { area of shaded section } \\
& \simeq \frac{1}{\Delta_{\text {m.p. }}^{*}}\left(x^{*}-10^{-4}\right)
\end{aligned}
$$


The width of the shaded section should be kept small enough to give good approximation. If $x^{*}=2 \times 10^{-4}$, the mid-point $x_{m \cdot p .}^{*}=1.5 \times 10^{-4}$ and the corresponding value for $1 / \Delta_{m \cdot p}^{*}$. is found to be 97.0874 . By Eq. (E-2),

$$
\begin{aligned}
\int_{10^{-4}}^{2 \times 10^{-4} \frac{d x^{*}}{\Delta^{*}}} & =97.0874\left(2 \times 10^{-4}-10^{-4}\right) \\
& =9.70874 \times 10^{-3}
\end{aligned}
$$

Therefore the integral of Eq. $(\mathrm{E}-1)$ is

$$
\begin{aligned}
\int_{0}^{2 \times 10^{-4} \frac{d x^{*}}{\Delta^{*}}} & =2.59679 \times 10^{-2}+9.70874 \times 10^{-3} \\
& =3.56766 \times 10^{-2}
\end{aligned}
$$

At $x^{*}=2 \times 10^{-4}$, the value of $\Delta^{*}=0.0147$, and the local Nusselt number by Eq. (5-9) will be

$$
\begin{aligned}
N u_{x^{*}=2 \times 10^{-4}} & =\frac{\frac{3}{2} \frac{1}{\Delta^{*}}}{1-\frac{3}{2 \operatorname{Pr}} \int_{0}^{2 \times 10^{-4}} \frac{d x^{*}}{\Delta}} \\
& =\frac{\frac{3}{2} \frac{1}{1-\frac{0147}{3 \times 3.56766 \times 10^{-2}}}}{2 \times 100} \\
& =125.0663
\end{aligned}
$$

If the next value of $\mathrm{Nu}$ is wanted at $x^{*}=4 \times 10^{-4}$, the integral of $\mathrm{Eq} .(\mathrm{E}-1)$ can be written as

$$
\begin{aligned}
\int_{0}^{4 \times 10^{-4}} \frac{d x^{*}}{\Delta^{*}} & =\int_{0}^{2 \times 10^{-4}} \frac{d x^{*}}{\Delta^{*}}+\int_{2 \times 10^{-4}}^{4 \times 10^{-4}} \frac{d x^{*}}{\Delta^{*}} \\
& =3.56766 \times 10^{-2}+\int_{z \times 10^{-4}}^{4 \times 10^{-4}} \frac{d x^{*}}{\Delta^{*}}
\end{aligned}
$$


Following the same procedure as illustrated in the graphical integration for $\mathbb{N u}_{x}$ at $x^{*}=2 \times 10^{-4}$, the integral $\int_{2 \times 10^{-4}}^{4 \times 10^{-4}} \frac{d x^{*}}{\Delta^{*}}$ is found to be $1.36054 \times 10^{-2}$. Hence

$$
\begin{aligned}
\int_{0}^{4 \times 10^{-4} \frac{d x^{*}}{\Delta^{*}}} & =3.56766 \times 10^{-2}+1.36054 \times 10^{-2} \\
& =4.92820 \times 10^{-2}
\end{aligned}
$$

At $x^{*}=4 \times 10^{-4}, \Delta^{*}=0.0170$; and the $N u_{x}$ is

$$
\begin{aligned}
N_{u_{x}=4 \times 10^{-4}} & =\frac{\frac{3}{2}\left(\frac{1}{.0170}\right)}{1-\frac{3}{2 \operatorname{Pr}} \int_{0}^{4 \times 10^{-4}} \frac{d x^{*}}{\Delta^{*}}} \\
& =88.3138
\end{aligned}
$$

Other Nux at higher values of $x^{*}$ is found in the same way; and the calculation is simplified by the additive property of the approximate graphical integration of the integral $\int_{0}^{x^{*}} \frac{d x^{*}}{\Delta^{*}}$ 


\section{APPENDIX F}

FIGURES

61 


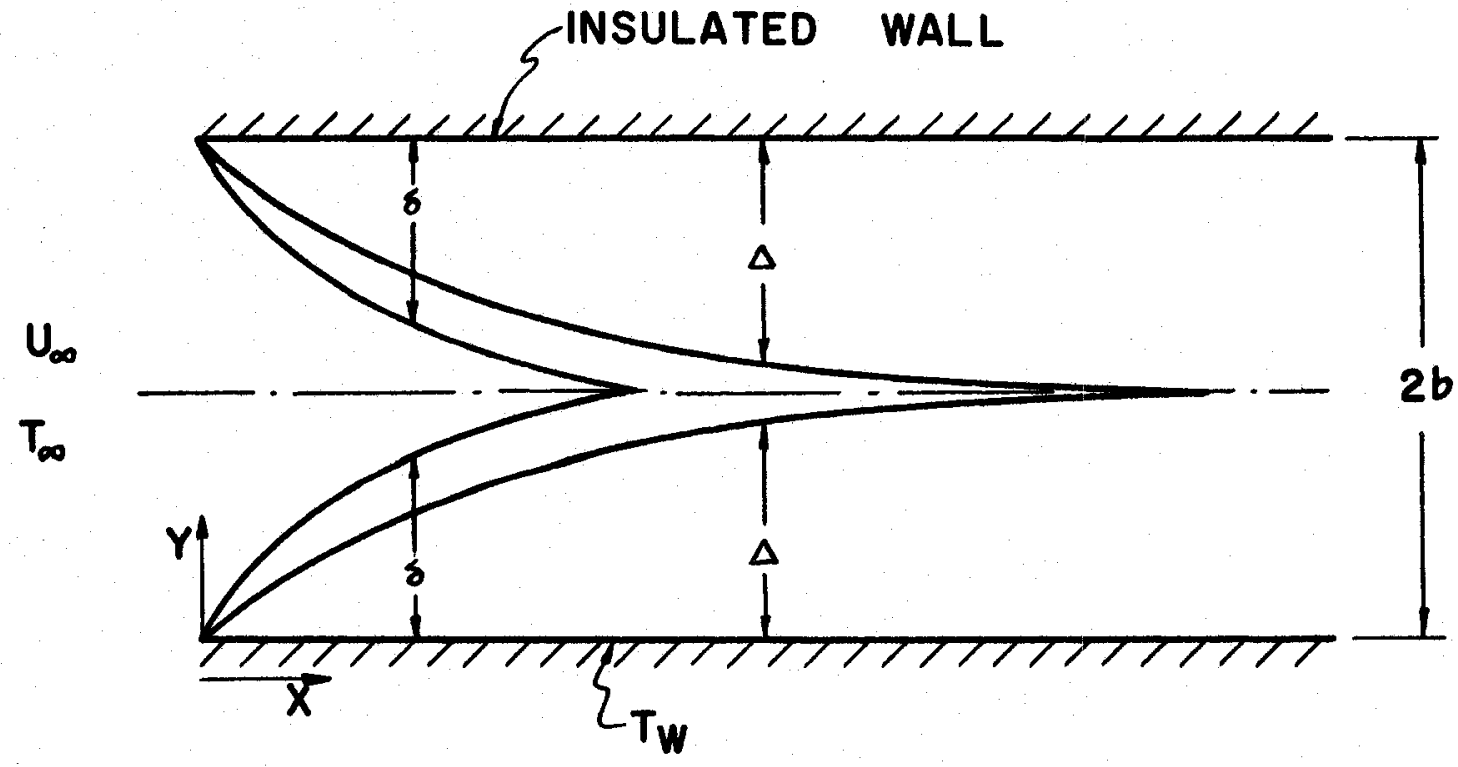

FIG. I SCHEMATIC DIAGRAM 


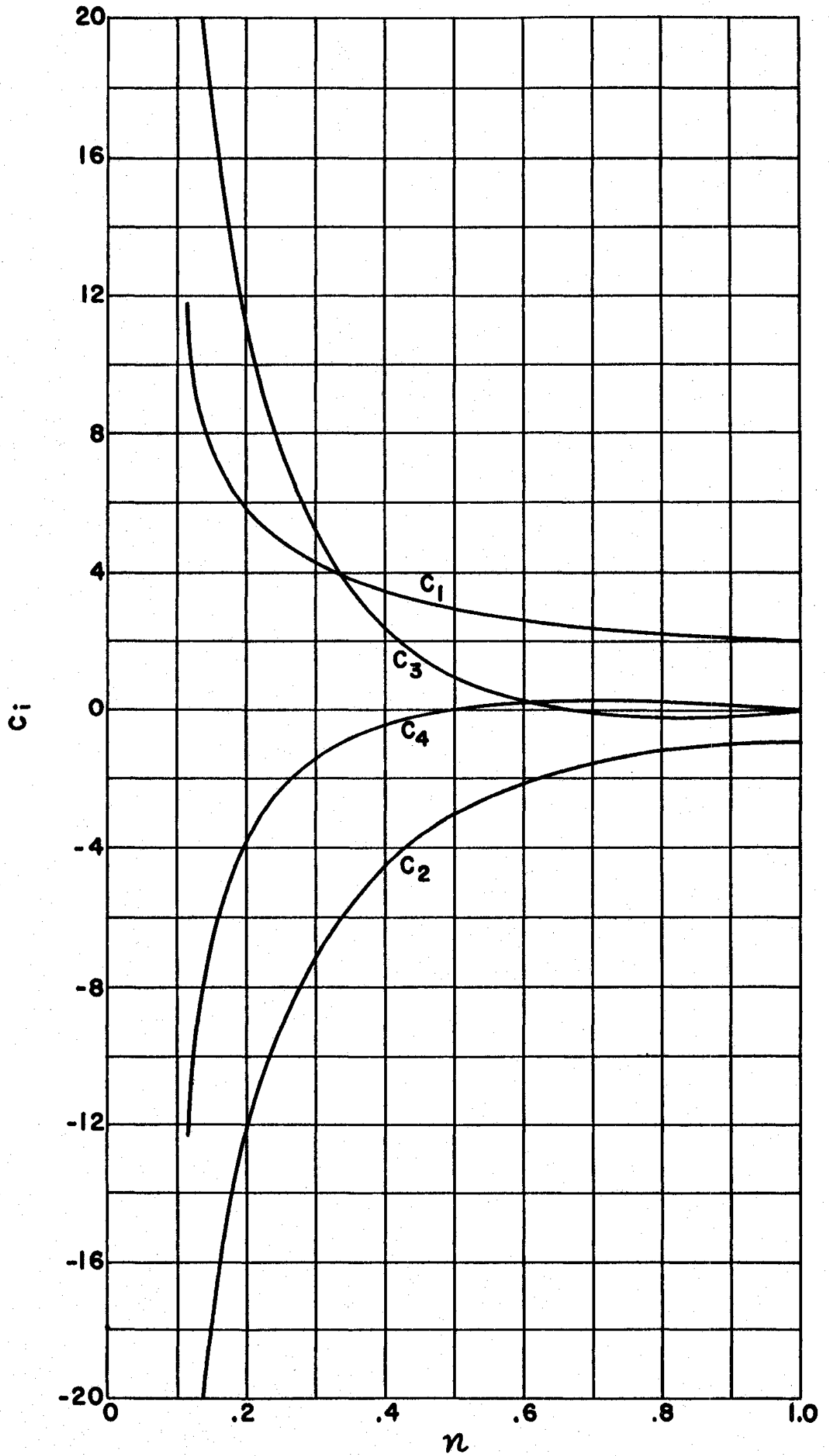

FIG. 2 COEFFICIENTS $c_{i}$ 's OF THE APPROXIMATE EXPRESSION FOR VELOCITY DISTRIBUTION FOR VARIOUS FLUIDS 


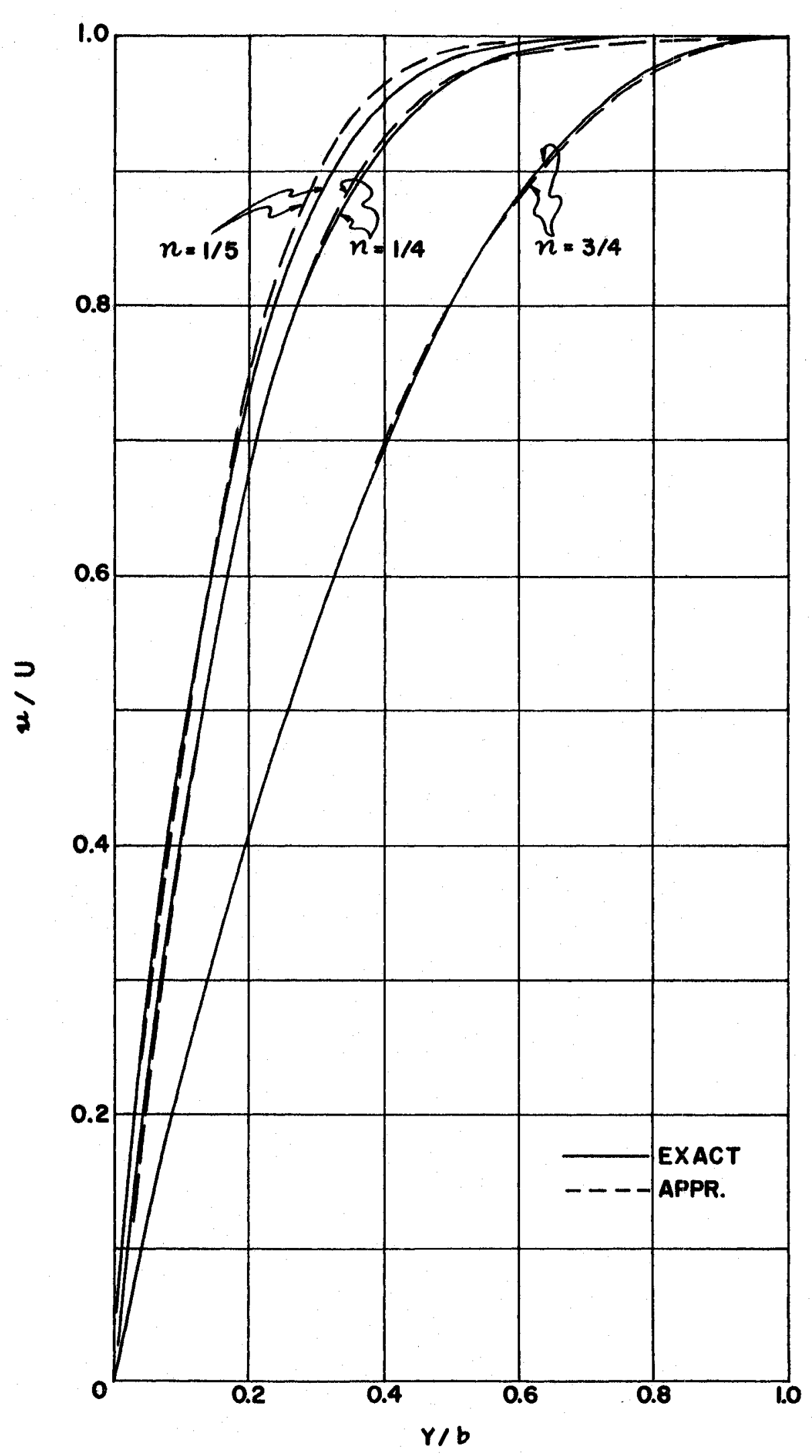

64

FIG. 3 COMPARISON OF EXACT a APPROXIMATE VELOCITY PROFILES 


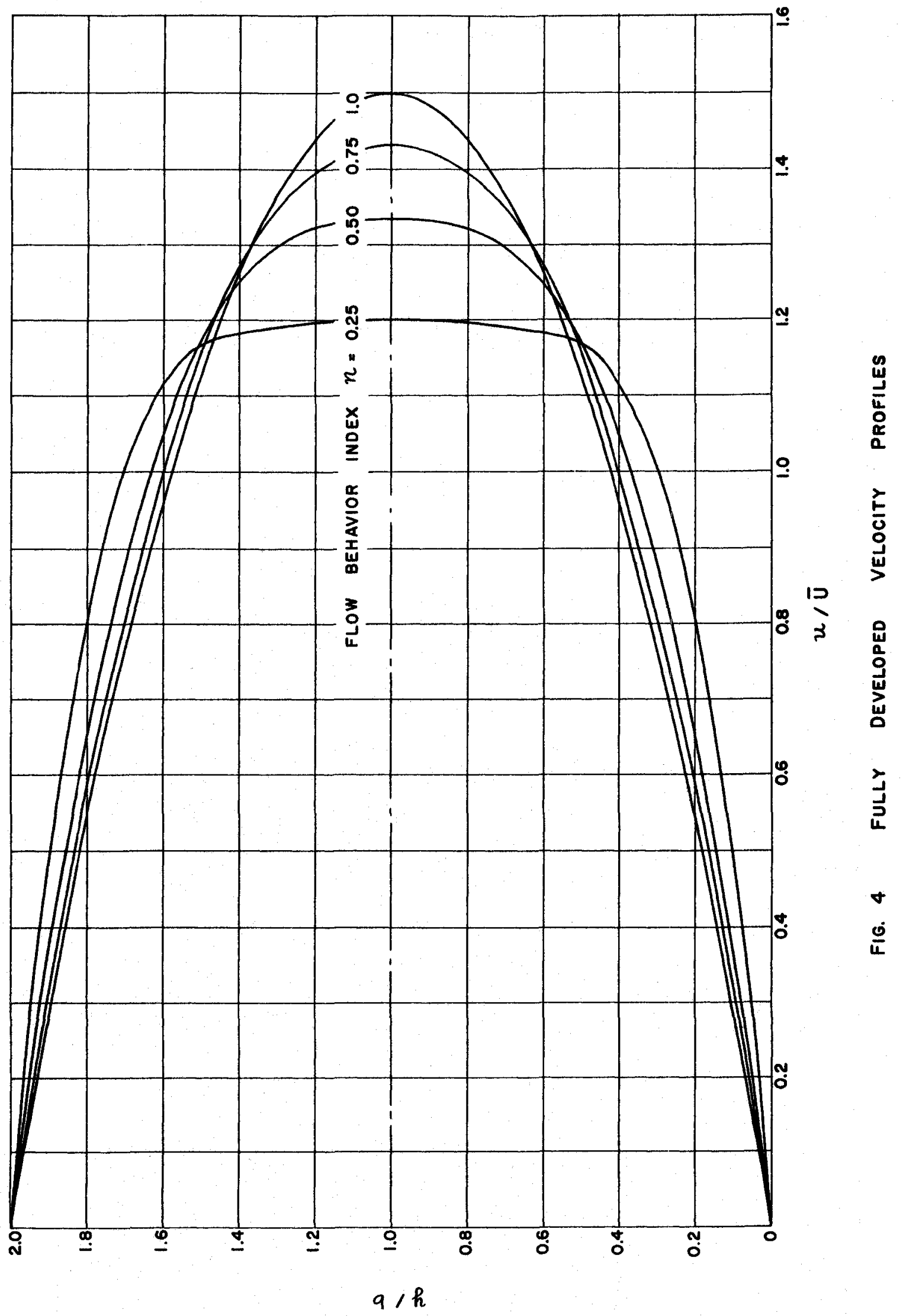




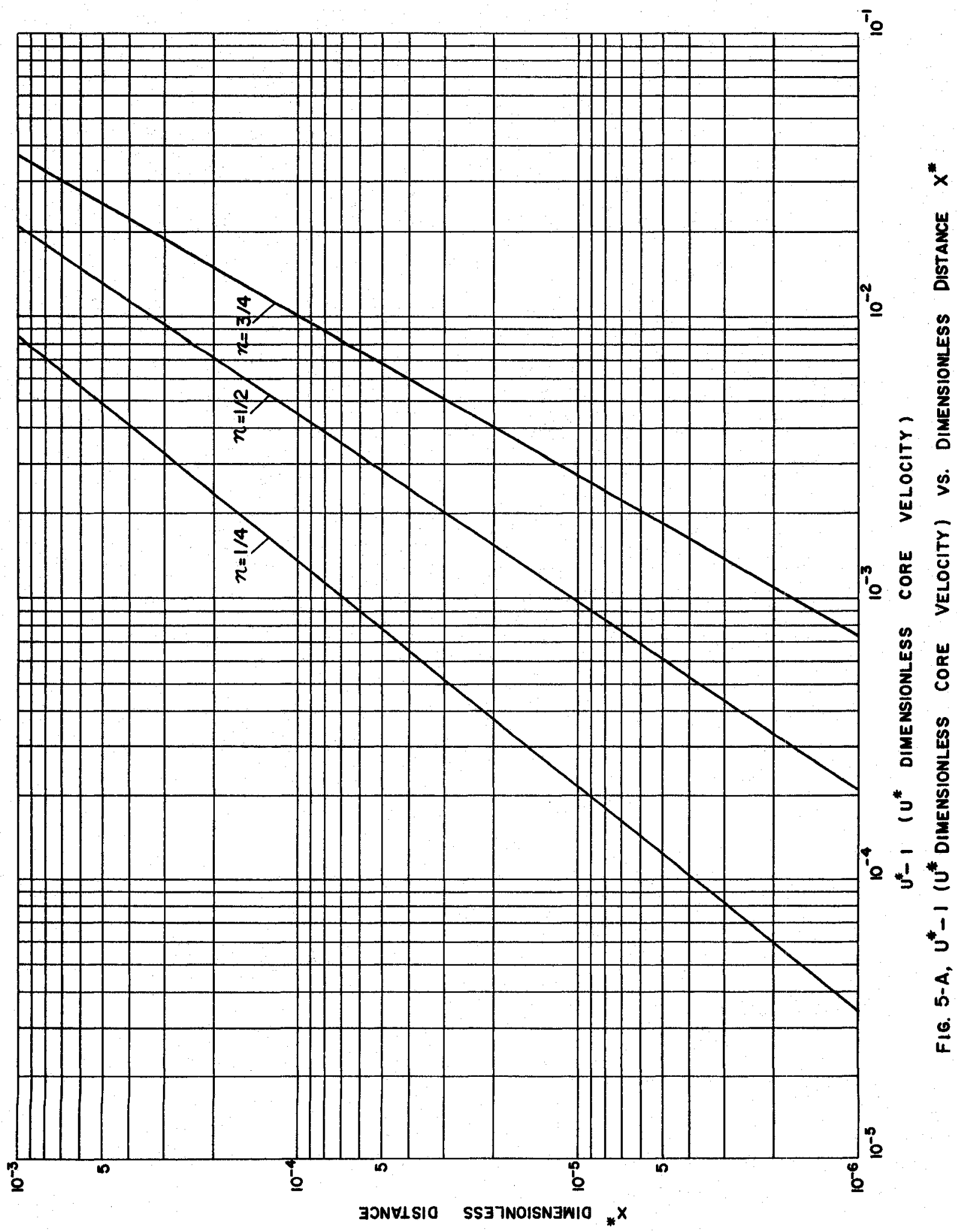




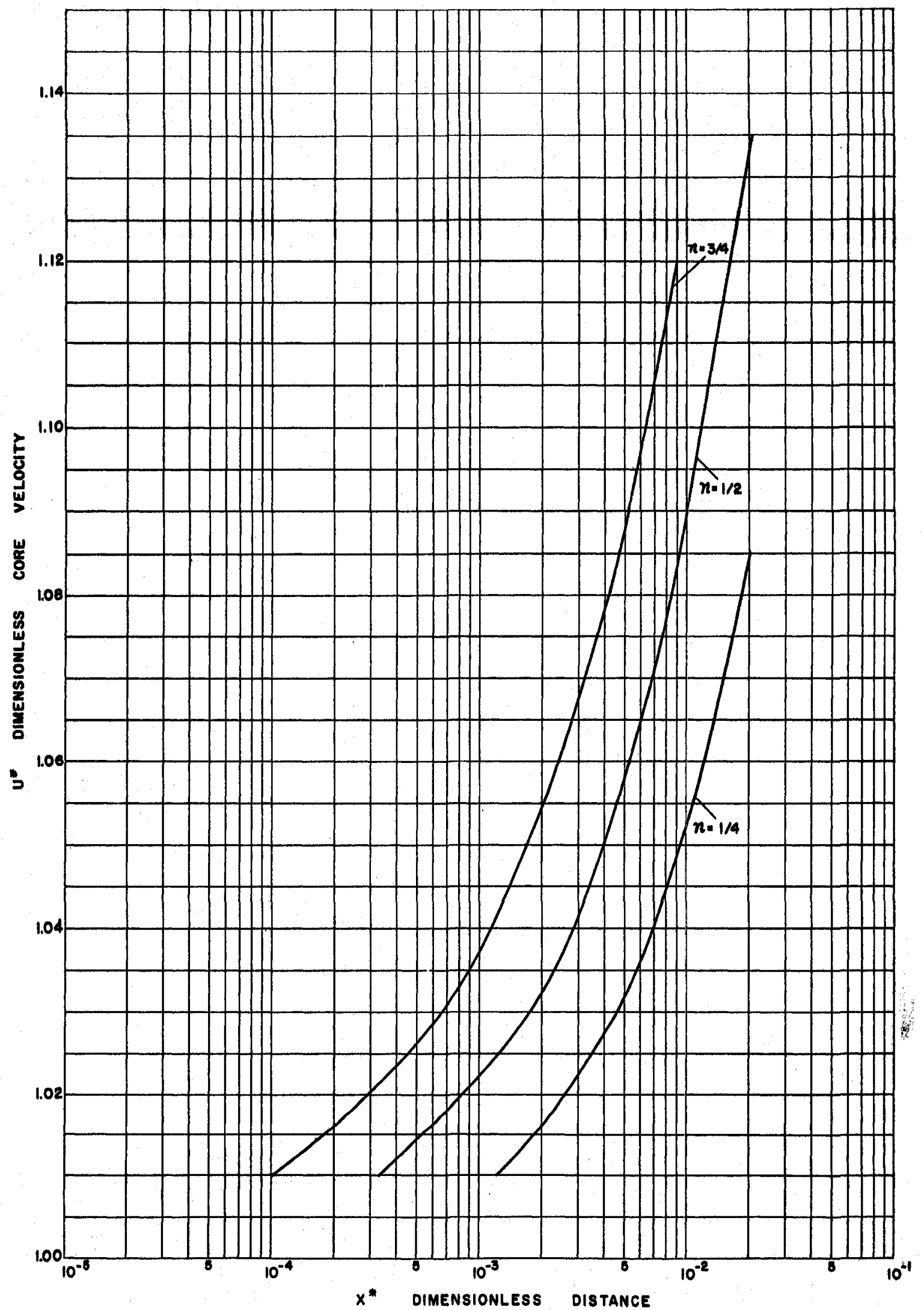

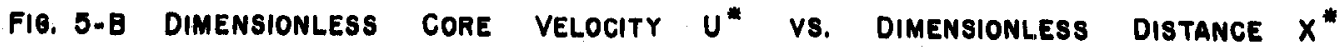




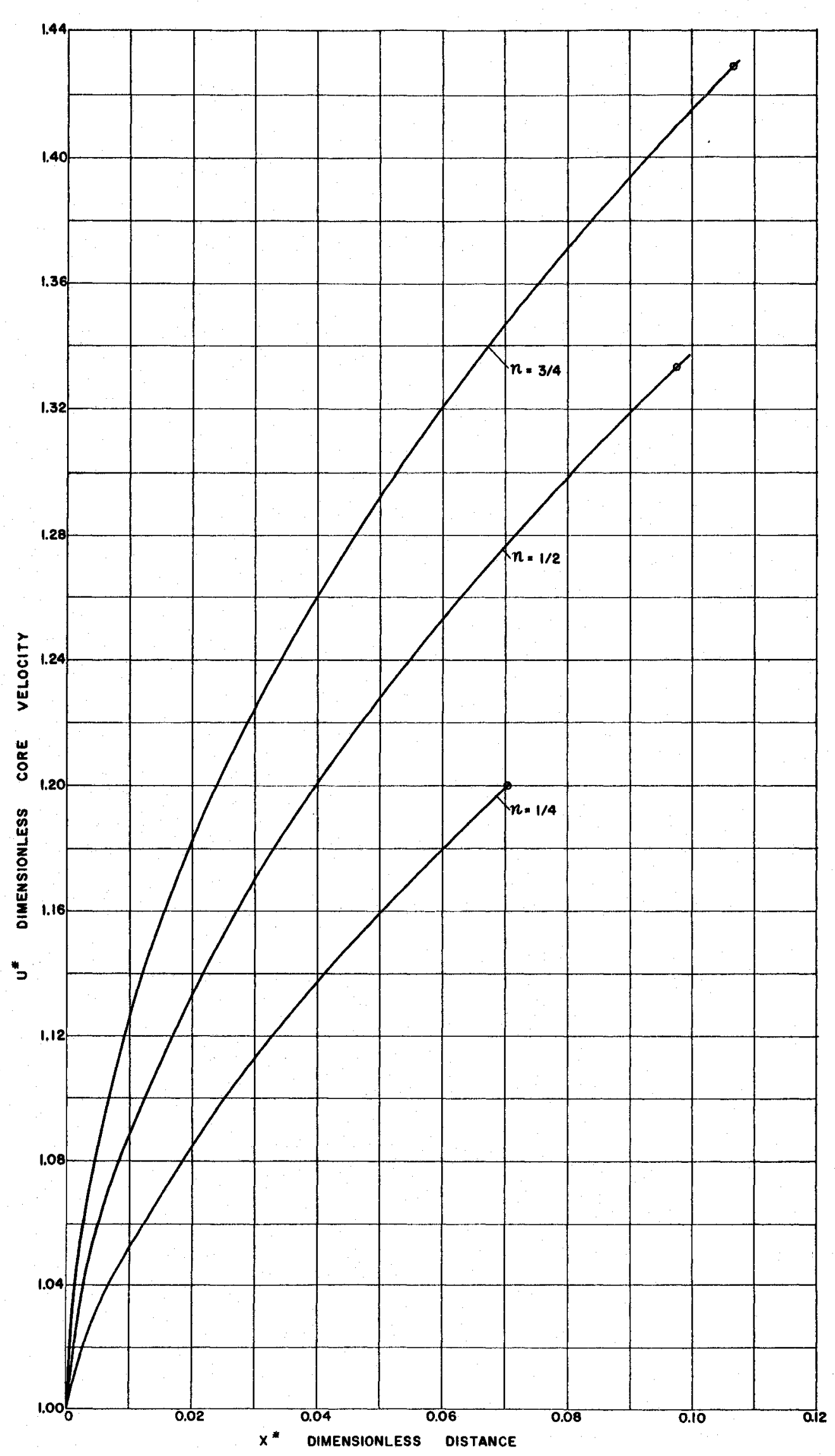

Fio. 5-C Dimensionless core Velocity $u^{*}$ vs. dimensionless distance $X^{*}$ 
To

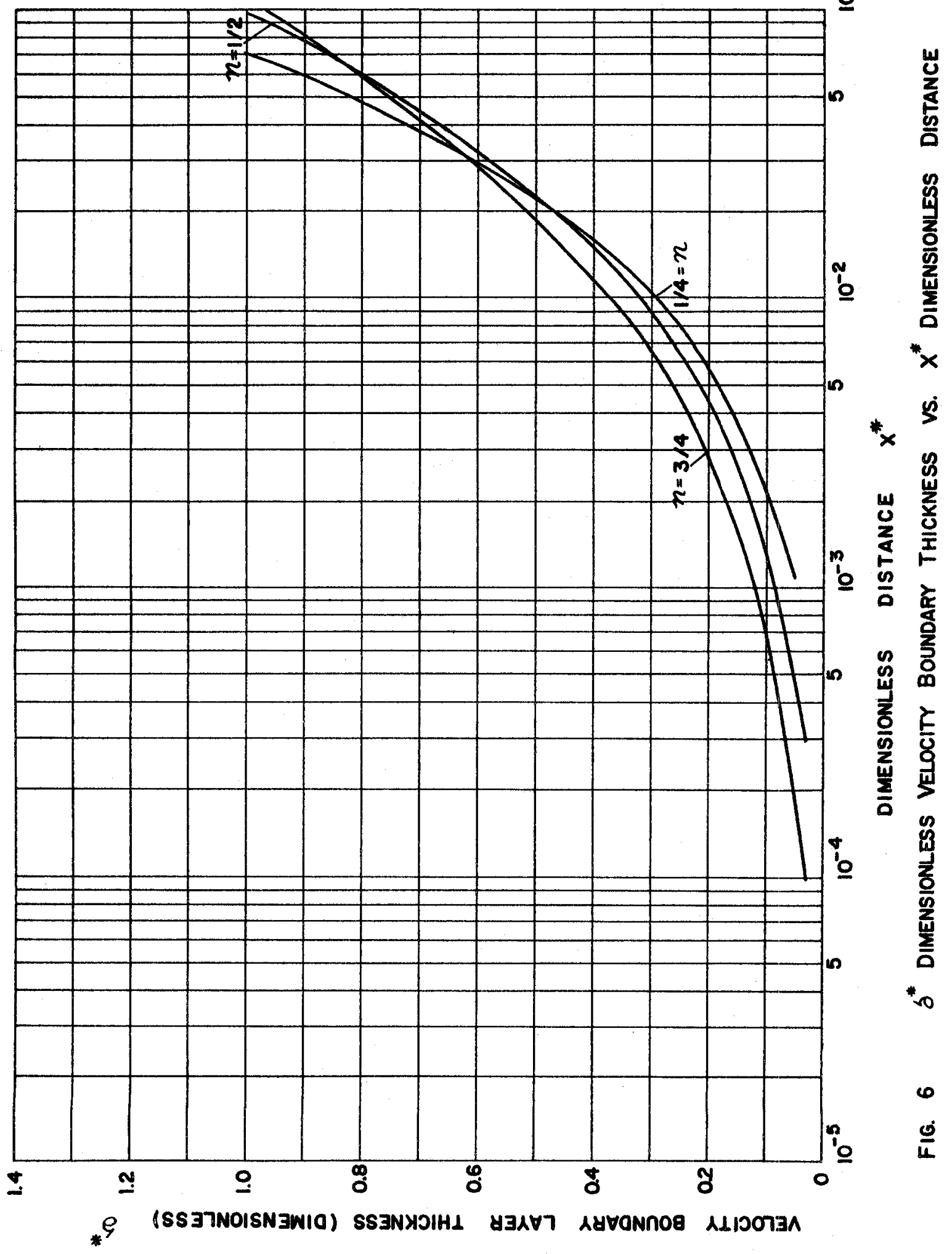




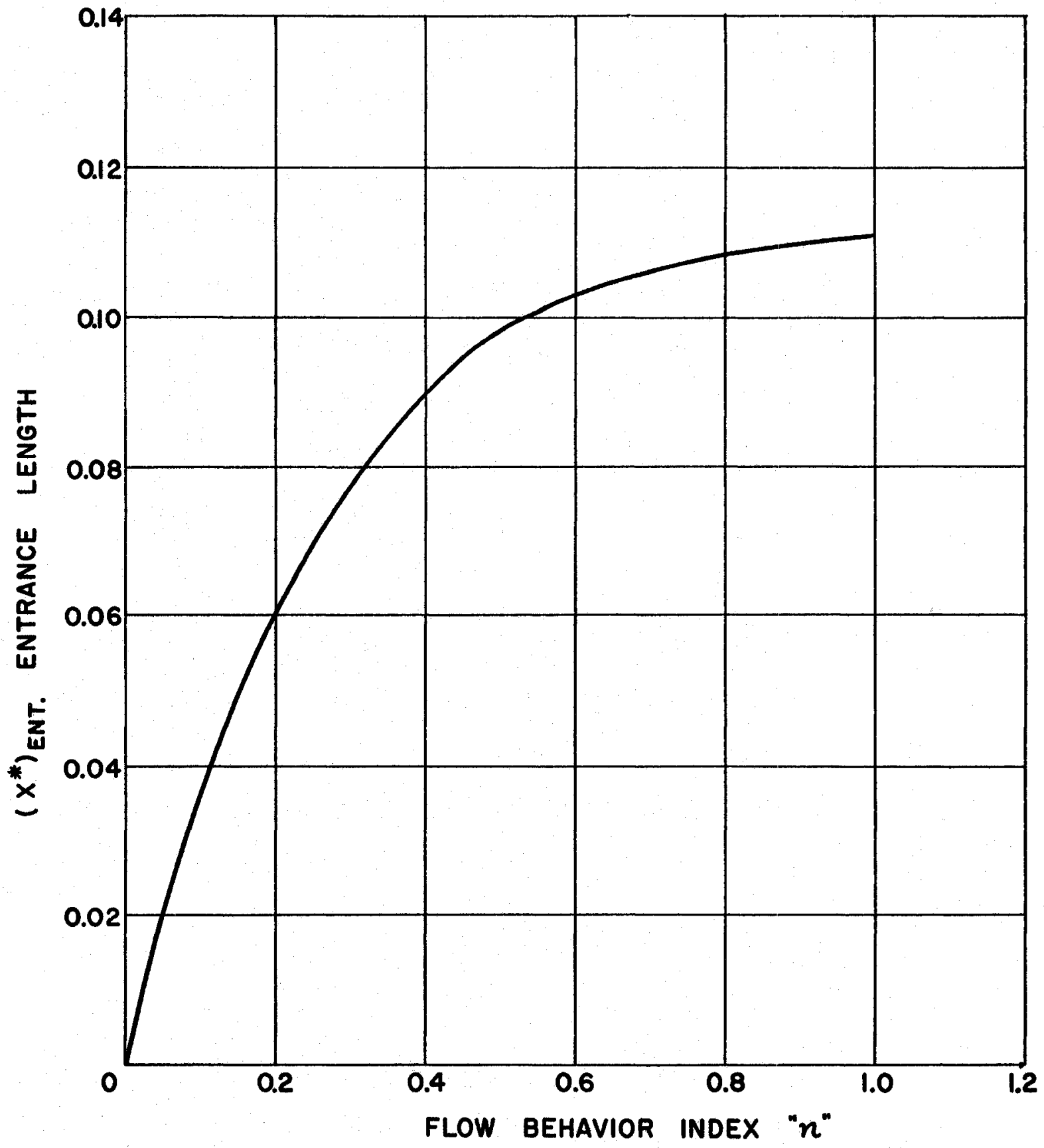

Fig. 7 ENTRANCE LENGTH $\left(X^{*}\right)_{\text {ENT. }}$ VS.

FLOW BEHAVIOR INDEX " $n$ " 


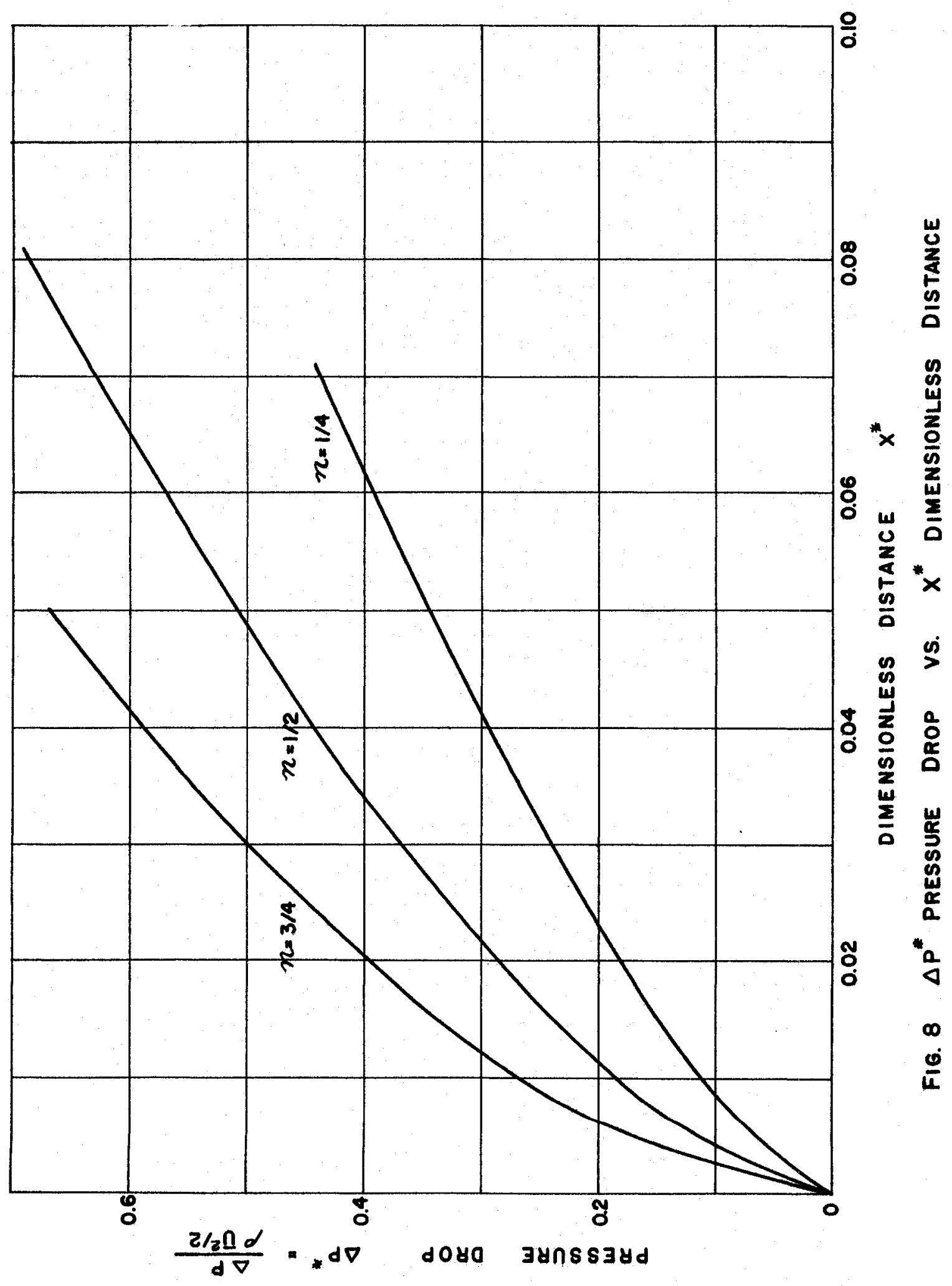




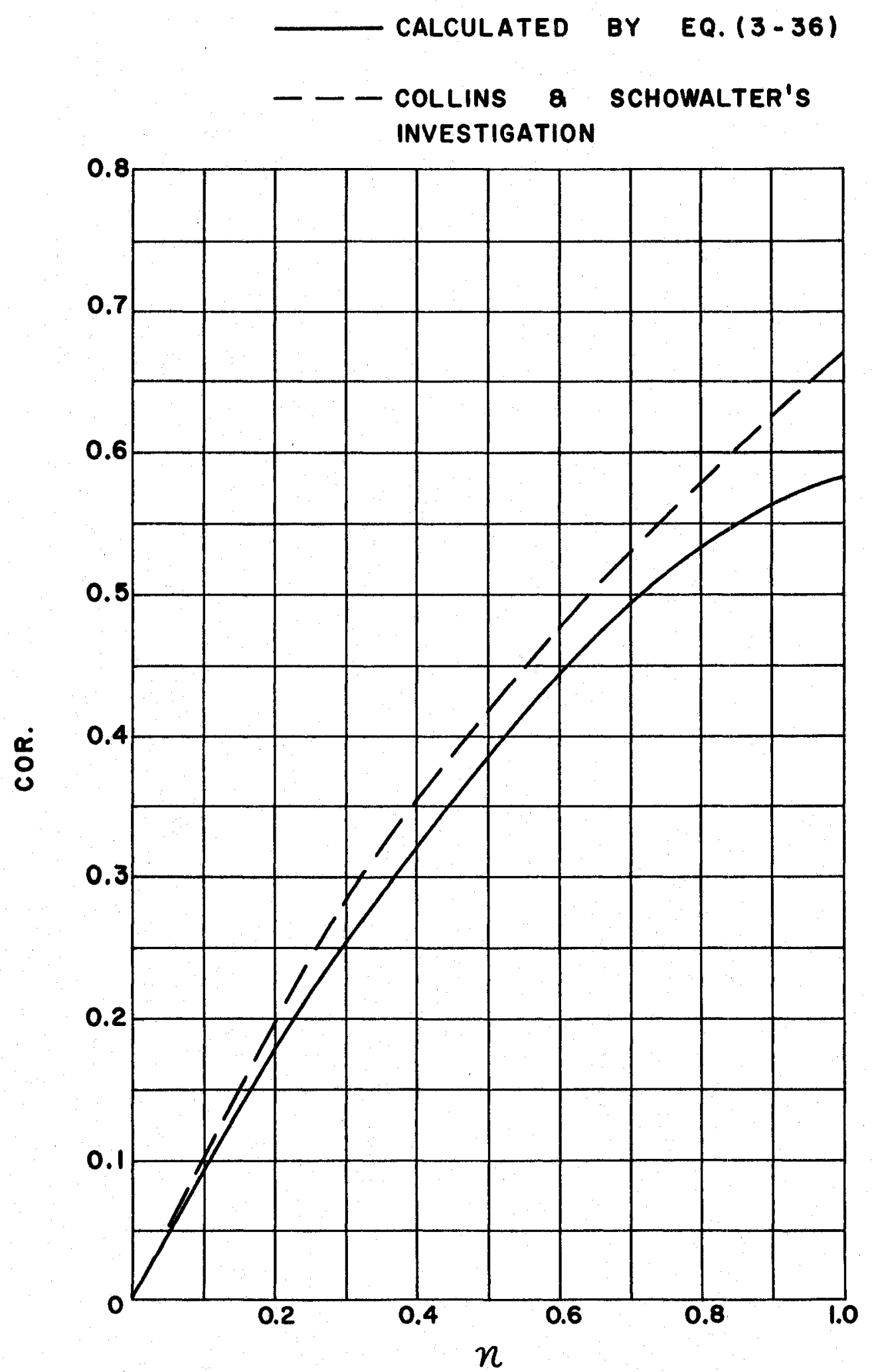

FIG. 9 ENTRY PRESSURE DROP CORRECTION "COR." VS. FLOW BEHAVIOR INDEX " $n$ " 


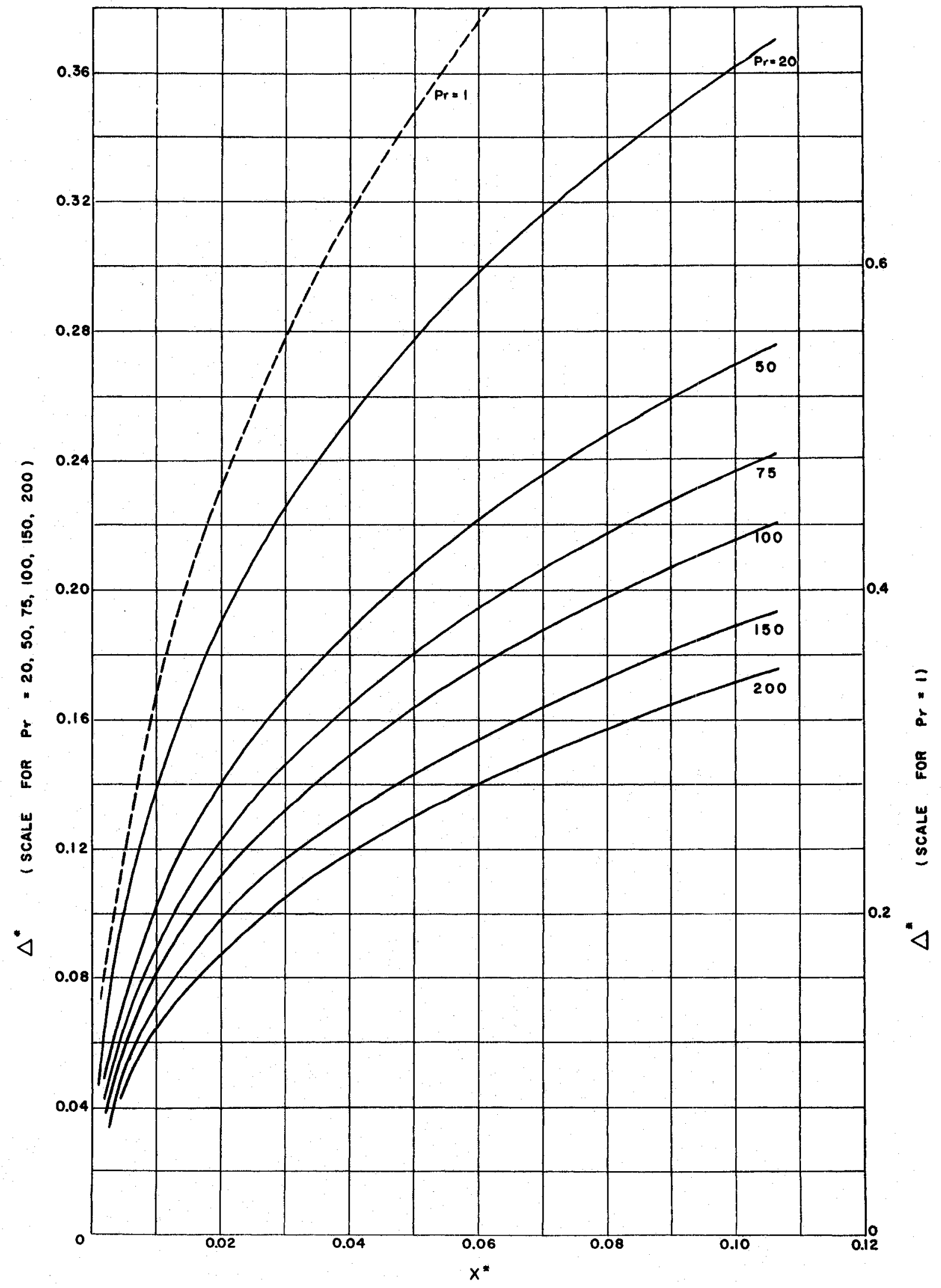

Fig. 10-A DimENSIONLESS THERMAL BOUNdARY LAYER THICKNESS $\Delta^{*}$ vS. Dimensionless Distance $x$ " FOR $n=3 / 4$ 


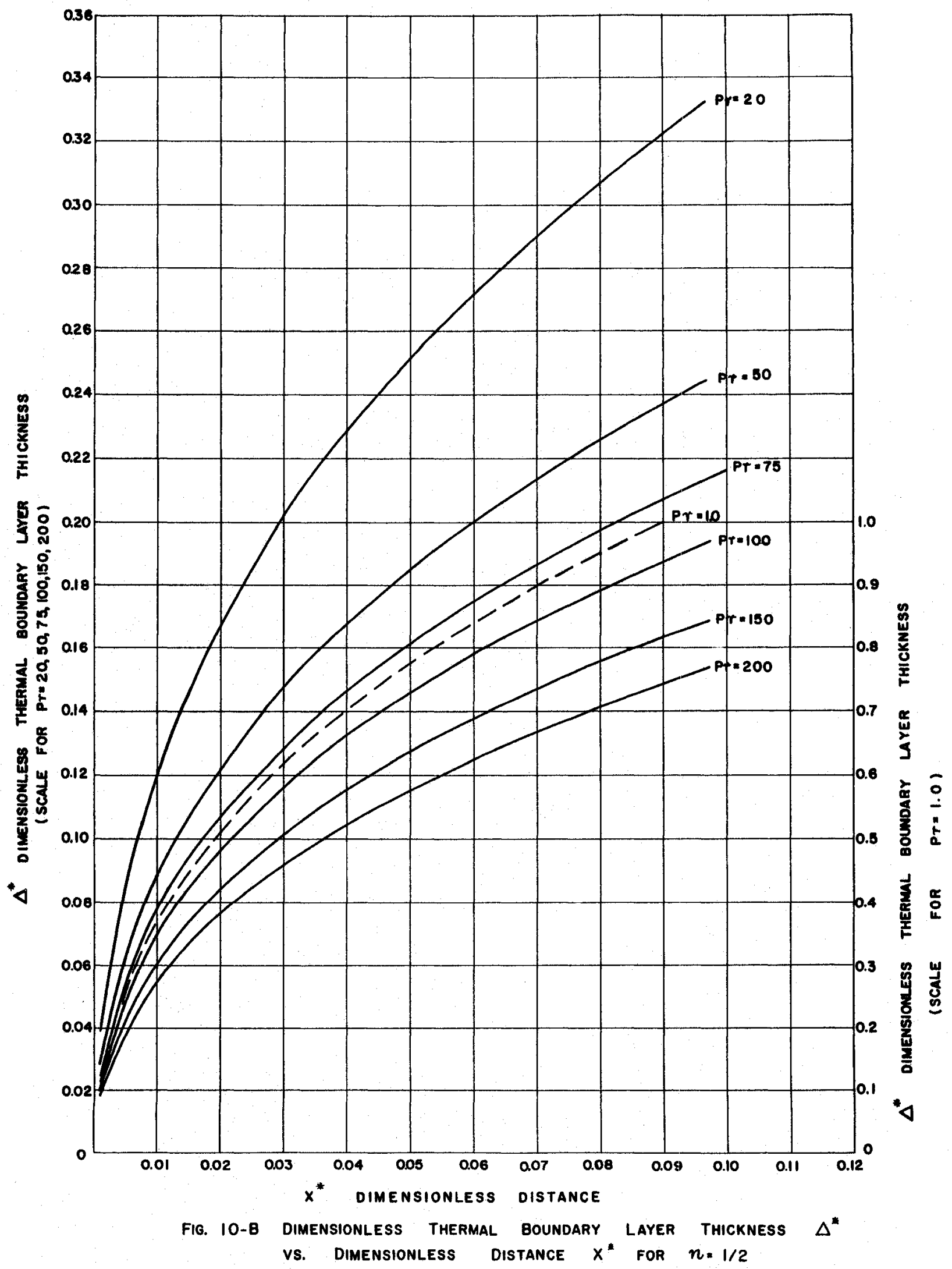

Reproduced with permission of the copyright owner. Further reproduction prohibited without permission. 


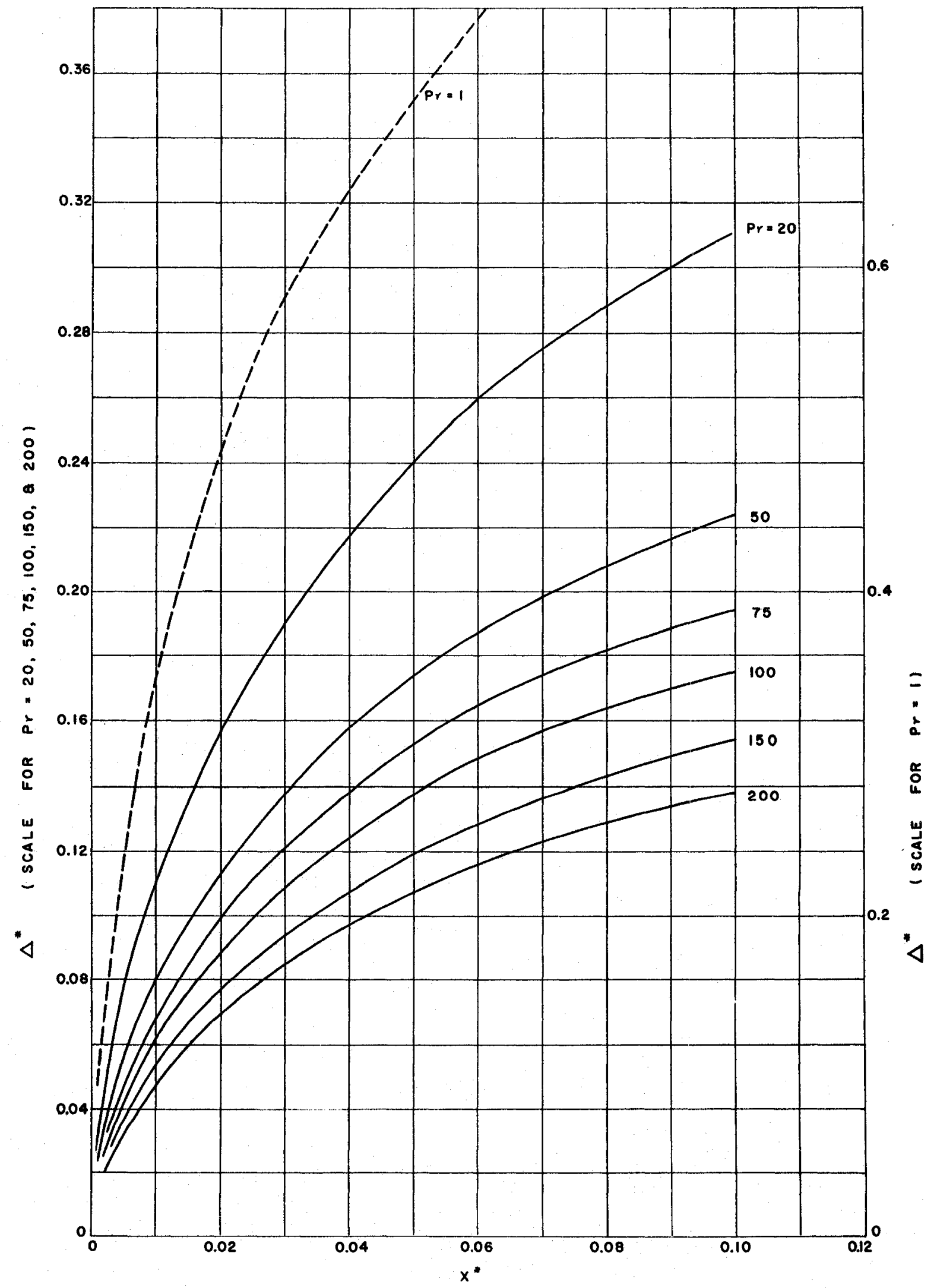

FIG. 10-C DIMENSIONLESS THERMAL BOUNDARY LAYER THICKNESS $\triangle^{*}$ VS. DIMENSIONLESS DISTANCE $x^{*}$ FOR $n=1 / 4$ 


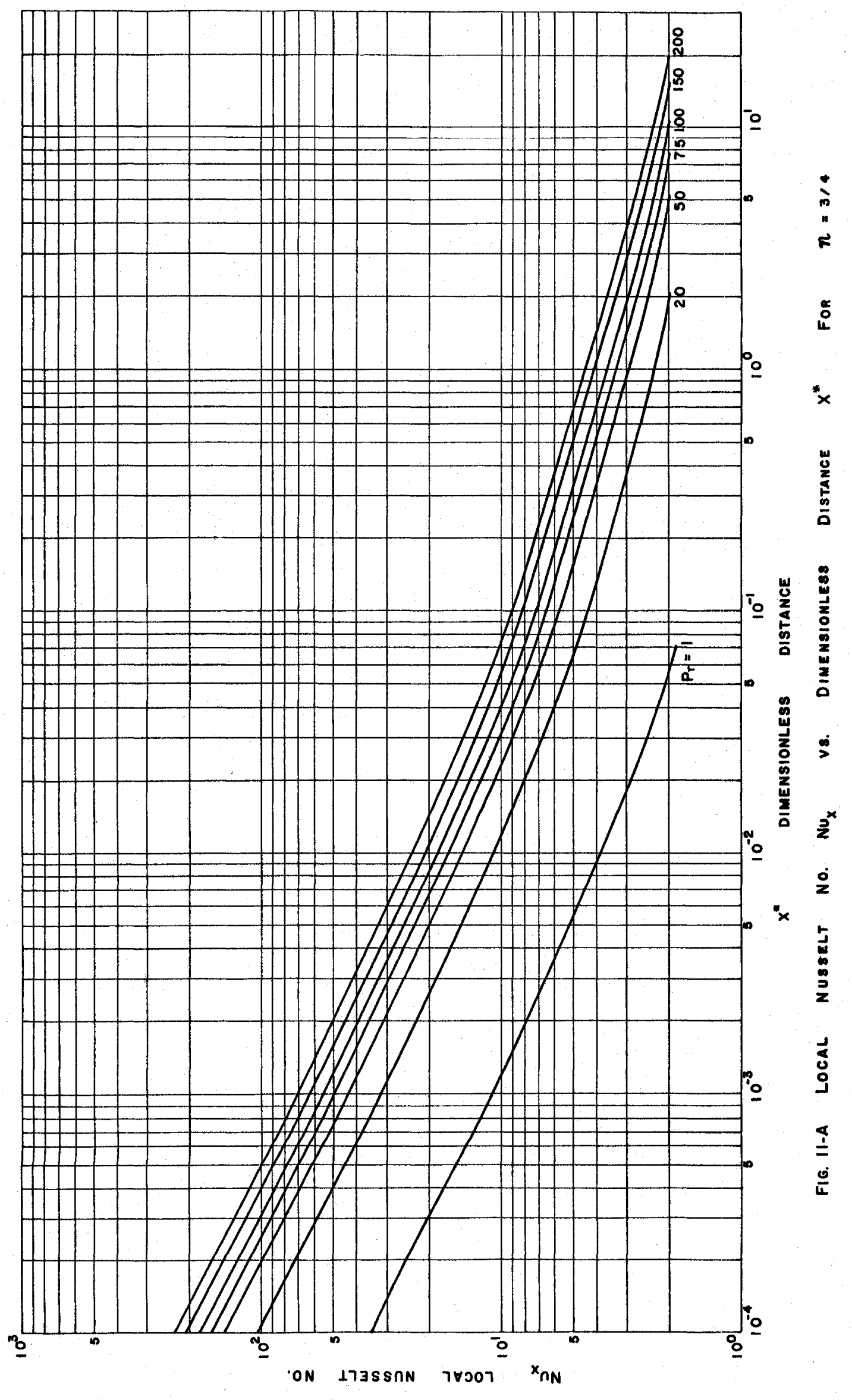




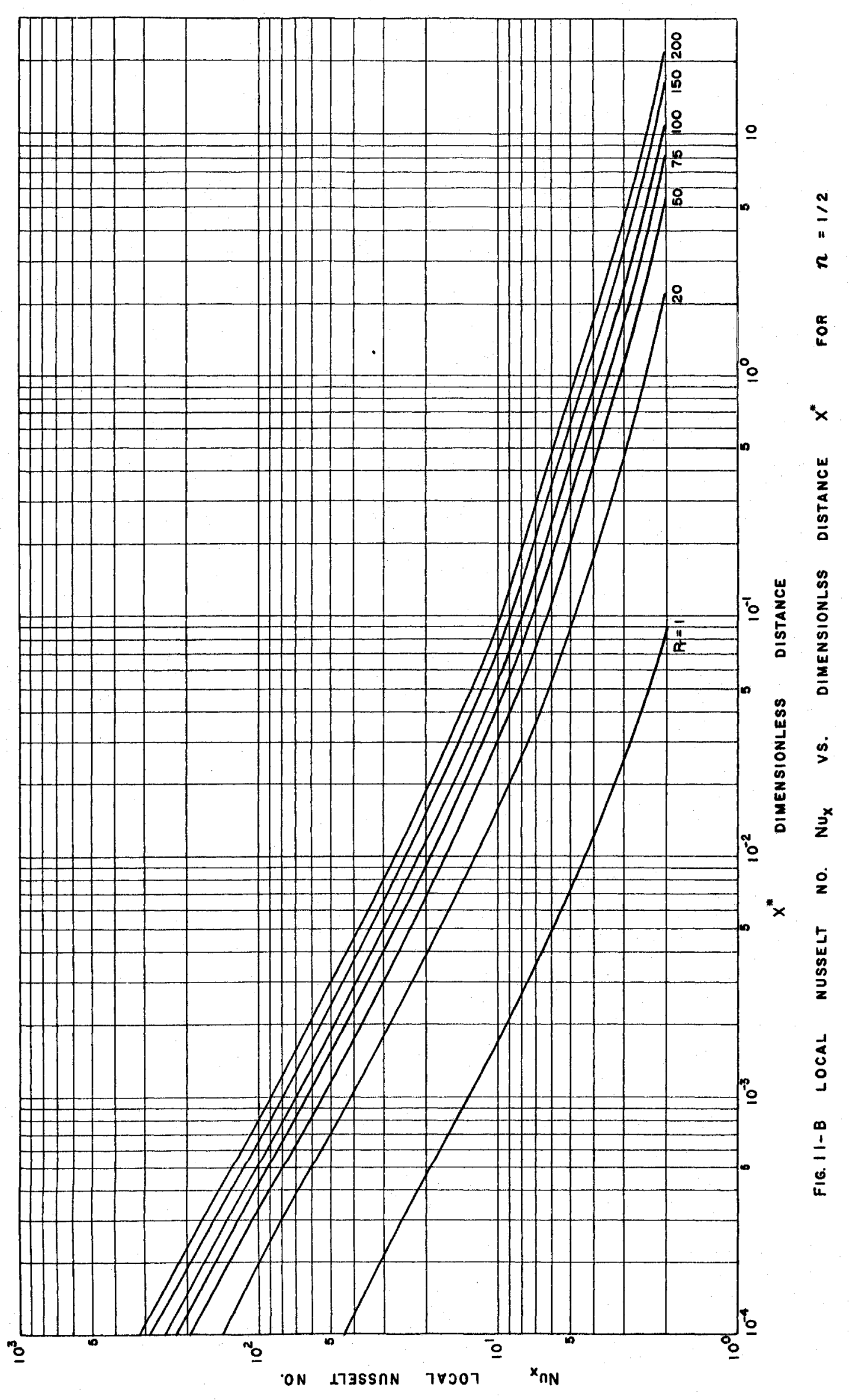




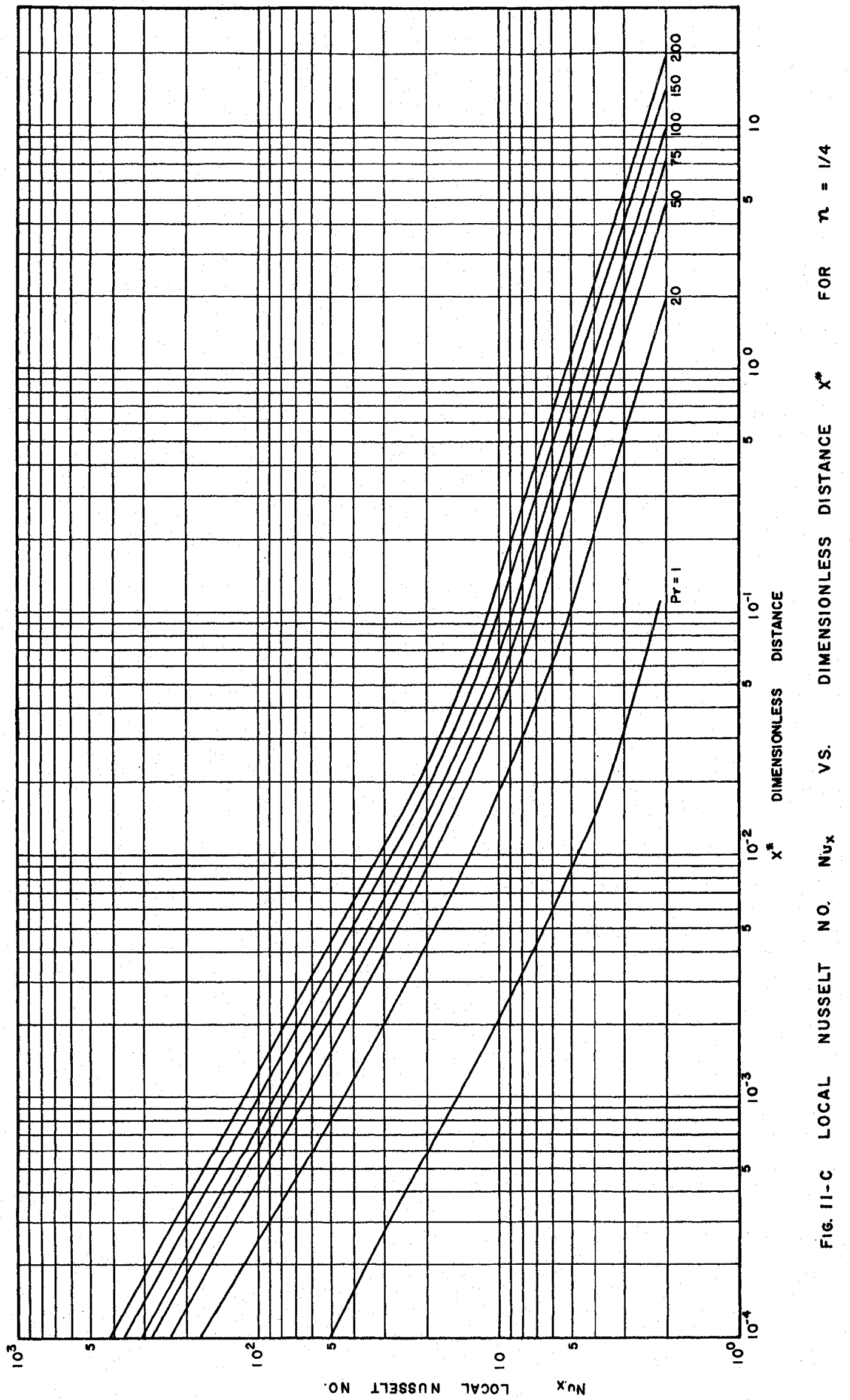


APPENDIX G

TABLES

79 
Table I

The Coefficients $C_{i}$ for Velocity Profile

\begin{tabular}{ccccc}
\hline $\mathrm{n}$ & $\mathrm{C}_{1}$ & $\mathrm{C}_{2}$ & $\mathrm{C}_{3}$ & $\mathrm{C}_{4}$ \\
\hline 1.00000 & 2.00000 & -1.00000 & 0 & 0 \\
0.80000 & 2.23169 & -1.27335 & -0.14836 & 0.19002 \\
0.75000 & 2.31379 & -1.41205 & -0.11727 & 0.21553 \\
0.60000 & 2.65392 & -2.12448 & 0.28718 & 0.18337 \\
0.50000 & 3.00000 & -3.00000 & 1.00000 & 0 \\
0.40000 & 3.51043 & -4.46358 & 2.39589 & -0.44273 \\
0.33333 & 4.00000 & -6.00000 & 4.00000 & -1.00000 \\
0.25000 & 4.91056 & -9.09755 & 7.4 .6340 & -2.27642 \\
0.20000 & 5.74544 & -12.14018 & 11.04406 & -3.64931 \\
0.11355 & 11.80586 & -28.90242 & 32.38726 & -12.29070 \\
\hline \hline
\end{tabular}


Table 2

Dimensionless Velocity $\left(U^{*}\right)$ and Dimensionless Velocity Boundary Layer Thickness $\left(\delta^{*}\right)$ as Function of Dimensionless Distance $\left(x^{m}\right)$

For $n=3 / 4$

\begin{tabular}{ccc}
\hline$x^{*}$ & $U^{*}$ & $\delta^{*}$ \\
\hline 0.00000000 & 1.00 & 0.00000000 \\
0.00029538 & 1.02 & 0.06535948 \\
0.00113981 & 1.04 & 0.12820512 \\
0.00243930 & 1.06 & 0.18867922 \\
0.00418350 & 1.08 & 0.24691354 \\
0.00637040 & 1.10 & 0.30303026 \\
0.00900079 & 1.12 & 0.35714281 \\
0.01207633 & 1.14 & 0.40935667 \\
0.01559882 & 1.16 & 0.45977005 \\
0.01956984 & 1.18 & 0.50847449 \\
0.02399056 & 1.20 & 0.55555547 \\
0.02886175 & 1.22 & 0.60109281 \\
0.03418370 & 1.24 & 0.64516119 \\
0.03995630 & 1.26 & 0.68783058 \\
0.04617899 & 1.28 & 0.72916655 \\
0.05285088 & 1.30 & 0.76923066 \\
0.05997071 & 1.32 & 0.80808069 \\
0.06753691 & 1.34 & 0.84577102 \\
0.07554764 & 1.36 & 0.88235281 \\
0.08400084 & 1.38 & 0.91787426 \\
0.09289418 & 1.40 & 0.95238082 \\
0.10222519 & 1.42 & 0.98591536 \\
0.10705399 & 1.43 & 1.00233090 \\
\hline
\end{tabular}




\section{Table 2 (cont'd)}

$$
\text { For } n=1 / 2
$$

\begin{tabular}{ccc}
\hline$x^{*}$ & $\sigma^{*}$ & $\delta^{*}$ \\
\hline 0.00000000 & 1.00 & 0.00000000 \\
0.00083559 & 1.02 & 0.07843138 \\
0.00270952 & 1.04 & 0.15384614 \\
0.00527146 & 1.06 & 0.22641507 \\
0.00845992 & 1.08 & 0.29629625 \\
0.01224573 & 1.10 & 0.36363632 \\
0.01661232 & 1.12 & 0.42857137 \\
0.02154915 & 1.14 & 0.49122800 \\
0.02704892 & 1.16 & 0.55172406 \\
0.03310614 & 1.18 & 0.61016939 \\
0.03971637 & 1.20 & 0.66666657 \\
0.04687582 & 1.22 & 0.72131137 \\
0.05458108 & 1.24 & 0.77419343 \\
0.06282895 & 1.26 & 0.82539670 \\
0.07161637 & 1.28 & 0.87499986 \\
0.08094034 & 1.30 & 0.92307679 \\
0.09853935 & 1.335 & 1.00374520 \\
\hline
\end{tabular}




$$
\begin{array}{cc}
\text { Table } 2 & \text { (cont'd) } \\
\text { For } & n=1 / 4
\end{array}
$$

\begin{tabular}{ccc}
\hline \hline$x^{*}$ & $U^{*}$ & $\delta^{*}$ \\
\hline 0.00000000 & 1.00 & 0.00000000 \\
0.00257890 & 1.02 & 0.11764472 \\
0.00698142 & 1.04 & 0.23076460 \\
0.01231706 & 1.06 & 0.33961581 \\
0.01846890 & 1.08 & 0.44443549 \\
0.02538204 & 1.10 & 0.54544356 \\
0.03302495 & 1.12 & 0.64284420 \\
0.04137727 & 1.14 & 0.73682726 \\
0.05042480 & 1.16 & 0.82756954 \\
0.06015701 & 1.18 & 0.91523579 \\
0.07056568 & 1.20 & 0.99997985 \\
0.07327274 & 1.205 & 1.02072630 \\
\hline
\end{tabular}




\section{Table 3}

Dimensionless Thermal Boundary Layer Thickness $\left(\Delta^{*}\right)$ as

Function of Dimensionless Distance $\left(x^{\prime \prime}\right)$

and PrandtI Number ( $\mathrm{Pr}$ )

$\Delta^{*}$ For $n=3 / 4$

\begin{tabular}{cccccccc}
\hline \hline$x$ & 1 & 20 & 50 & 75 & 100 & 150 & 200 \\
\hline 0.0001 & 0.0430 & 0.0145 & 0.0105 & 0.0092 & 0.0083 & 0.0072 & 0.0065 \\
0.0002 & 0.0615 & 0.0206 & 0.0150 & 0.0128 & 0.0120 & 0.0102 & 0.0094 \\
0.0004 & 0.0872 & 0.0295 & 0.0215 & 0.0185 & 0.0170 & 0.0148 & 0.0134 \\
0.0006 & 0.1070 & 0.0360 & 0.0268 & 0.0230 & 0.0210 & 0.0183 & 0.0164 \\
0.0008 & 0.126 & 0.0420 & 0.0310 & 0.0271 & 0.0243 & 0.0212 & 0.0190 \\
0.0010 & 0.142 & 0.0470 & 0.0347 & 0.0304 & 0.0273 & 0.0236 & 0.0214 \\
0.0020 & 0.200 & 0.0660 & 0.0490 & 0.0425 & 0.0385 & 0.0335 & 0.0300 \\
0.0040 & 0.275 & 0.0920 & 0.0675 & 0.0580 & 0.0530 & 0.0471 & 0.0425 \\
0.0060 & 0.330 & 0.110 & 0.0800 & 0.0700 & 0.0640 & 0.0570 & 0.0512 \\
0.0080 & 0.375 & 0.125 & 0.0920 & 0.0810 & 0.0730 & 0.0660 & 0.0580 \\
0.0100 & 0.420 & 0.139 & 0.103 & 0.0890 & 0.0815 & 0.0710 & 0.0635 \\
0.0200 & 0.580 & 0.190 & 0.141 & 0.123 & 0.111 & 0.0980 & 0.0870 \\
0.0400 & 0.785 & 0.253 & 0.187 & 0.165 & 0.149 & 0.131 & 0.119 \\
0.0600 & 0.930 & 0.298 & 0.222 & 0.194 & 0.176 & 0.154 & 0.140 \\
0.0715 & 1.000 & - & - & - & - & - & - \\
0.0800 & & 0.333 & 0.248 & 0.218 & 0.198 & 0.173 & 0.157 \\
0.1000 & & 0.362 & 0.270 & 0.237 & 0.215 & 0.188 & 0.172 \\
0.2000 & & 0.447 & 0.327 & 0.286 & 0.260 & 0.227 & 0.216 \\
0.4000 & & 0.556 & 0.407 & 0.354 & 0.322 & 0.280 & 0.253 \\
0.6000 & & 0.638 & 0.465 & 0.404 & 0.365 & 0.318 & 0.287 \\
0.8000 & & 0.707 & 0.512 & 0.444 & 0.402 & 0.350 & 0.316 \\
1.0000 & & 0.766 & 0.551 & 0.479 & 0.433 & 0.377 & 0.340 \\
2.0000 & & 0.985 & 0.705 & 0.608 & 0.549 & 0.475 & 0.430
\end{tabular}


Table 3 (cont' $a)$.

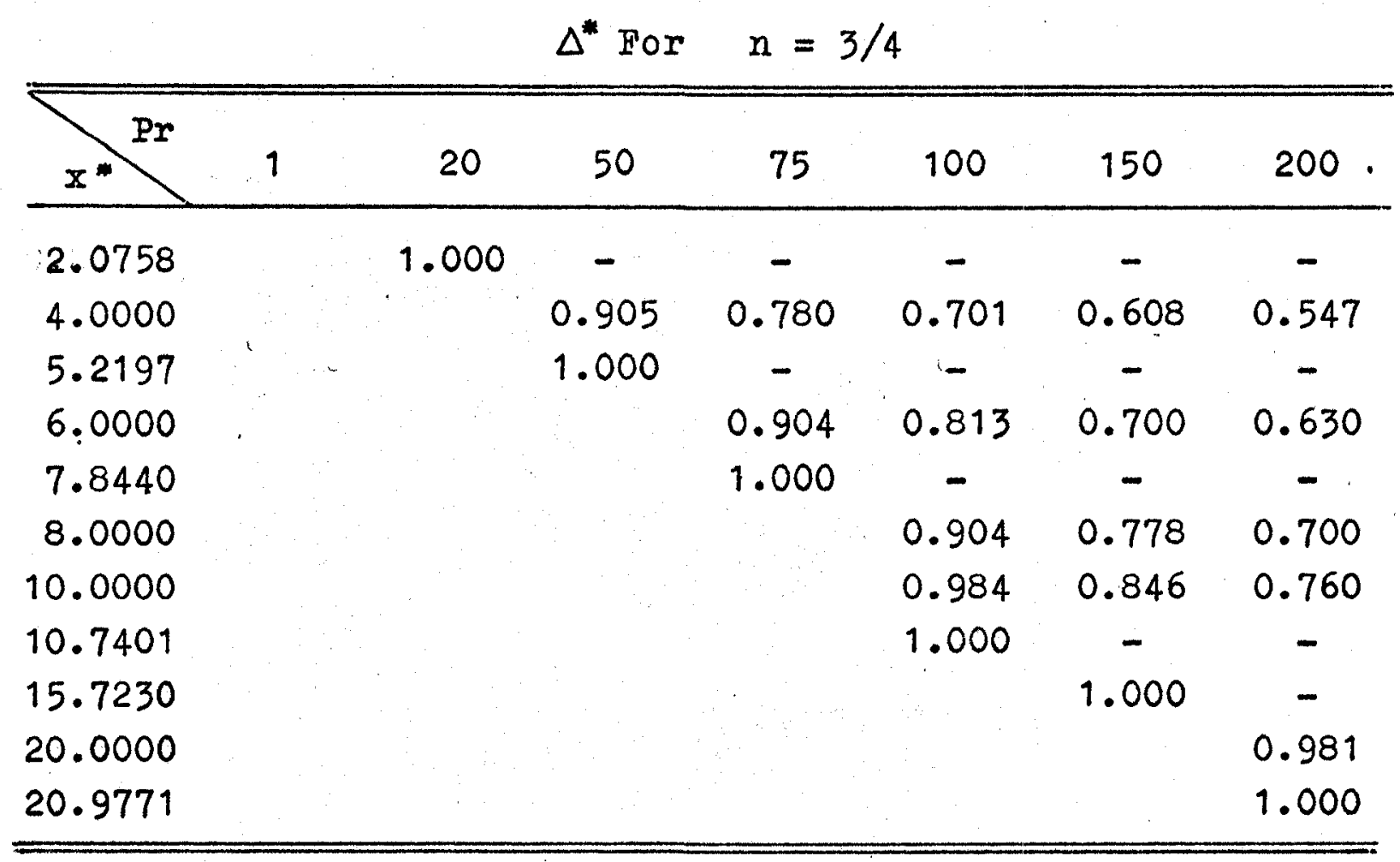


Table 3 (cont'd)

$\Delta *$ For $n=1 / 2$

\begin{tabular}{cccccccc}
\hline \hline Pr & 1 & 20 & 50 & 75 & 100 & 150 & 200 \\
\hline 0.0001 & 0.0345 & 0.0105 & 0.0077 & 0.0067 & 0.0060 & 0.0053 & 0.0048 \\
0.0002 & 0.0485 & 0.0150 & 0.0113 & 0.0098 & 0.0088 & 0.0076 & 0.0069 \\
0.0004 & 0.0708 & 0.0218 & 0.0164 & 0.0143 & 0.0128 & 0.0112 & 0.0100 \\
0.0006 & 0.0870 & 0.0273 & 0.0205 & 0.0179 & 0.0162 & 0.0141 & 0.0124 \\
0.0008 & 0.103 & 0.0323 & 0.0242 & 0.0211 & 0.0192 & 0.0166 & 0.0146 \\
0.0010 & 0.116 & 0.0365 & 0.0275 & 0.0240 & 0.0216 & 0.0187 & 0.0167 \\
0.0020 & 0.168 & 0.0540 & 0.0403 & 0.0346 & 0.0313 & 0.0272 & 0.0242 \\
0.0040 & 0.240 & 0.0770 & 0.0576 & 0.0492 & 0.0443 & 0.0385 & 0.0345 \\
0.0060 & 0.294 & 0.0940 & 0.0702 & 0.0600 & 0.0540 & 0.0473 & 0.0426 \\
0.0080 & 0.335 & 0.1070 & 0.0806 & 0.0693 & 0.0615 & 0.0550 & 0.0494 \\
0.0100 & 0.372 & 0.1220 & 0.0890 & 0.0776 & 0.0702 & 0.0610 & 0.0554 \\
0.0200 & 0.508 & 0.1665 & 0.1217 & 0.1060 & 0.0965 & 0.0847 & 0.0754 \\
0.0400 & 0.702 & 0.229 & 0.168 & 0.146 & 0.133 & 0.116 & 0.105 \\
0.0600 & 0.840 & 0.272 & 0.200 & 0.174 & 0.158 & 0.138 & 0.125 \\
0.0800 & 0.955 & 0.307 & 0.226 & 0.198 & 0.179 & 0.156 & 0.142 \\
0.0900 & 1.000 & - & - & - & - & - & - \\
0.1000 & & 0.337 & 0.248 & 0.216 & 0.196 & 0.170 & 0.156 \\
0.2000 & & 0.410 & 0.305 & 0.265 & 0.240 & 0.208 & 0.189 \\
0.4000 & & 0.527 & 0.382 & 0.333 & 0.301 & 0.261 & 0.237 \\
0.6000 & & 0.612 & 0.440 & 0.382 & 0.345 & 0.300 & 0.271 \\
0.8000 & & 0.680 & 0.488 & 0.422 & 0.381 & 0.330 & 0.299 \\
1.0000 & & 0.740 & 0.529 & 0.456 & 0.412 & 0.356 & 0.323 \\
2.0000 & & 0.964 & 0.681 & 0.586 & 0.526 & 0.454 & 0.411 \\
2.1892 & & 1.000 & - & - & - & - & - \\
4.0000 & & & 0.884 & 0.758 & 0.680 & 0.585 & 0.526 \\
\hline
\end{tabular}

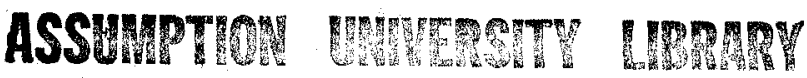


Table 3 (cont'd)

$\Delta^{*}$ For $n=1 / 2$

\begin{tabular}{|c|c|c|c|c|c|c|c|}
\hline$x^{\prime \prime}$ & 1 & 20 & 50 & 75 & 100 & 150 & 200 \\
\hline 5.4658 & & & 1.000 & - & - & - & - \\
\hline 6.0000 & & $\checkmark$ & & 0.884 & 0.790 & 0.680 & 0.611 \\
\hline 8.0000 & & . & & 0.991 & 0.884 & 0.758 & 0.679 \\
\hline 8.2064 & & & & 1.000 & - & $\cdot-$ & - \\
\hline 10.0000 & & & . & & 0.964 & 0.824 & 0.739 \\
\hline 10.9480 & . & & & & 1.000 & - & - \\
\hline 16.4306 & & & & & & 1.000 & - \\
\hline 20.0000 & & & & & & & 0.963 \\
\hline 21.9144 & & & & & & & 1.000 \\
\hline
\end{tabular}


Table 3 (cont'd)

$\Delta^{*}$ For $\mathrm{n}=1 / 4$

\begin{tabular}{|c|c|c|c|c|c|c|c|}
\hline$x^{*}$ & 1 & 20 & 50 & 75 & 100 & 150 & 200 \\
\hline 0.0001 & 0.0300 & 0.00860 & 0.00644 & 0.00570 & 0.00492 & 0.00415 & 0.00360 \\
\hline 0.0002 & 0.0417 & 0.0130 & 0.00960 & 0.00840 & 0.00715 & 0.00610 & 0.00528 \\
\hline 0.0004 & 0.0625 & 0.0198 & 0.0142 & 0.0119 & 0.0104 & 0.00900 & 0.00780 \\
\hline 0.0006 & 0.0782 & 0.0252 & 0.0177 & 0.0148 & 0.0130 & 0.0113 & 0.00975 \\
\hline 0.0 .008 & 0.0920 & 0.0300 & 0.0208 & 0.0174 & 0.0153 & 0.0132 & 0.0115 \\
\hline 0.0010 & 0.104 & 0.0380 & 0.0236 & 0.0197 & 0.0173 & 0.0150 & 0.0131 \\
\hline 0.0020 & 0.155 & .0 .0510 & 0.0355 & 0.0295 & 0.0262 & 0.0226 & 0.0202 \\
\hline 0.0040 & 0.217 & 0.0730 & 0.0508 & 0.0430 & 0.0384 & 0.0330 & 0.0288 \\
\hline 0.0060 & 0.265 & 0.0884 & 0.0622 & 0.0533 & .0 .0474 & 0.0407 & 0.0356 \\
\hline 0.0080 & 0.305 & 0.101 & 0.0707 & 0.0612 & 0.0548 & 0.0470 & 0.0416 \\
\hline 0.0100 & 0.344 & 0.111 & 0.0790 & 0.0684 & 0.0612 & 0.0527 & 0.0475 \\
\hline 0.0200 & 0.490 & 0.157 & 0.113 & 0.0990 & 0.0885 & 0.0768 & 0.0700 \\
\hline 0.0400 & 0.646 & 0.217 & 0.158 & 0.137 & 0.124 & 0.108 & 0.0975 \\
\hline 0.0600 & 0.742 & 0.260 & 0.188 & 0.164 & 0.149 & 0.130 & 0.118 \\
\hline 0.0800 & 0.835 & 0.287 & 0.206 & 0.179 & 0.162 & 0.139 & 0.128 \\
\hline 0.1000 & 0.950 & 0.310 & 0.223 & 0.194 & 0.174 & 0.150 & 0.137 \\
\hline 0.1103 & 1.000 & - & - & - & - & - & - \\
\hline 0.2000 & & 0.392 & 0.278 & 0.243 & 0.220 & 0.188 & 0.171 \\
\hline 0.4000 & & 0.505 & 0.356 & 0.306 & 0.275 & 0.237 & 0.214 \\
\hline 0.6000 & & 0.593 & 0.413 & 0.354 & 0.318 & 0.274 & 0.247 \\
\hline 0.8000 & & 0.669 & 0.461 & 0.394 & 0.353 & 0.304 & 0.274 \\
\hline 1.0000 & & 0.735 & 0.502 & 0.428 & 0.383 & 0.331 & 0.296 \\
\hline 1.9416 & & 1.000 & - & - & - & - & - \\
\hline 2.0000 & & & 0.662 & 0.562 & 0.501 & 0.417 & 0.383 \\
\hline 4.0000 & & & 0.907 & 0.752 & 0.666 & 0.561 & 0.199 \\
\hline 4.8732 & & & 1.000 & - & - & - & - \\
\hline 6.0000 & & & & 0.910 & 0.795 & 0.663 & 0.587 \\
\hline 7.3172 & & & & 1.000 & - & - & - \\
\hline 8.0000 & & & & & 0.906 & 0.751 & 0.662 \\
\hline 9.7624 & & & & & 1.000 & - & - \\
\hline 10.0000 & & & & & & 0.830 & 0.730 \\
\hline 14.6530 & & & & & & 1.000 & - \\
\hline 19.5443 & & & & & & & 1.000 \\
\hline
\end{tabular}


Table 4

The Local Nusselt Number $\left(\mathbb{N} u_{x}\right)$ as Function of Dimensionless Distance $\left(x^{*}\right)$ and PrandtI Number (Pr)

For $n=3 / 4$

\begin{tabular}{|c|c|c|c|c|c|c|c|}
\hline$x *$ & 1 & 20 & 50 & 75 & 100 & 150 & 200 \\
\hline 0.0001 & 35.1786 & 103.5662 & 142.9454 & 163.1204 & 180.7933 & 208.3952 & 230.8259 \\
\hline 0.0002 & 24.6669 & 7.2 .9290 & 100.0849 & 117.2641 & 125.0663 & 147.1190 & 159.6286 \\
\hline 0.0004 & 17.5073 & 50.9567 & 69.8494 & 81.1548 & 88.3005 & 101.4088 & 111.9929 \\
\hline 0.0006 & 14.2791 & 41.7749 & 56.0496 & 65.2893 & 71.5885 & 82.0234 & 91.5155 \\
\hline 0.0008 & 12.1580 & 35.8208 & 48.4659 & 55.6265 & 61.7922 & 70.8104 & 78.9991 \\
\hline 0.0010 & 10.8129 & 32.0210 & 43.3058 & 49.1125 & 55.0081 & 63.6150 & 70.1446 \\
\hline 0.0020 & 7.7463 & 22.8327 & 30.6894 & 35.3627 & 40.5843 & 44.8308 & 50.0654 \\
\hline 0.0040 & 5.7074 & 16.4106 & 22.3009 & 25.9328 & 28.3654 & 31.9695 & 35.3444 \\
\hline 0.0060 & 4.8064 & 13.7456 & 18.8317 & 21.5004 & 23.5021 & 26.3708 & 29.4630 \\
\hline 0.0080 & 4.2678 & 12.1116 & 16.3868 & 18.5904 & 20.6136 & 22.7823 & 25.9143 \\
\hline 0.0100 & 3.8413 & 10.9042 & 14.6457 & 16.9247 & 18.4710 & 21.1841 & 23.6754 \\
\hline 0.0200 & 2.8733 & 8.0138 & 10.7248 & 12.2711 & 13.5755 & 15.3657 & 17.2974 \\
\hline 0.0400 & 2.2300 & 6.0922 & 8.1160 & 9.1728 & 10.1419 & 11.5159 & 12.6643 \\
\hline 0.0600 & 1.9617 & 5.1727 & 6.8723 & 7.8999 & 8.6019 & 9.8097 & 10.7770 \\
\hline 0.0715 & $1.8648^{8}$ & - & - & - & - & - & - \\
\hline 0.0800 & & 4.6518 & 6.1538 & 6.9720 & 7.6587 & 8.7430 & 9.6198 \\
\hline 0.1000 & & 4.2982 & 5.6658 & 6.4244 & 7.0635 & 8.0544 & 8.7890 \\
\hline 0.2000 & & 3.5489 & 4.7260 & 5.4238 & 5.8778 & 6.7034 & 7.1263 \\
\hline 0.4000 & & 2.9455 & 3.8628 & 4.3900 & 4.7958 & 5.4779 & 6.0382 \\
\hline 0.6000 & & 2.6389 & 3.4293 & 3.8891 & 4.2690 & 4.8564 & 5.3529 \\
\hline 0.8000 & & 2.4424 & 3.1556 & 3.5740 & 3.9078 & 4.4397 & 4.8866 \\
\hline 1.0000 & & 2.3083 & 2.9683 & 3.3434 & 3.6555 & 4.1454 & 4.5631 \\
\hline 2.0000 & & 1.9936 & 2.4457 & 2.7406 & 2.9779 & 3.3714 & 3.6812 \\
\hline 2.0758 & & 1.9786 & - & - & - & - & - \\
\hline
\end{tabular}

${ }^{3}$ Value of $N u_{x}$ when $\Delta^{*}=1$. 
Table 4 (cont'd)

$$
N u_{x} \text { For } n=3 / 4
$$

\begin{tabular}{|c|c|c|c|c|c|c|c|}
\hline$x=$ & 1 & 20 & 50 & 75 & 100 & 150 & 200 \\
\hline 4.0000 & & & 2.0960 & 2.2806 & 2.4593 & 2.7407 & 2.9892 \\
\hline 5.2197 & & & 1.9933 & - & - & - & - \\
\hline 6.0000 & & & & 2.0847 & 2.2221 & 2.4637 & 2.6692 \\
\hline 7.8440 & & & & 1.9808 & - & - & - \\
\hline 8.0000 & & - & & & 2.0850 & 2.2877 & 2.4645 \\
\hline 10.0000 & & & & & 1.9951 & 2.1672 & 2.3247 \\
\hline 10.4701 & & & & & 1.9836 & - & $\dot{-}$ \\
\hline 15.7230 & & & & & & 1.9837 & - \\
\hline 20.0000 & & & & & & & 2.0017 \\
\hline 20.9771 & & & & & & & 1.9837 \\
\hline
\end{tabular}


Table 4 (cont'd)

$\mathrm{Nu}_{\mathrm{x}} \quad$ For $\mathrm{n}=1 / 2$

\begin{tabular}{|c|c|c|c|c|c|c|c|}
\hline$x^{P r}$ & 1 & 20 & 50 & 75 & 100 & 150 & 200 \\
\hline 0.0001 & 43.9556 & 143.0781 & 196.2431 & 224.0241 & 250.1322 & 285.8296 & 315.8948 \\
\hline 0.0002 & 31.3800 & 100.2135 & 132.8834 & 153.1960 & 170.5786 & 169.4445 & 217.8071 \\
\hline 0.0004 & 21.6029 & 68.9996 & 91.6019 & 105.0219 & 117.3048 & 134.2712 & 150.8509 \\
\hline 0.0006 & 17.6487 & 55.1406 & 73.3054 & 83.9202 & 92.7043 & 106.4816 & 121.0610 \\
\hline 0.0008 & 14.9552 & 46.6286 & 62.1150 & 71.2081 & 78.2326 & 90.4570 & 102.8303 \\
\hline 0.0010 & 13.3206 & 41.2810 & 54.6738 & 62.6150 & 69.5543 & 80.3078 & 89.9082 \\
\hline 0.0020 & 9.2937 & 27.9487 & 37.3410 & 43.4615 & 48.0234 & 55.2352 & 62.0665 \\
\hline 0.0040 & 6.6052 & 19.6448 & 26.1730 & 30.5932 & 33.9574 & 39.0526 & 43.5584 \\
\hline 0.0060 & 5.4573 & 16.0960 & 21.4954 & 25.1048 & 27.8741 & 31.7970 & 35.2898 \\
\hline 0.0080 & 4.8387 & 14.1842 & 18.7367 & 21.7492 & 24.4878 & 27.3562 & 30.4419 \\
\hline 0.0100 & 4.3976 & 12.4558 & 16.9804 & 19.4336 & 21.4626 & 24.6739 & 27.1528 \\
\hline 0.0200 & 3.3431 & 9.2745 & 12.4530 & 14.2572 & 15.6411 & 17.7942 & 19.9745 \\
\hline 0.0400 & 2.5595 & 6.7360 & 9.0797 & 10.3552 & 11.4037 & 13.0748 & 14.3670 \\
\hline 0.0600 & 2.2428 & 5.7040 & 7.6339 & 8.7192 & 9.5975 & 10.9922 & 12.0646 \\
\hline 0.0800 & 2.0590 & 5.0781 & 6.7750 & 7.7102 & 8.5057 & 9.6965 & 10.6793 \\
\hline 0.0900 & 2.0067 & - & - & - & - & - & - \\
\hline 0.1000 & & 4.6425 & 6.1901 & 7.0637 & 7.7632 & 8.9204 & 9.7346 \\
\hline 0.2000 & & 3.8980 & 5.0895 & 5.8064 & 6.3841 & 7.3297 & 8.0445 \\
\hline 0.4000 & & 3.1384 & 4.1376 & 4.6843 & 5.1481 & 5.8941 & 6.4608 \\
\hline 0.6000 & & 2.7832 & 3.6470 & 4.1313 & 4.5349 & 5.1656 & 5.6827 \\
\hline 0.8000 & & 2.5723 & 3.3353 & 3.7792 & 4.1420 & 4.7280 & 5.1788 \\
\hline 1.0000 & & 2.4233 & 3.1166 & 3.5315 & 3.8610 & 4.4089 & 4.8255 \\
\hline 2.0000 & & 2.0759 & 2.5591 & 2.8648 & 3.1288 & 3.5475 & 3.8675 \\
\hline 2.1892 & & 2.0405 & - & - & - & - & - \\
\hline 4.0000 & & & 2.2037 & 2.3708 & 2.5580 & 2.8698 & 3.1268 \\
\hline 5.4658 & & & 2.0251 & - & - & - & - \\
\hline 6.0000 & & & & 2.1532 & 2.3113 & 2.5596 & 2.7110 \\
\hline 8.0000 & & & & 2.0354 & 2.1581 & 2.3727 & 2.5609 \\
\hline 8.2064 & & & & 2.0284 & - & - & - \\
\hline 0.0000 & & & & & 2.0643 & 2.2535 & 2.4124 \\
\hline
\end{tabular}




\section{Table 4 (cont'd)}

$\mathrm{Nu}_{\mathrm{x}} \quad$ For $\mathrm{n}=1 / 2$

\begin{tabular}{|c|c|c|c|c|c|c|c|}
\hline$x^{*}$ & 1 & 20 & 50 & 75 & 100 & 150 & 200 \\
\hline 10.9480 & & & & & 2.0296 & - & - \\
\hline 16.4306 & & & & & & 2.0341 & - \\
\hline 20.0000 & & & & & & & 2.0652 \\
\hline 21.9144 & & & & & & & 2.0279 \\
\hline
\end{tabular}


Table 4 (cont'd)

$\mathrm{Nu}_{\mathrm{x}} \quad$ For $\mathrm{n}=1 / 4$

\begin{tabular}{|c|c|c|c|c|c|c|c|}
\hline $\mathrm{Pr}$ & 1 & 20 & 50 & 75 & 100 & 150 & 200 \\
\hline 0.0001 & 50.5706 & 174.6970 & 233.1681 & 263.3440 & 305.0968 & 361.6526 & 416.8668 \\
\hline 0.0002 & 36.5324 & 115.6485 & 156.4740 & 178.7746 & 210.0048 & 246.0896 & 284.2748 \\
\hline 0.0004 & 24.5147 & 75.9996 & 105.8383 & 126.2425 & 144.2687 & 166.8378 & 192.4802 \\
\hline 0.0006 & 19.6785 & 59.7538 & 84.9417 & 101.5361 & 115.5712 & 132.9050 & 154.0110 \\
\hline 0.0008 & 16.7872 & 50.2206 & 72.3344 & 86.3856 & 98.2184 & 113.3639 & 130.5926 \\
\hline 0.0010 & 14.8969 & 39.6654 & 63.7433 & 76.3164 & 86.8796 & 100.1523 & 114.6564 \\
\hline 0.0020 & 10.1150 & 29.6060 & 42.4184 & 51.0049 & 57.4061 & 66.5078 & 74.3894 \\
\hline 0.0040 & 7.3468 & 20.7334 & 29.6838 & 35.0297 & 39.1976 & 45.5797 & 52.2073 \\
\hline 0.0060 & 6.0961 & 17.1535 & 24.2688 & 28.2838 & 31.7820 & 36.9767 & 42.2547 \\
\hline 0.0080 & 5.3571 & 15.0376 & 21.3704 & 24.6501 & 27.5065 & 32.0356 & 36.1743 \\
\hline 0.0100 & 4.7982 & 13.7024 & 19.1406 & 22.0690 & 24.6428 & 28.5822 & 31.6917 \\
\hline 0.0200 & 3.5056 & 9.7420 & 13.4230 & 15.2839 & 17.0750 & 19.6849 & 21.5321 \\
\hline 0.0400 & 2.8250 & 7.1052 & 9.6730 & 11.0815 & 12.2702 & 14.0633 & 15.4863 \\
\hline 0.0600 & 2.5459 & 5.9684 & 8.1105 & 9.2535 & 10.1927 & 11.6489 & 12.8137 \\
\hline 0.0800 & 2.3766 & 5.4379 & 7.4265 & 8.5242 & 9.3932 & 10.9111 & 11.8272 \\
\hline 0.1000 & 2.1859 & 5.0771 & 6.7751 & 7.8018 & 8.7360 & 10.1250 & 11.0930 \\
\hline 0.1103 & 2.1237 & - & - & - & - & - & - \\
\hline 0.2000 & & 4.0926 & 5.6000 & 6.3507 & 6.9824 & 8.1263 & 8.9067 \\
\hline 0.4000 & & 3.2392 & 4.4595 & 5.1192 & 5.6466 & 6.5078 & 7.1733 \\
\hline 0.6000 & & 2.8919 & 3.9083 & 4.4815 & 4.9423 & 5.6744 & 6.2562 \\
\hline 0.8000 & & 2.6348 & $3: 5538$ & 4.0724 & 4.4942 & 5.1512 & 5.6731 \\
\hline 1.0000 & & 2.4600 & 3.3084 & 3.7883 & 4.1783 & 4.7624 & 5.2802 \\
\hline 1.9416 & & 2.0036 & - & - & - & - & - \\
\hline 2.0000 & & & 2.6127 & 3.0148 & 3.3128 & 3.8866 & 4.1756 \\
\hline 4.0000 & & & 2.1294 & 2.4176 & 2.6406 & 3.0195 & 3.3239 \\
\hline 4.8732 & & & 2.0033 & - & - & - & - \\
\hline 6.0000 & & & & 2.1212 & 2.3236 & 2.6511 & 2.9143 \\
\hline 7.3172 & & & & 2.0013 & - & - & - \\
\hline 8.0000 & & & & & 2.1314 & 2.4204 & 2.6107 \\
\hline 9.7624 & & & & & 2.0027 & - & - \\
\hline 0.0000 & & & & & & 2.2593 & 2.4716 \\
\hline 4.6530 & & & & & & 2.0034 & - \\
\hline 9.5443 & & & & & & & 2.0036 \\
\hline
\end{tabular}


Table 5

Sample Computer Results of Integration of Equations (4-15) and (4-16) by Runge-Kutta Method For $n \cdot=1 / 4$ \& $\operatorname{Pr}=100$

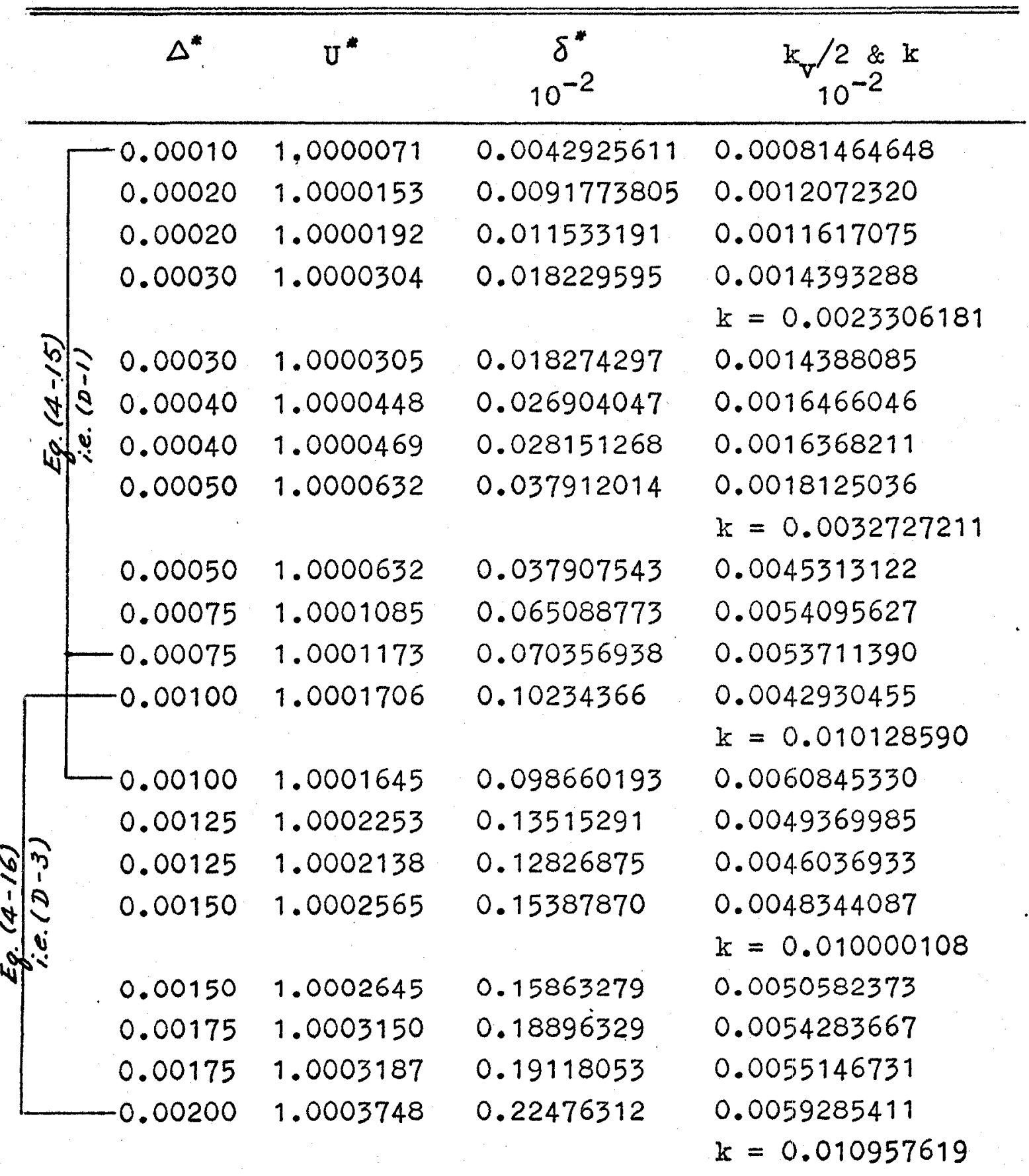


Table 5 (cont'd)

For $n=1 / 4 \quad \& \quad P r=100$

\begin{tabular}{|c|c|c|c|c|}
\hline & $\Delta^{*}$ & $U^{*}$ & $\begin{array}{c}\delta^{*} \\
10^{-2}\end{array}$ & $\underset{\nabla}{k / 2 \& k} 0^{-2}$ \\
\hline \multirow{19}{*}{ 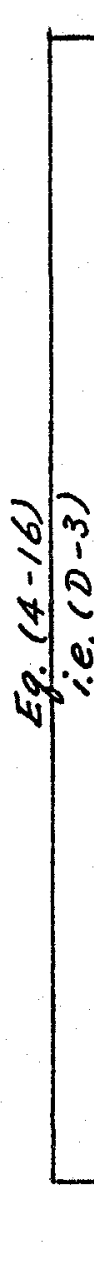 } & 0.00200 & 1.0003740 & 0.22433398 & 0.0059143098 \\
\hline & 0.00225 & 1.0004332 & 0.25978960 & 0.0063219337 \\
\hline & 0.00225 & 1.0004373 & 0.26223258 & 0.0063912083 \\
\hline & 0.00250 & 1.0005019 & 0.30095818 & 0.0068128806 \\
\hline & & & & $k=0.012717825$ \\
\hline & - & - & - & - \\
\hline & - & - & - & - \\
\hline & - & - & - & • \\
\hline & - & - & - & - \\
\hline & 0.14000 & 1.1639869 & 84.528050 & 1.7159599 \\
\hline & 0.15000 & 1.1811466 & 92.016551 & 1.7855563 \\
\hline & 0.15000 & 1.1818425 & 92.315683 & 1.7849031 \\
\hline & 0.16000 & 1.1996850 & 99.866056 & 1.8646692 \\
\hline & & & & $\mathrm{k}=3.5707100$ \\
\hline & 0.16000 & -1.1996940 & 99.869825 & 1.8552415 \\
\hline & 0.17000 & 1.2182465 & 107.48596 & 1.9266213 \\
\hline & 0.17000 & 1.2189603 & 107.77435 & 1.9257606 \\
\hline & 0.18000 & 1.2382093 & 115.42616 & 1.9983201 \\
\hline & & & & $k=3.8527751$ \\
\hline
\end{tabular}




\section{VIMA AUCTORTS}

1939 Born in Macau, Chine, on May $7,1939$.

1950 Finished public school at Iing Ying Primary School, Hong Kong, in JuIy.

1956 Graduated Prom St. Paul's Co-educational College, Hong Kong, with Fong Kong Government School Leaving Certicicate, in June.

1961 Received the Degree of Bachelor of Applied Science in Mechanical Engineering trom hssunption University of Windsor, Windsor, Ontario, in June. 1962 Currentiy a canidate for the Degree of llaster of Applied Science in a combined programme of Chemical and Hechanical Engineering at Assumption Univeroity of rindsor. 